Prepared in cooperation with the National Park Service

\title{
Impacts of White-Tailed Deer on Red Trillium (Trillium recurvatum): Defining a Threshold for Deer Browsing Pressure at the Indiana Dunes National Lakeshore
}

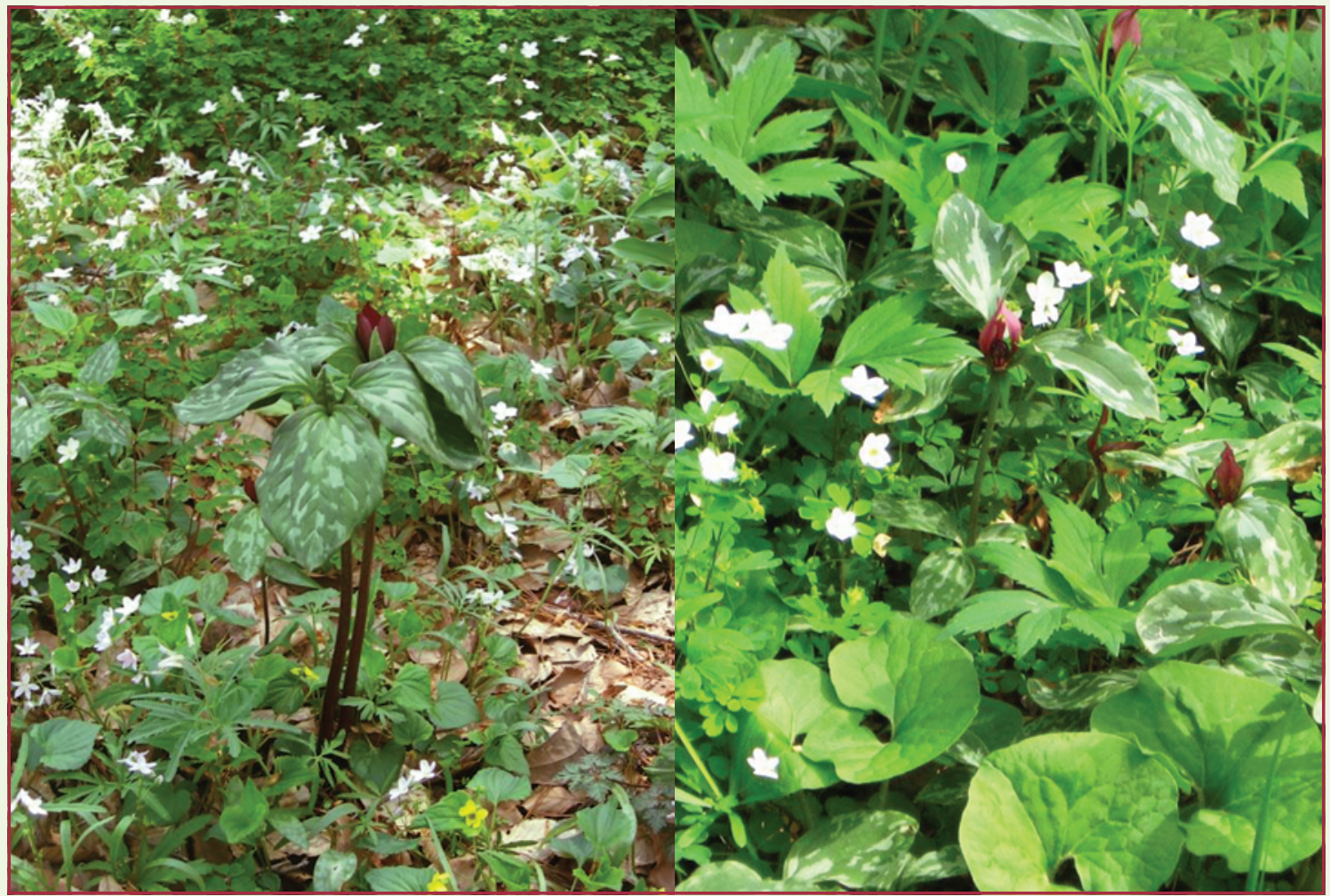

Scientific Investigations Report 2014-5070 
Cover. Two patches of red trillium (Trillium recurvatum), full sized (left) and browsed (right). Note the relative size of the pink spring beauty flowers between the photographs. The photo on the left was taken by Noel Pavlovic (U.S. Geological Survey) from a private yard south of Chesterton, Indiana. The photo on the right was taken by Krystal Frohnapple (U.S. Geological Survey) at the Indiana Dunes National Lakeshore. 


\section{Impacts of White-Tailed Deer on Red Trillium (Trillium recurvatum): Defining a Threshold for Deer Browsing Pressure at the Indiana Dunes National Lakeshore}

By Noel B. Pavlovic, Stacey A. Leicht-Young, and Ralph Grundel

Prepared in cooperation with the National Park Service

Scientific Investigations Report 2014-5070 


\title{
U.S. Department of the Interior SALLY JEWELL, Secretary
}

\section{U.S. Geological Survey \\ Suzette M. Kimball, Acting Director}

\author{
U.S. Geological Survey, Reston, Virginia: 2014
}

For more information on the USGS - the Federal source for science about the Earth, its natural and living resources, natural hazards, and the environment, visit http://www.usgs.gov or call 1-888-ASK-USGS.

For an overview of USGS information products, including maps, imagery, and publications, visit http://www.usgs.gov/pubprod

To order this and other USGS information products, visit http://store.usgs.gov

Any use of trade, firm, or product names is for descriptive purposes only and does not imply endorsement by the U.S. Government.

Although this information product, for the most part, is in the public domain, it also may contain copyrighted materials as noted in the text. Permission to reproduce copyrighted items must be secured from the copyright owner.

Suggested citation:

Pavlovic, N.B., Leicht-Young, S.A., and Grundel, R., 2014, Impacts of white-tailed deer on red trillium (Trillium recurvatum)—Defining a threshold for deer browsing pressure at the Indiana Dunes National Lakeshore: U.S. Geological Survey Scientific Investigations Report 2014-5070, 37 p., http://dx.doi.org/10.3133/sir20145070.

ISSN 2328-0328 (online) 


\section{Contents}

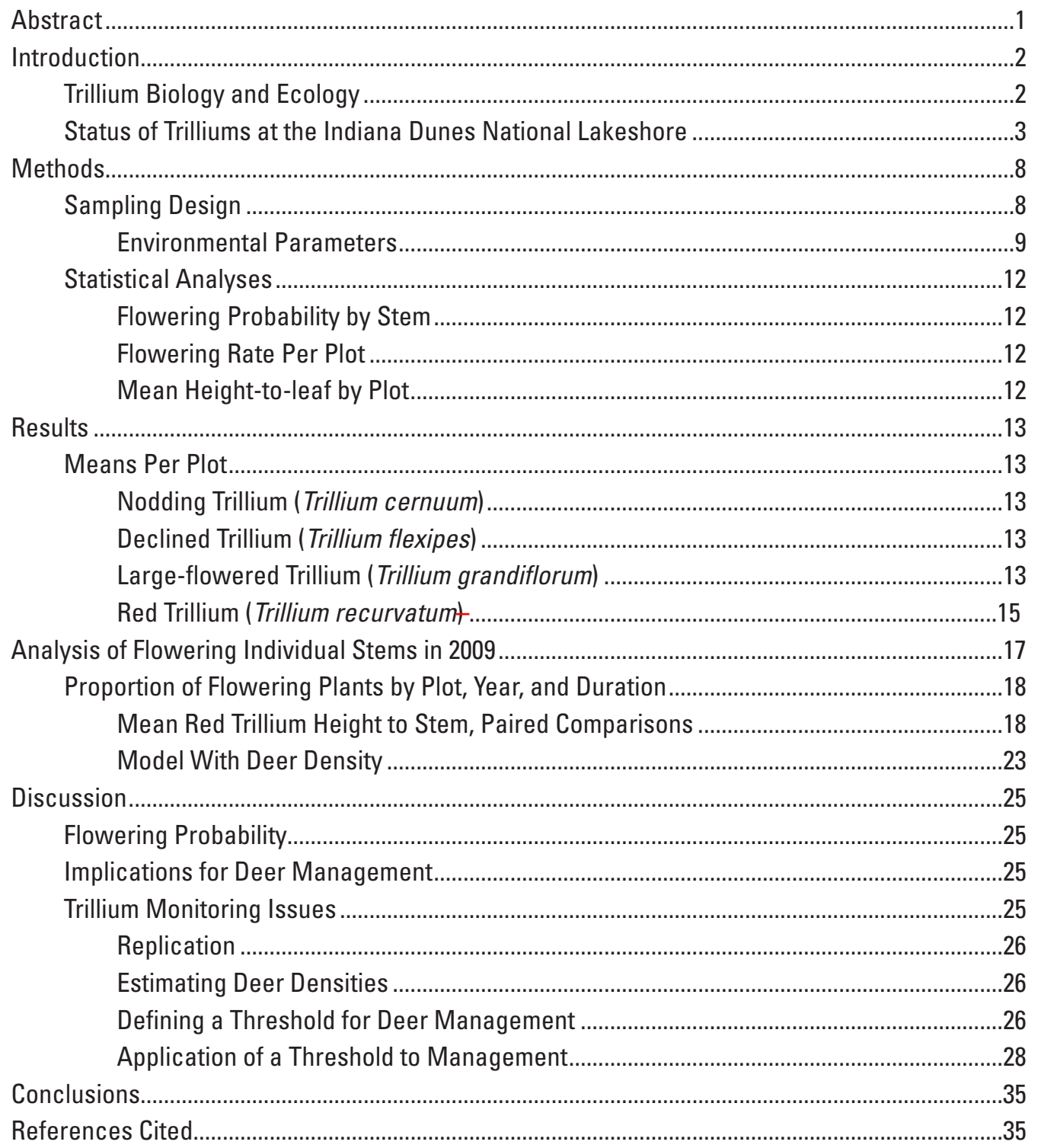




\section{Figures}

1. Flowering large-flowered trillium at Warren Dunes in 2009.

Inset closeup of flowers

2. Large-flowered trillium growing on the south side of East State Park Road.

Ten years later, in 1991, this population was completely nonflowering ....

3. Large-flowered trillium (Trillium grandiflorum) in bloom at the Heron Rookery on May 4, 1984

4. Chicago South Shore and South Bend Railroad Poster showing the abundance of large-flowered trillium (Trillium grandiflorum) on the dune slopes ...............................6

5. Nodding trillium (Trillium cernuum) flowering in a deer exclosure .....................................7

6. Declined trillium (Trillium flexipes) at the Heron Rookery...................................................

7. Deer management zones (DMZs) within the Indiana Dunes National Lakeshore ..........10

8. Locations of the paired plots within the DMZs.................................................................11

9. Mean height-to-leaf for nodding trillium (Trillium cernuum), by year..............................13

10. Temporal trends in red trillium (Trillium recurvatum) .......................................................16

11. Logistic regression model of flowering probability of red trillium (Trillium recurvatum), by height-to-leaf and substrate.

12. Predicted mean percentage of flowering by height of stem and duration of protection for red trillium ( Trillium recurvatum) ..................................................................20

13. Height-to-leaf, by treatment and duration.............................................................................21

14. Changes in estimated deer densities for the Dune Ridge and Wood deer management zones (DMZs) based on spotlight surveys and distance sampling............23

15. Interaction between change in snowfall and change in deer density in relation to height to leaf (in centimeters) in red trillium (Trillium recurvatum) ...............................24

16. Negative correlation between change in snowfall and change in deer density.............24

17. Patterns in proportion of flowering of red trillium in the Dune Ridge, Dune Wood, Heron Rookery, Little Calumet, and Cowles Dunes deer management zones from 2001 to 2010

18. Patterns in change in height-to-leaf in red trillium in the Dune Ridge, Dune Wood, Heron Rookery, Little Calumet, and Cowles Dunes deer management units from 200 to 2010 


\section{Tables}

1. Trillium species sampled during 2002-2010: plot name, date of first enclosure, deer management zone, density (minimum, maximum), first year of sampling (year 1 ) and final year of sampling (end year).................................

2. Mean height-to-leaf per stem (plus or minus standard error) and percentage of flowering in Trillium species studied from 2002 to 2010.

3. Comparison of large-flowered trillium (Trillium grandiflorum) percentage flowering and height-to-leaf (plus or minus standard error) between treatments, by year and duration, based on paired t-tests

4. Statistics for models of red trillium flowering probability (logistic regression) and proportion of plants flowering (GLM regression)

5. Mean percent flowering plants per paired control and exclosure plots for red trillium (Trillium recurvatum).

6. Mean standard deviation of height-to-leaf (SD height) and percent browsed individuals of red trillium (Trillium recurvatum) per paired control and exclosure plots

7. Mean percent flowering plants per paired control and exclosure plots, by deer management zones (Dune Wood and Little Calumet), for red trillium (Trillium recurvatum).

8. Mean percent flowering plants per paired control and exclosure plots for red trillium (Trillium recurvatum) for the Riverine and East Unit deer management zones (DMZs)

9. Mean height-to-leaf of red trillium (Trillium recurvatum) plants, by year and duration.

10. Parameters for model of red trillium (Trillium recurvatum) height-to-leaf and change in height to leaf between years.

11. Mean red trillium (Trillium recurvatum) height to leaf with paired t-test sample size, by treatment by duration of exclosure

12. Mean red trillium (Trillium recurvatum) height to leaf with paired t-test sample size, by treatment by duration of exclosure

13. Mean height-to-leaf, by treatment, for each level of duration for the East Unit.............22

14. Results of general linear model regression of change in height-to-leaf versus change in total snowfall and change in deer density...

15. Growth stages of Trillium and implications of browsing on plant and monitoring ..........26

16. Proportion of population that flowers for Trillium species, as reported or estimated from the literature 


\section{Conversion Factors}

\begin{tabular}{lcl}
\hline \multicolumn{1}{c}{ Multiply } & By & \multicolumn{1}{c}{ To obtain } \\
\hline & Length & \\
\hline centimeter $(\mathrm{cm})$ & 0.3937 & inch (in) \\
\hline & Area & \\
\hline square centimeter $\left(\mathrm{cm}^{2}\right)$ & 0.1550 & square inch $\left(\mathrm{in}^{2}\right)$ \\
square meter $\left(\mathrm{m}^{2}\right)$ & 10.76 & square foot $\left(\mathrm{ft}^{2}\right)$ \\
square kilometer $\left(\mathrm{km}^{2}\right)$ & 0.3861 & square mile $\left(\mathrm{mi}^{2}\right)$ \\
\hline
\end{tabular}




\title{
Impacts of White-Tailed Deer on Red Trillium (Trillium recurvatum): Defining a Threshold for Deer Browsing Pressure at the Indiana Dunes National Lakeshore
}

\author{
By Noel B. Pavlovic, Stacey A. Leicht-Young, and Ralph Grundel
}

\section{Abstract}

Overabundant white-tailed deer (Odocoileus virginianus) have been a concern for land managers in eastern North America because of their impacts on native forest ecosystems. Managers have sought native plant species to serve as phytoindicators of deer impacts to supplement deer surveys. We analyzed experimental data about red trillium (Trillium recurvatum), large flowered trillium (T. grandiflorum), nodding trillium (T. cernuum), and declined trillium (T. flexipes) growth in paired exclosure (fenced) plots and control (unfenced) plots from 2002 to 2010 at the Indiana Dunes National Lakeshore. The latter two species lacked replication, so statistical analysis was not possible. All red trillium plants were surveyed for height-to-leaf, effects of browsing, and presence of flowers.

Data from individuals in 2009 demonstrated a sigmoidal relationship between height-to-leaf and probability of flowering. The relationship on moraine soils was shifted to taller plants compared to those on sand substrates, with respectively 50 percent flowering at 18 and $16 \mathrm{~cm}$ and 33 percent flowering at 16 and $14 \mathrm{~cm}$ height-to-leaf. On a plot basis, the proportion of plants flowering was influenced by height to leaf, duration of protection, and deviation in rainfall. The proportion of plants flowering increased ninefold in exclosures (28 percent) compared to control plots ( 3 percent) over the 8 years of protection. The mean height-to-leaf was a function of the interaction between treatment and duration, as well as red trillium density. Changes in height-to-leaf in control plots from year to year were significantly influenced by an interaction between change in deer density and change in snowfall depth. There was a significant negative correlation between change in deer density and snowfall depth. Plants in the exclosures increased in height at a rate of $1.5 \mathrm{~cm} \mathrm{yr}^{-1}$ whereas control plants decreased in height by $0.9 \mathrm{~cm} \mathrm{yr}^{-1}$. In all, 78 percent of the control plots lacked flowering individuals over the 9 years of study, indicating that red trillium is being negatively affected by deer throughout the East Unit of the park. Of the five deer management zones studied, only one showed pre-impact height-to-leaf and flowering percentages in control plots that then declined after 2005 .
The results of this study demonstrate that Trillium species growing in the lands of the Indiana Dunes National Lakeshore are being suppressed reproductively by deer browsing. Specifically, we demonstrate, for the first time, the utility of using red trillium (Trillium recurvatum) height-to-leaf and percentage of flowering as indicators of the impacts of deer browsing. Application of the recommended thresholds demonstrates their utility in adopting red trillium as a phytoindicator of deer impact. Responses of plants to protection from deer suggest that deer culling might be necessary for 6 or more years for red trillium populations and rare trillium species to recover.

The bullets below summarize these results.

- With regard to nodding trillium (Trillium cernuum), flowering plants have been seen only in the exclosure and under protecting brush piles.

- Declined trillium (Trillium flexipes) flowered every year in the exclosure but only in 2 years out of 9 outside the exclosures.

- Large flowered trillium (Trillium grandiflorum) heightto-leaf was significantly greater in the exclosures compared to the controls, especially after 2005 .

- The utility of using height-to-leaf measurements of red trillium as an indicator of deer browsing impacts is demonstrated for the first time. This additional deer browsing phytoindicator will benefit land managers by expanding the range of habitats where such tools can be used.

- Seventy-eight percent of the control (unfenced) plots had no flowering red trilliums over the 9 years of investigation.

- Analysis of data from two deer management zones indicates that the change in height-to-leaf from year to year is related to an interaction between change in total snowfall and change in change in deer density. 
- At the Heron Rookery deer management zone, data for declined, large flowered, and red trillium indicate that browsing by white-tailed deer began to harm these species around 2005-6.

- The data indicate that throughout the East Unit of the Indiana Dunes, white-tailed deer are dense enough to reduce trillium height-to-leaf, and to reduce flower and seed production.

- The proportion of flowering plants increased ninefold in exclosures (28 percent) compared to control plots ( 3 percent) over the 8 years of protection.

- Based on our results and analysis, the use of a heightto-leaf threshold of $18 \mathrm{~cm}$ on moraine soils and 16 $\mathrm{cm}$ on sandy soils, at approximately $33 \%$ flowering might be used as an initial target for when to begin or cease culling of deer as a means of protecting trillium populations in the Indiana Dunes. This target could be modified as more data are collected.

\section{Introduction}

As human-dominated landscapes have increased in coverage worldwide, the abundance of herbivores also has often increased, resulting in further alterations to ecosystems (Fuller and Gill, 2001; Augustine and DeCalesta, 2003; Chee and Wintle, 2010). In eastern North America, overabundant white-tailed deer (Odocoileus virginianus) have had cascading effects on species, populations, and plant communities (Beguin and others, 2011). Overabundant deer have been shown to affect tree regeneration, herbaceous ground layer diversity, soil properties, and tick abundance (Jones and others, 1998; Tallmon and others, 2003; Knight and others, 2009b; Mudrak and others, 2009; Powers and Nagel, 2009; Rooney, 2009; Koh and others, 2010). In addition to harming palatable herbs by eating them, overabundant white-tailed deer can harm nonpalatable herbs simply by walking on them or through indirect effects on soil structure (Heckel and others, 2010). As these effects and pressures have increased, land managers have sought tools to quantify the impact of deer.

Data on deer abundance are relevant to understanding resource impacts from selective browsing and grazing by deer. Unfortunately, research and practice have shown that deer surveys are expensive and are prone to general biases (Begier, 1996; Tappe and others, 2003; Underwood and Knutson, 2011). Because aerial and spotlighting surveys are expensive, researchers have sought easily obtained alternative metrics to determine when deer impacts are severe enough to warrant management action. Also, the same deer density may have different levels of effect on vegetation at different locations, in part because of the quality and spatial pattern of the vegetation and palatable herbs where the deer are foraging (Koh and others, 2010). Metrics that have been used to assess deer overpopulation include plant diversity, height, and flowering of specific plants (Williams and others, 2000; Fletcher and others, 2001, Webster and others, 2001; Anderson and others, 2005, Kirschbaum and Anacker, 2005; Thompson and Sharpe, 2005; Webster and others, 2005, Koh and others, 2010). For example, Anderson (1994) found that height to leaf of large flowered trillium (Trillium grandiflorum) was a good index of deer browsing pressure in forests in the Chicago metropolitan area.

In this document, we report on the results of trillium exclosure experiments at the Indiana Dunes National Lakeshore (INDU) from 2002 to 2010. We asked whether height to leaf of the congeneric $T$. recurvatum, red trillium, might be used in more xeric habitats to assess deer impact (compared to large flowered trillium, which grows in more mesic habitats).

\section{Trillium Biology and Ecology}

The genus Trillium (43 species) is distributed across Asia and North American, predominantly in deciduous forests (Case and Case, 1997). In North America, 30 and 8 species occur respectively east and west of the Mississippi River. If subspecies are included, there are a total of 46 taxa (Utech, 2002). Generally, trillium species are classified into two groups: the Trillium subgenus or pedicillate trilliums and the Phyllantherum or sessile trilliums (Gates, 1917; Case and Case, 1997). The latter group only occurs in North America. Three of the trillium species at INDU belong to the pedicillate subgenus, whereas red trillium (T. recurvatum) belongs to the sessile group.

The trillium plant arises from a segmented rhizome with the youngest segment becoming the next year's shoot. The rhizome axis produces no true leaves, but instead has internodes covered by papery modified leaves called cataphylls. Vegetative reproduction is possible by branching of the rhizome, which can produce multiple shoots. The rhizome branches arise from dormant buds within the axils of the cataphylls. The name trillium derives from "tres" or three or "all the [plant] parts being in threes" (Fernald, 1970). The flowering shoot consists of the peduncle, the three bracts, the three sepals, three petals, six stamens, and an ovary of three carpels fused with a three-forked style (Case and Case, 1997). Red trillium produces the smallest seeds of any North American Trillium species and has on average 29 seeds per fruit (Sawyer, 2010).

Plants can be classified into four or five stage classes: (A1) seedling with cotyledons, (A2) one-leaflet stage, (A3) nonflowering three-leaf stage, and (A4) flowering three-leaf stage; or (B1) seedling with cotyledons, (B2) one-leaflet stage, (B3) three-leaflet stage with $<36 \mathrm{~cm}^{2}$ in leaf area, (B4) threeleaf stage with $>36 \mathrm{~cm}^{2}$ leaf area, and (B5) flowering adult. Trilliums exhibit epicotyl (shoot) dormancy during the first year as a seedling. This means that the plant develops roots the first year and shoots the next. The photosynthetic structures of trilliums are commonly referred to as "leaves," but technically, the three "leaves" are bracts (Case and Case, 1997; Utech, 2002). 
Leaf area and rhizome volume have been shown to be better indicators of large flowered trillium reproductive success (that is, flowering) than is age (Hanzawa and Kalisz, 1993). The greater the local flowering density, the greater the reproductive success (Knight, 2003). Light availability also influences reproduction. In T. apetalon, a petalless species from Japan, translocation of carbohydrate has priority to the rhizome when light levels are high, but carbohydrate is translocated to the fruit when light levels are low; resources for rhizome and reproduction in subsequent years are limited in the latter case (Ida and Kudo, 2008).

Trillium plants produce seeds that have eliasomes, oilrich fleshy appendages, that attract ants. Dispersal by ants results in short-distance dispersal of up to $50 \mathrm{~cm}$. Ant dispersal can decrease the probability that a large-flowered trillium seed has nearby competing siblings (Kalisz and others, 1999). Long-distance dispersal of large flowered trillium seeds can occur as a result of deer ingestion of fruits (Vellend and others, 2003). For painted trillium (T. undulatum), a specific ant species (Aphaenogaster rudis) appears most important in seed dispersal (Zelikova and others, 2008). Numerous studies have shown that if browsed for too long by overabundant deer, forest vegetation has been altered enough to require plant species reintroduction to restore the groundlayer (Webster (C.R.) and others, 2005; Asnani and others, 2006). Early season browsing of large flowered trillium by deer has been found to be more detrimental to reproduction of plants the following year, than late season browsing (Knight, 2007).

\section{Status of Trilliums at the Indiana Dunes National Lakeshore}

Four Trillium species ${ }^{1}$ are found at the Indiana Dunes National Lakeshore (INDU) (Wilhelm, 1990): nodding trillium (T. cernuum, also called whip-poor-will flower and nodding wakerobin), declined trillium (T. flexipes, also called bent trillium, nodding wakerobin, wood lily, and trinity flower), large flowered trillium (T. grandiflorum, also called large-flowered wakerobin, white trillium, great white trillium, white wakerobin, and trille blanc), and red trillium (T. recurvatum, also called bloody butcher, purple trillium, prairie trillium, purple

\footnotetext{
${ }^{1}$ Common names for these species conform to those in Swink and Wilhelm 1994.
}

wakerobin, bloody noses, and toadshade). Noel Pavlovic found a clump of the white form of ill-scented trillium ( $T$. erectum) growing at a home site north of Hawleywood Road and east of Tremont Road. A specimen was collected there by Ken Klick on May 11, 1989, and is in the INDU herbarium. Otherwise, the population of ill-scented trillium has disappeared, possibly because of white-tailed deer browsing and overcollecting. This species was likely planted by the homeowner at the homesite.

Large flowered and red trillium were probably equally abundant in presettlement times, but habitat destruction, overabundance of deer, and plant poaching have greatly diminished the large flowered trillium populations. Springtime visitors at the Warren Dunes State Park in Sawyer, Michigan, can see hundreds of large flowered trilliums in bloom, as visitors at the Indiana Dunes used to see years ago (fig. 1). At Warren Dunes, deer hunting has prevented deer from decimating the palatable plant populations. Pepoon (1927) stated that large flowered trillium was very abundant in Porter County. Along East State Park Road, there was a large large flowered trillium population that disappeared around 1991 (fig. 2), but it is still common at the Heron Rookery (fig. 3). The famous South Shore and South Bend Railroad poster, printed in 1928, shows abundant large-flowered trillium in a mesophytic pocket slope (fig. 4) (Cohen and McShane, 1998). Red trillium is still widespread, especially in the East Unit of INDU.

Nodding trillium (T. cernuum) was abundant in Chicago but was largely reduced by urban expansion (Pepoon, 1927). The Web site Vplants (www.vplants.org ) has records of two specimens housed at the Morton Arboretum in Lisle, Illinois. One was collected at INDU by Ron Hiebert in 1982 and another by Gerould Wilhelm in 1987. Because the deer have decimated the local nodding trillium population that spans a Glenwood dune ridge, further collections could be devastating, and photographs are more appropriate documentation (fig. 5). The only flowering plants are in an exclosure erected by Noel Pavlovic in the early 1990s, and those are under brush piles that are not accessible to deer.

Declined trillium (T. flexipes) is quite abundant only in the higher quality areas of the Heron Rockery (fig. 6). Declined trillium was reported at the Dunes State Park on the basis of a specimen housed at the Morton Arboretum collected by Floyd Swink on May 4, 1946. It is also reported from Cowles Dunes, Furnessville, Keiser and Pinhook Bog units of the park. 


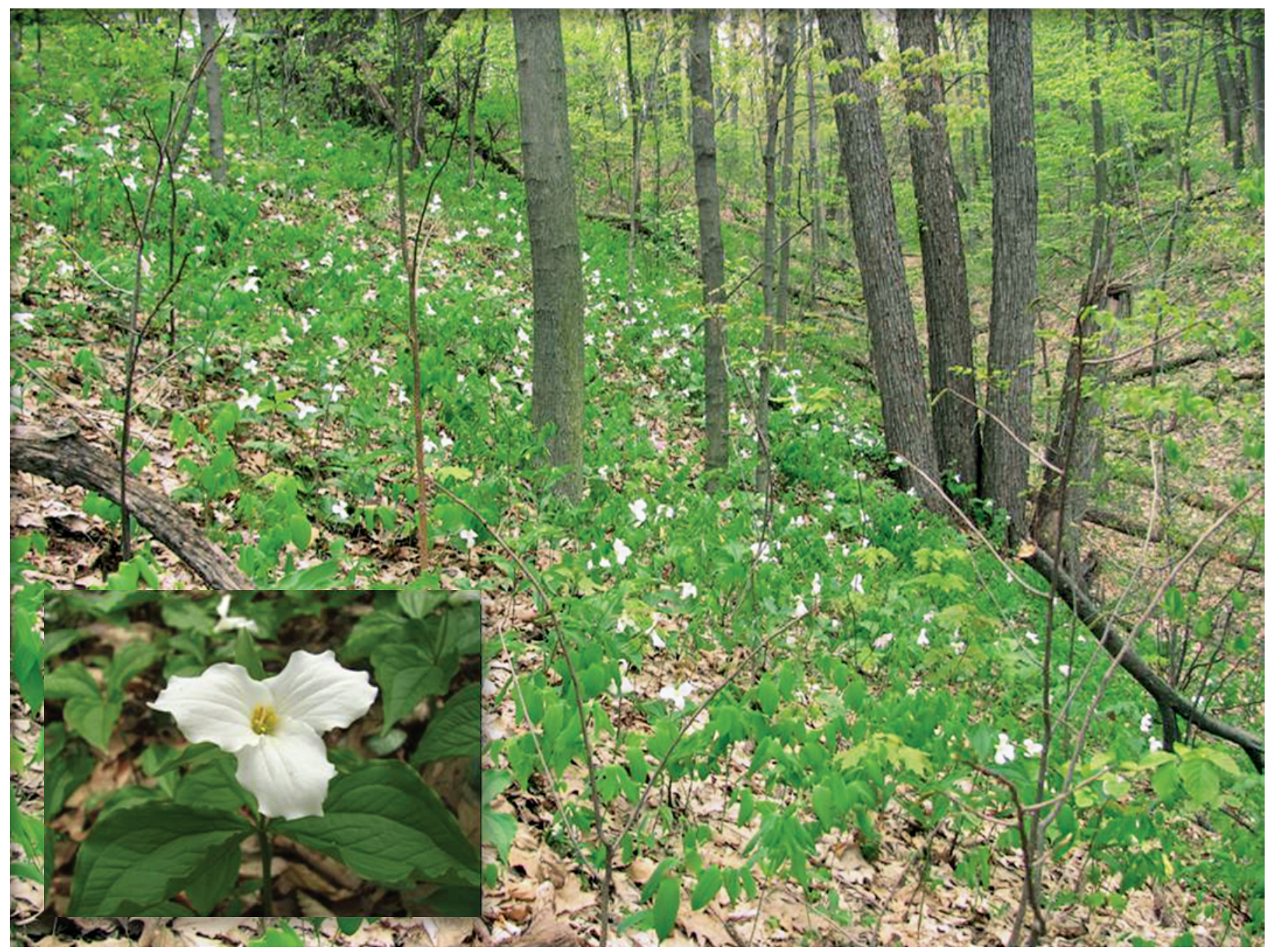

Figure 1. Flowering large-flowered trillium at Warren Dunes in 2009. Inset closeup of flowers. Photographs taken by Stacey LeichtYoung, U.S. Geological Survey. 


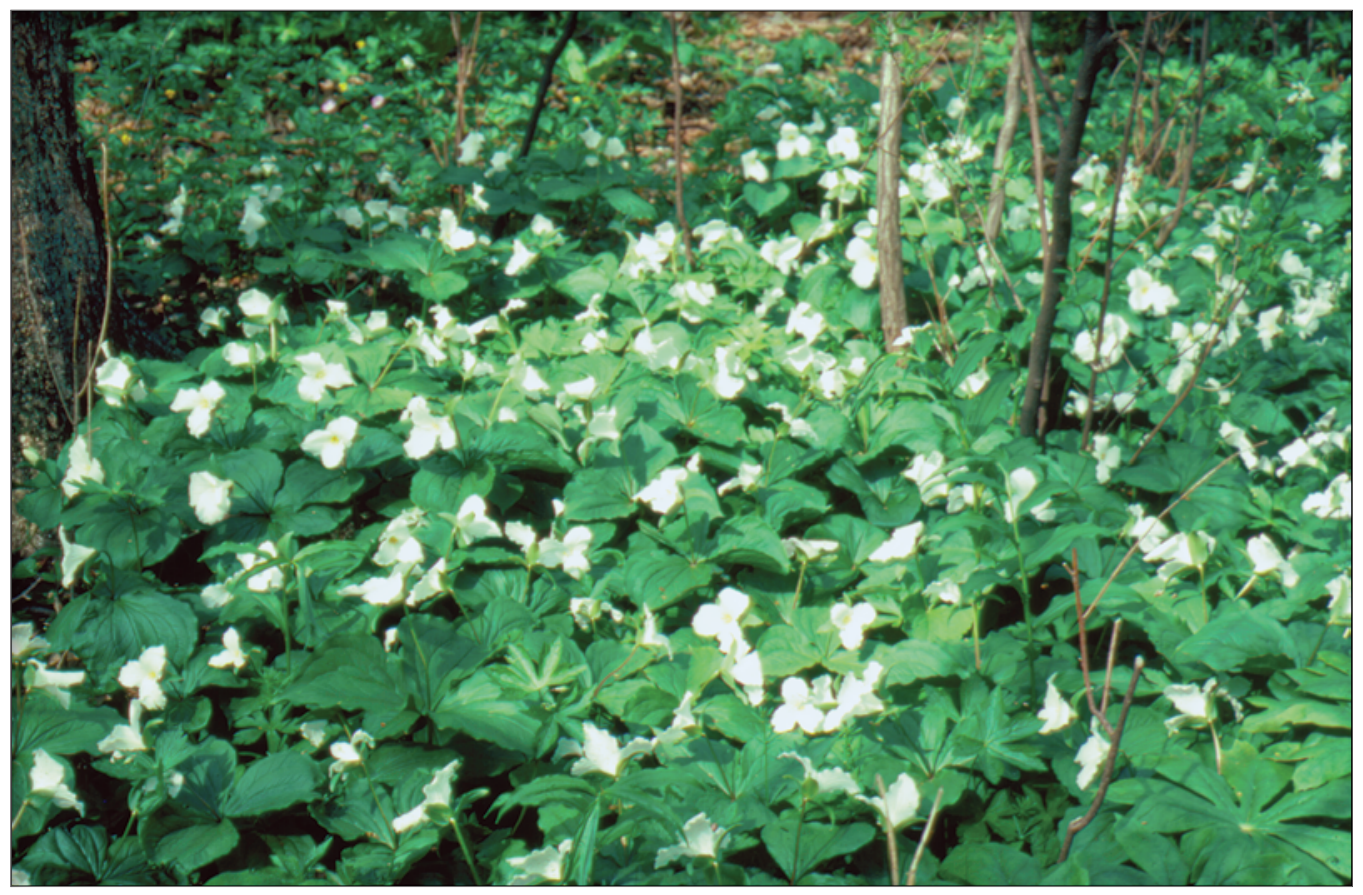

Figure 2. Large-flowered trillium growing on the south side of East State Park Road. Ten years later, in 1991, this population was completely nonflowering. Photograph taken by naturalist Emma Bickham (“Bickie") Pitcher in May 1981.

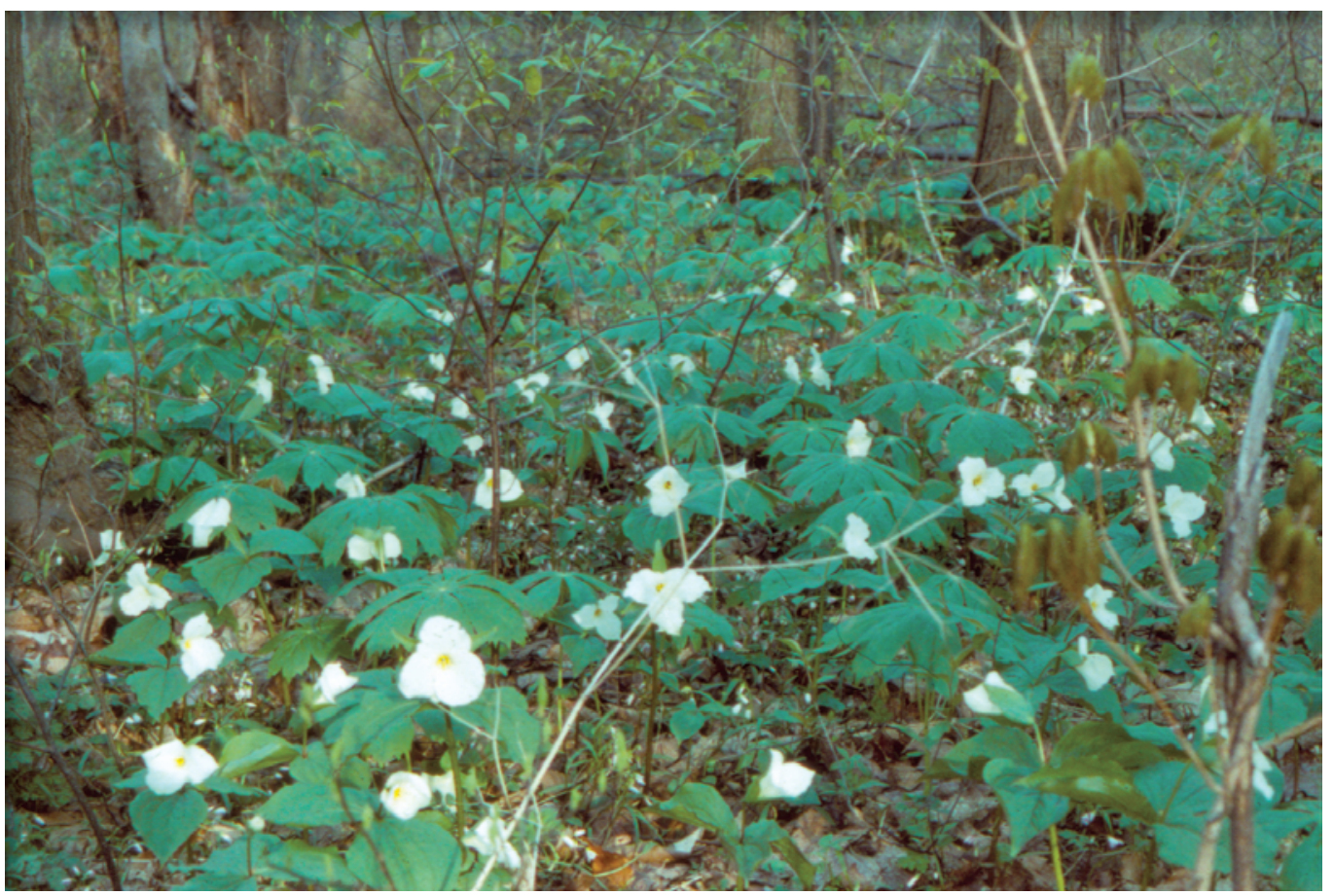

Figure 3. Large-flowered trillium (Trillium grandiflorum) in bloom at the Heron Rookery on May 4, 1984. Photograph taken by Noel Pavlovic, U.S. Geological Survey. 


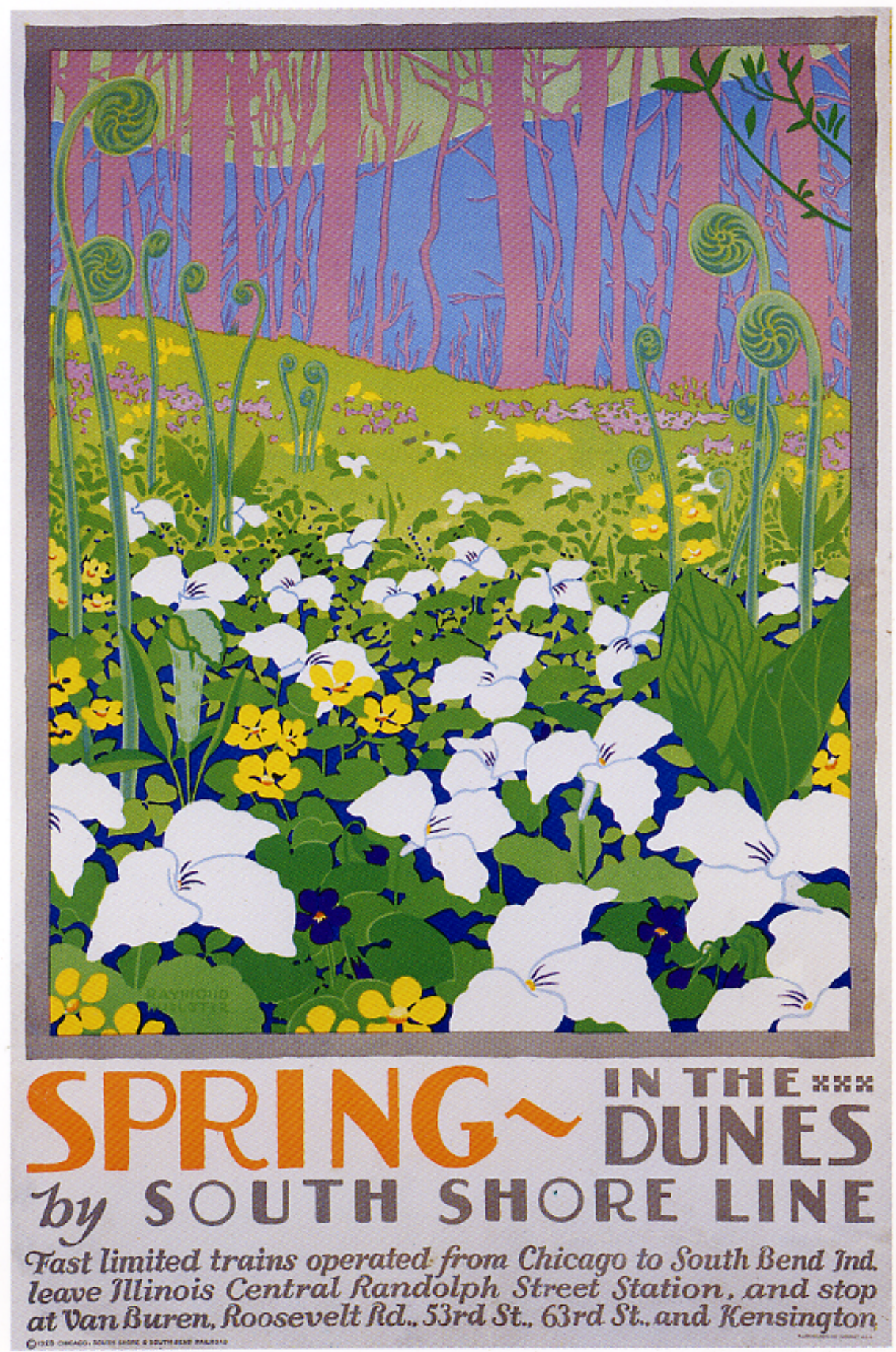

Figure 4. Chicago South Shore and South Bend Railroad Poster showing the abundance of large-flowered trillium (Trillium grandiflorum) on the dune slopes. 


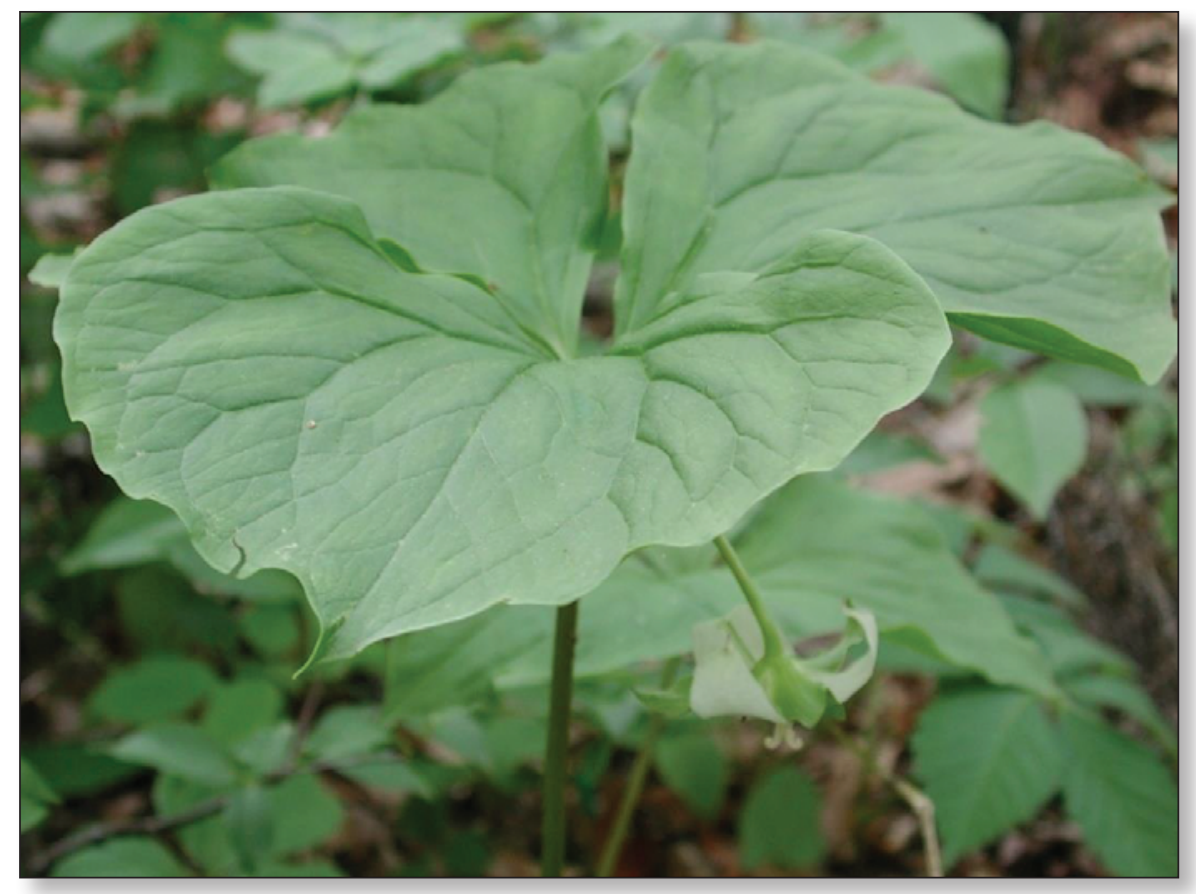

Figure 5. Nodding trillium (Trillium cernuum) flowering in a deer exclosure. Photograph taken by Noel B. Pavlovic, U.S. Geological Survey.

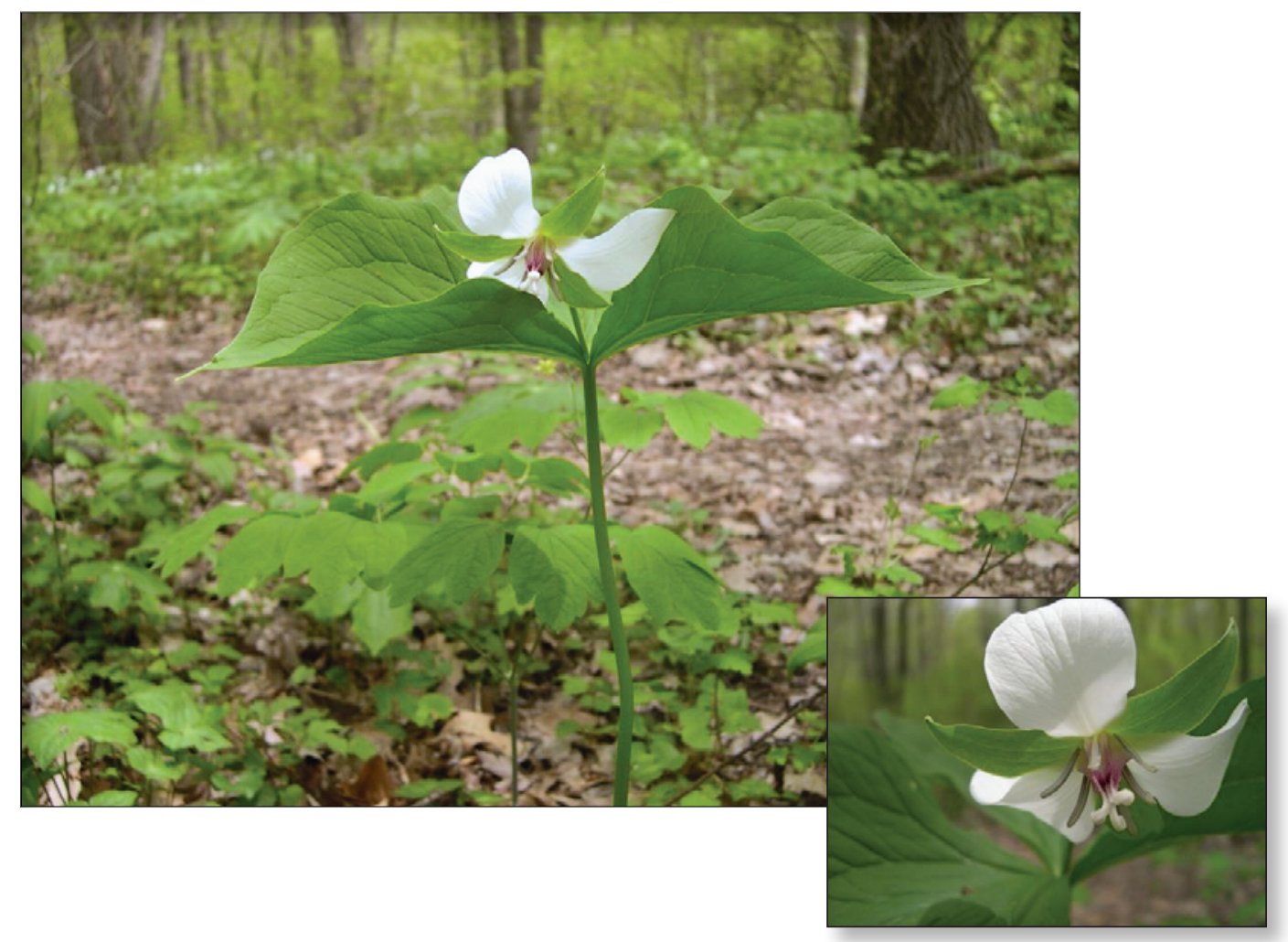

Figure 6. Declined trillium (Trillium flexipes) at the Heron Rookery. Photographs by Stacey Leicht-Young, formerly with U.S. Geological Survey. 


\section{Methods}

\section{Sampling Design}

To assass impacts of herbivory, paired plots were erected between 2002 and 2010 across the East Unit of IDNU at 28 sites (table 1). One plot of each pair was protected (fenced) from deer browsing but permitted access to other, smaller herbivores. The other plot was the control (unfenced), which was exposed to all herbivory. Owing to the rarity of the trillium species, searches for patches required extensive surveys. When an area harboring the target trillium species was located, all patches were flagged. Two patches were then randomly selected for treatment. Once a pair was selected, a coin toss determined which plot was fenced.
Plots were $1 \mathrm{~m}^{2}$ and had different densities among the pairs (table 1). Within each plot, all Trillium stems were measured for height-to-leaf from the ground surface to where the leaf (bracts) attached at the top or to the top of the pedicel to the nearest half centimeter. Flowering (yes or no) was recorded as well as the condition of the leaf (none, incomplete, and yes). When individuals were leaning to one side, the vertical height was measured, not the actual length of the stem.

The data for nodding trillium (T. cernuum) and declined trillium (T. flexipes) were each from a single plot pair. Multiple stems or individuals were sampled in each plot, but these were pseudoreplicates because of plot and density effects (Hurlbert, 1984; Heffner and others, 1996). Each plant was not necessarily independent of each other either because some stems were probably ramets (that is, vegetatively connected). Because growth of stems within a plot was likely to vary as

Table 1. Trillium species sampled by paired plots from 2002-2010. Densities are based on the sum of the enclosed and unenclosed plots.

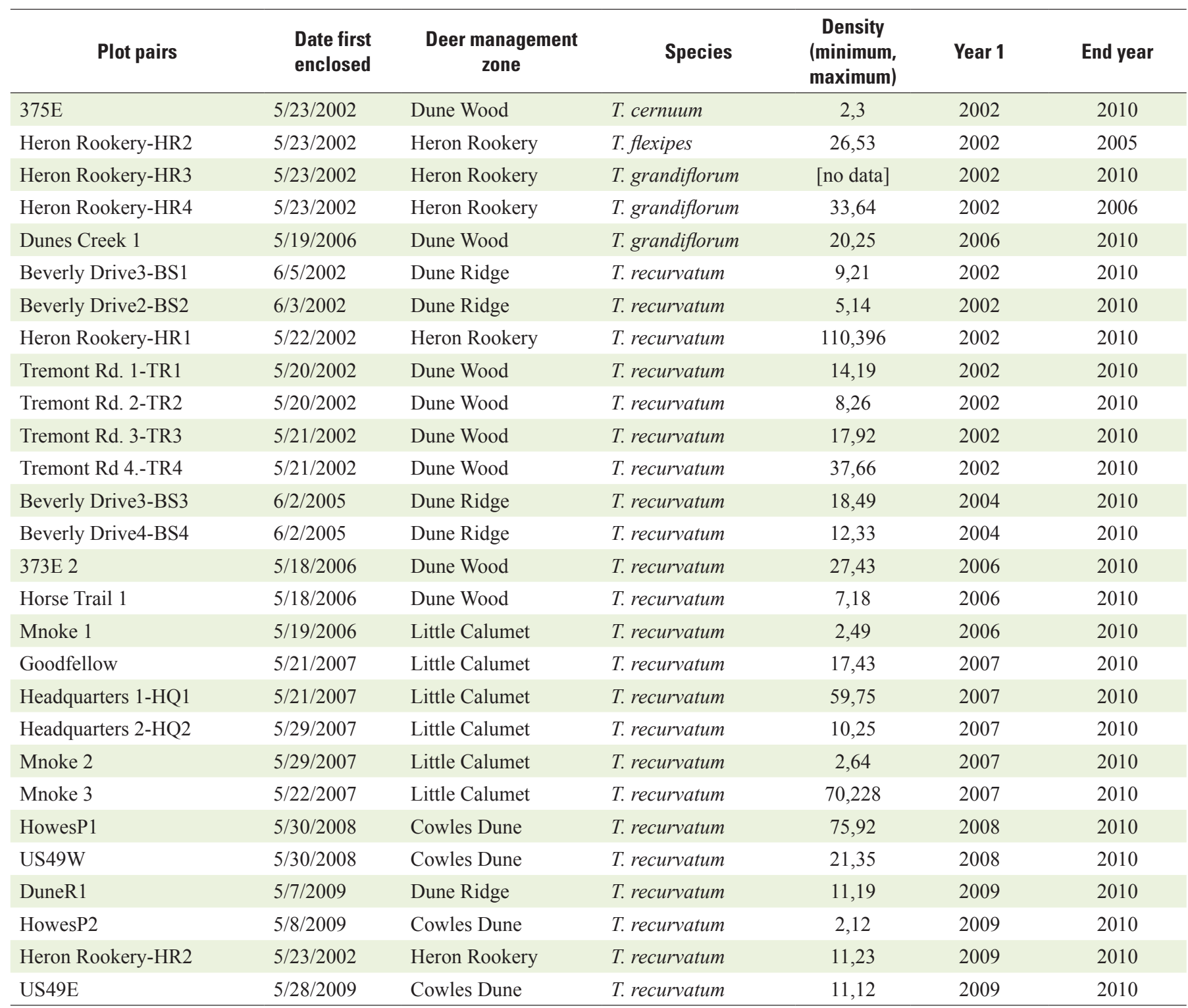


a function of density, any changes due to treatments could be contravened as a result of density effects. Because there was no replication, it is impossible to identify a significant change in height as a result of the treatments for these two species. Large-flowered trillium was sampled from two plots at the Heron Rookery and one from Dune Ridge; however, plot HR4 at the rookery was destroyed after 2005; so, there are two replicates for every year except for three replicates in 2006. Red trillium provided the best possibilities for analysis: we sampled 23 plot pairs. This species has been little studied (Sawyer, 2010). Seven plots were established in 2002, two established in 2004, three in 2006, five in 2007, two in 2008, and four in 2009.

\section{Environmental Parameters}

To capture the weather conditions that Trillium species have experienced, we set the year, "Trillium year," from March 1 to the end of the following February. Because trilliums form the bud for the next year's shoot and go dormant in the fall, we defined growing season as commencing around
March 1, a month before first flowering dates. First flowering dates for nodding trillium, declined trillium, large-flowered trillium, and red trillium were respectively, May 10, April 15, April 6, and April 12 (Swink and Wilhelm, 1994). Weather data from 1952 to 2010 were aggregated by year from March 1 to the end of February to yield total rainfall, total snowfall, mean maximum temperature, and mean minimum temperature.

We used deer density estimates ( no. $\mathrm{km}^{-2}$ ) from spotlighting surveys during 2002 to 2006 to examine deer impacts on trillium height to stem and flowering (Underwood and Knutson, 2011). Surveys were conducted in late February and early March; thus, density estimates preceded measurement of trillium height to stem by 2 months at least. INDU established a total of 11 deer management zones (DMZs) throughout the park (fig. 7). Of these 11 zones, 5 are relevant to our study: Cowles Dune, Dune Ridge, Dune Wood, Heron Rookery, and Little Calumet. Only surveys from the Dune Ridge and Dune Woods DMZs were spatially compatible with the trillium monitoring plot locations (figs.7 and 8) The two DMZs correspond respectively with Beverly Shore 1-4 and Tremont 1-4 plot pairs. 


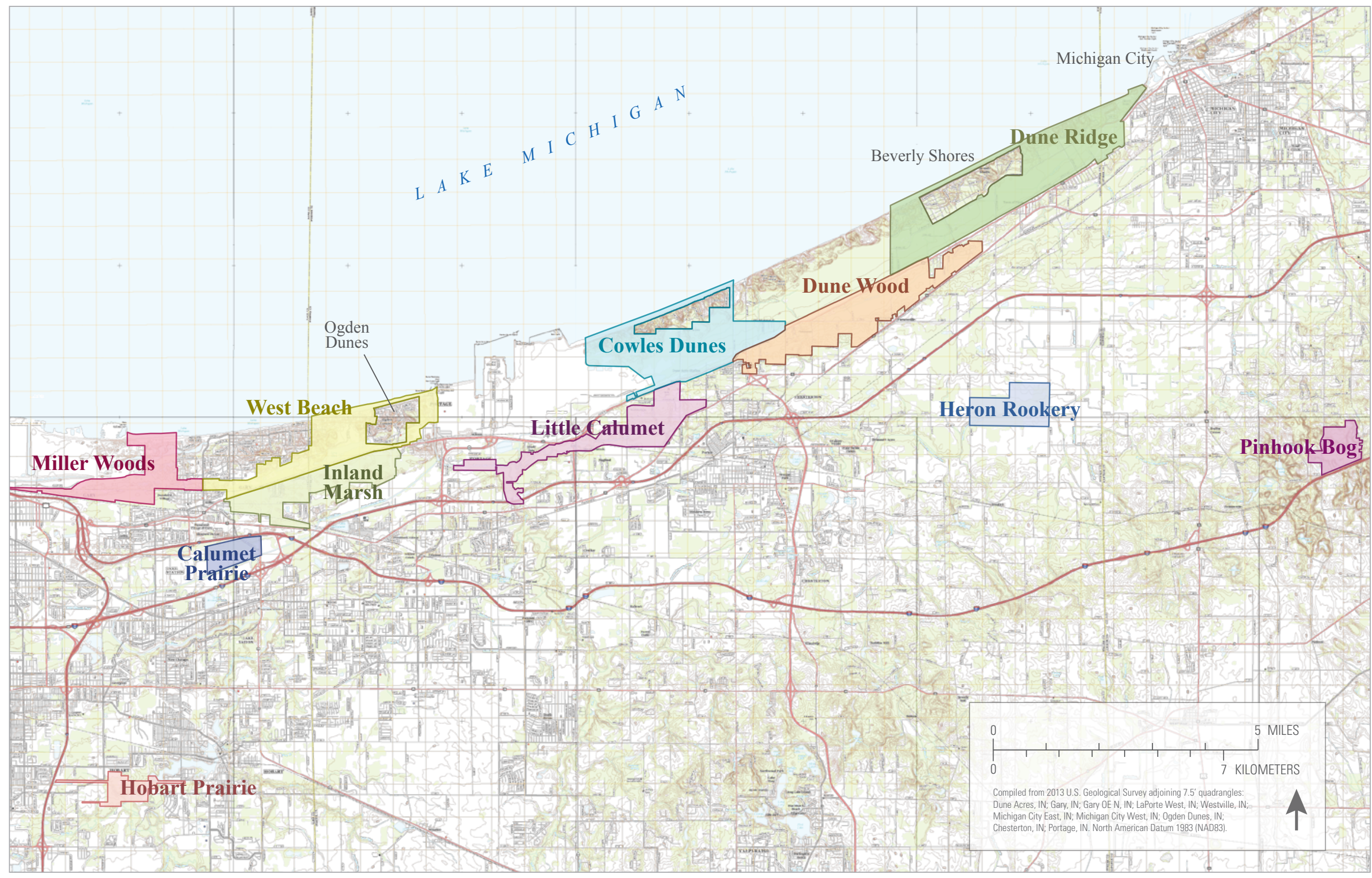

Figure 7. Deer management zones (DMZs) within the Indiana Dunes National Lakeshore. 


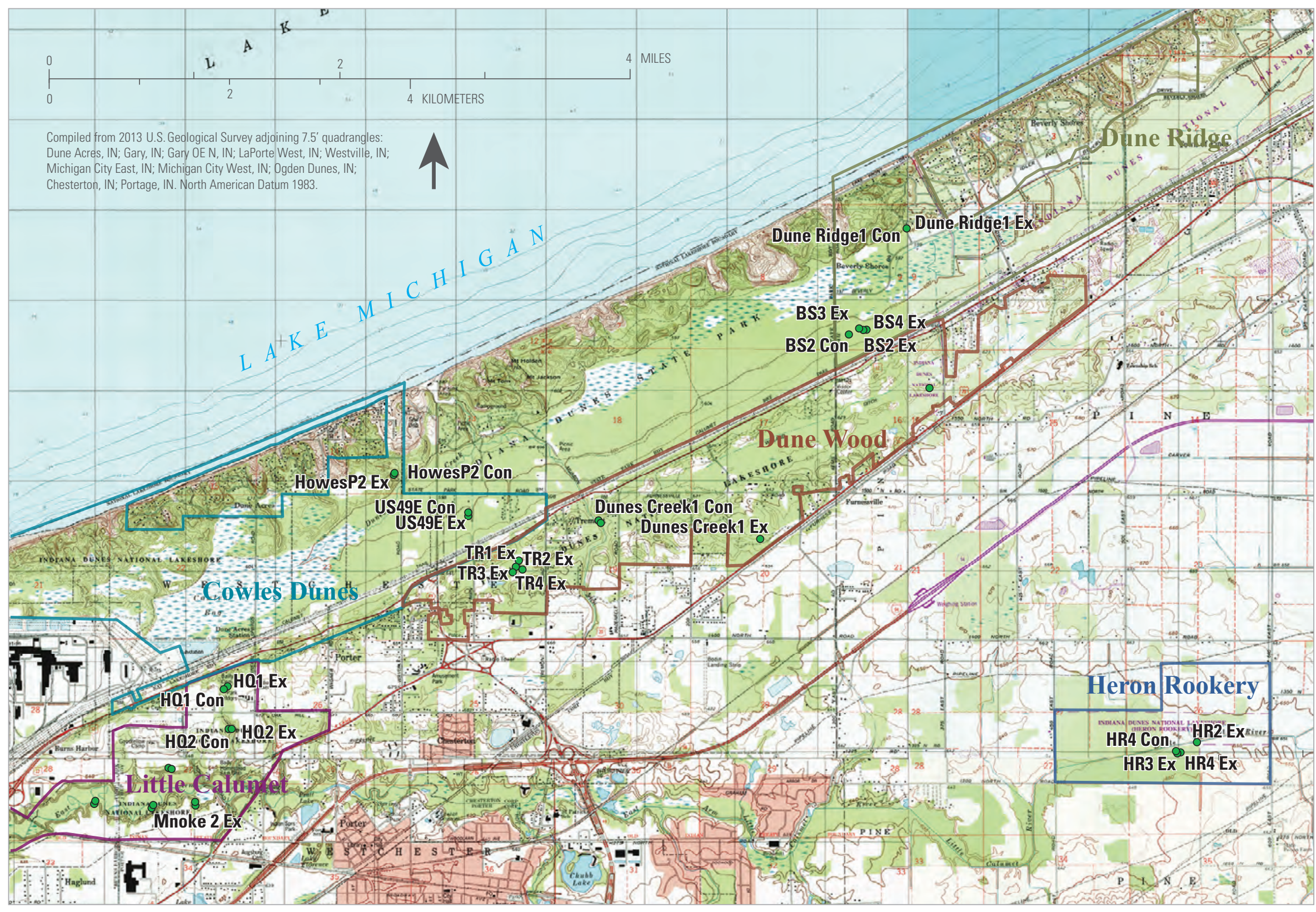

Figure 8. Locations of the paired plots within the DMZs. 


\section{Statistical Analyses}

\section{Flowering Probability by Stem}

The red trillium dataset was analyzed for 2009 , the year when the greatest number of stems was sampled. We calculated general summary statistics of height-to-leaf and substrate for flowering and nonflowering plants. We used logistic regression to examine the probability of flowering for this species. Explanatory variables included height-to-leaf, substrate (moraine versus sand), and their interaction. Nonsignificant two-way interactions were removed first from the models, followed by single effects unless the model fit (Akaike Information Criterion, or AIC) did not improve (Burnham and Anderson, 2002).

\section{Flowering Rate Per Plot}

To examine the relationship between proportion of flowering and explanatory variables, we used generalized linear model (GLM) regression (Crawley, 2007). Explanatory variables were height-to-leaf (ln), substrate, rainfall deviation, temperature deviation, density (ln), and the interactions of substrate by rainfall deviation, substrate by temperature deviation, and height-to-leaf by duration. Because the frequency of flowering was very low in the control treatments, possibly as a result of deer browsing, these control plots were eliminated from the analysis, and treatment was excluded as an explanatory variable. Because plants were sampled without tagging specific individuals, it was impossible to examine the flowering history of any individual. In addition, because measurements were repeated every year, comparisons among years were not independent. We did not use year as an explanatory variable. Residuals were examined for trends that might indicate poor fit of data. Response and explanatory variables were tested for normality, heterogeneity, and multicolinearity by graphical and statistical methods (Tabachnick and Fidell, 2001). Collinear variables were eliminated on the basis of high variance inflation factor (VIF), high correlations, and biological determination of which variable might be most fundamental in relation to the response variable. VIF values greater than 3 were cause to eliminate a variable from the model (Burnham and Anderson, 2002).

\section{Mean Height-to-leaf by Plot}

Histograms of trillium height-to-leaf for the three most common species were examined by species, treatment, and year. Mean heights to leaf and flowering frequency were calculated for each combination of species, treatment, and year. Because the design is a paired-plot treatment, we employed paired t-tests to examine differences in proportion of plants flowering and mean height-to-leaf overall, by year and by duration, for red and large-flowered trillium only.
For red trillium, we used linear regression models in the $\mathrm{R}$ software environment to examine the effects of treatment on mean height-to-leaf. We had to transform the reponse variable because without the transformation heteroscedasticity (Zuur and others, 2010). Independent variables included treatment, substrate, trillium density (ln), rainfall deviation, high-temperature deviation, duration, and the following two-way interactions: treatment $(\mathrm{t})$ by substrate, $\mathrm{t}$ by density, $\mathrm{t}$ by rainfall deviation, $t$ by high-temperature deviation, $t$ by duration, substrate by precipitation deviation, and substrate by high-temperature deviation. Models of mean height to stem were estimated, but lagged raw data suggested strong temporal autocorrelation. We examined the correlation between residuals that were lagged by different time intervals. Correlation coefficients were statistically significantly greater than 0 up to a 4-year lag (2-year lag, $\mathrm{r}=0.69, \mathrm{P}<0.001$; 3-year lag, $\mathrm{r}=0.54, \mathrm{P}<0.001$; 4-year lag, $\mathrm{r}=0.10, \mathrm{P}=0.58$ ), so only models with duration of 0,4 , and 8 years were tested. AIC, deviance, and other statistics were examined to determine the best-fitting model.

To examine importance of deer populations on treatment, we analyze a 2002 to 2006 subset of the previously mentioned plots where deer abundance data were available (Dune Ridge and Dune Wood DMZs) (Underwood and Knutson, 2011). For height, percent flowering, and percent browsed, we calculated the difference between the current-year value and the previous-year value. Similar values were calculated for precipitation, snowfall, mean high temperature, and deer density. The difference in mean high temperature was significantly correlated with the difference in mean low temperature $(\mathrm{r}=0.958, \mathrm{n}$ $=53$ ); consequently, the latter variable was excluded from the analyses. Deviations from mean rainfall and snow were also significantly correlated $(-0.914)$. We removed rainfall from the analysis because snowfall was considered a better variable to use because it might directly influence winter mortality of deer (Potvin and Huot, 1983; Patterson and Power, 2002) and thus indirectly influence trillium height. In a model of change in mean height of trillium for 2002-2006, significant relations were found with treatment, duration, change in deer density, change in mean high temperature, change in trillium density, change in snow cover, and interactions of change in deer density by change in total snowfall and treatment by duration. This model was not significant for changes in percentage flowering and percentage browsed.

For some of the analyses above, we lumped DMZs into larger areas for analysis. The Riverine DMZ included the Little Calumet and the Heron Rookery DMZ. The East Unit DMZ included Cowles Dunes, Dune Ridge, and Dune Wood DMZs. 


\section{Results}

The rank of Trillium species in decreasing order of individual stems sampled was red trillium, 5,774; declined trillium, 366; large-flowered trillium, 345; and nodding trillium, 20. While we present information about all species, only the data from red trillium has a large sample sizes and thus is statistically analyzable.

\section{Means Per Plot}

\section{Nodding Trillium (Trillium cernuum)}

The height-to-leaf of nodding trillium peaked in 2008 and 2009 and ranged from 6 to $36 \mathrm{~cm}$ (fig. 9). Nodding trillium bloomed in 2005-6 and 2008-10. There does not appear to be a height threshold for flowering within the height variation range above. There was only one plant in the control plotpresent only in 2007-and its height was $6 \mathrm{~cm}$. Nothing can be said here about deer pressure on nodding trillium except that the only flowering plants we have seen in the past 20 years are within the deer exclosure and under a brush pile stacked by the INDU Resource Management Staff (fig. 5). Within the

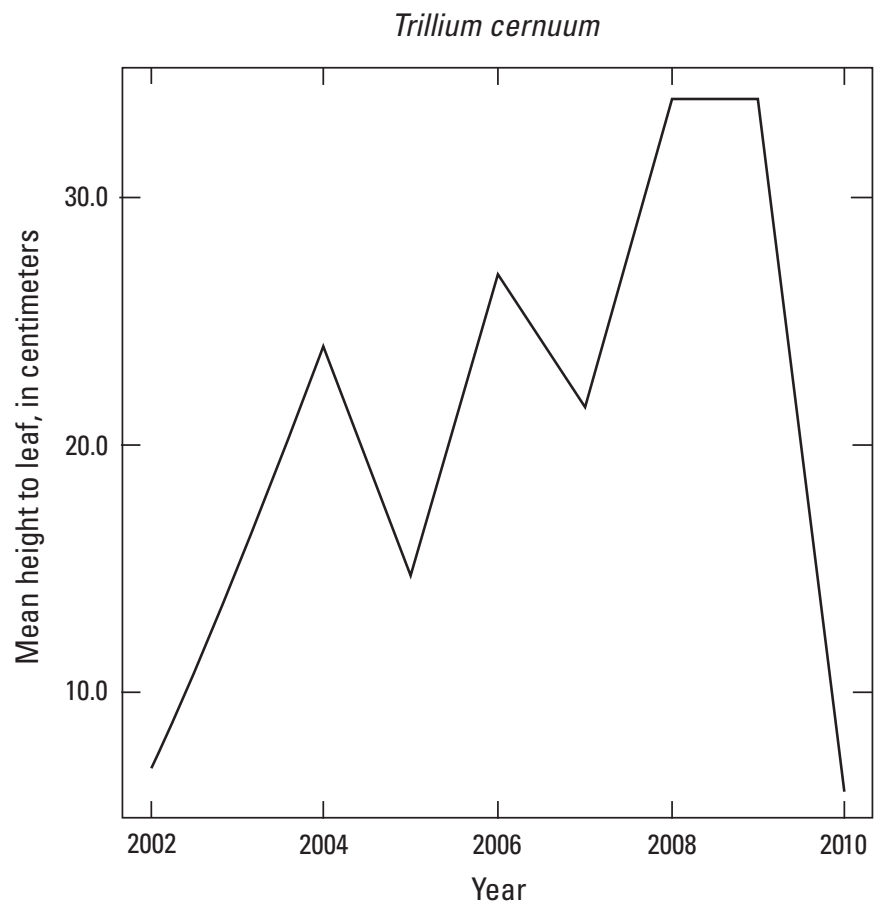

Figure 9. Mean height-to-leaf for nodding trillium (Trillium cernuum), by year. exclosure in 2003 and 2009, plants that flowered were $28 \mathrm{~cm}$ taller than those that did not flower (2003: F 1, 37 =63, P < 0.001; 2009: F 1, $16=28, \mathrm{P}<0.001$, based on square root transformed data). Nonflowering plants were $6.5 \pm 1.1 \mathrm{~cm}$ tall in 2003 and $12.5 \pm 1.7 \mathrm{~cm}$ tall in 2009 , whereas flowering plants were $34 \pm 4.5 \mathrm{~cm}$ tall in 2003 and $40.3 \pm 5.9 \mathrm{~cm}$ tall in 2009.

\section{Declined Trillium (Trillium flexipes)}

Declined trillium was sampled at the Heron Rookery from 2002 to 2010. The data show that plants in the exclosure were 10 to $20 \mathrm{~cm}$ taller than those in the presence of deer and that they regularly flowered at higher frequency compared to those in the presence of deer, especially after 2005 (table 2). In most years, no plants flowered outside the exclosures. Over the 9-year period, flowering outside the exclosures ranged from 0 to 25 percent, whereas flowering in the exclosures ranged from 8 to 72 percent. Without replication, we cannot conclude that there are differences in flowering rate with the observed degree of overlap in flowering rate.

\section{Large-flowered Trillium (Trillium grandiflorum)}

Large-flowered trillium was sampled at the Heron Rookery and the Dune Wood DMZ (table 1). HR3 was sampled even though a tree fell on the plot between 2003 and 2004. Like declined trillium, heights and frequency of flowering of large-flowered trillium in enclosures were greater compared to those in the control plots that were exposed to deer, especially after 2005 (table 2). In the absence of deer, large-flowered trilliums were 6 to $19 \mathrm{~cm}$ taller than outside the exclosures. Over the nine 9-year period, flowering ranged from 0 to 34 percent outside the exclosure and 26 to 82 percent inside the exclosure. These data suggest that the large-flowered trilliums are not blooming because of deer browsing and that deer population reduction could improve trillium blooming success.

Examining the difference by paired t-test in height-to-leaf and percentage flowering by year shows significant differences in only one instance for each variable (table 3 ). If differences between treatments are examined by duration, height-to-leaf become significant in 3 of 5 years. Flowering percentage differed between treatments only in the third year after the exclosure was installed (table 3 ).

As is evident from the discussion of red trillium below, significance is difficult to demonstrate when sample sizes are low; that is, fewer than five replicates (table 3). Nevertheless, we have demonstrated that large-flowered trillium becomes shorter in the presence of deer browsing and also becomes taller in the absence of deer browsing. These size differences have not translated to significant differences in flowering percentage. 
Table 2. Mean height-to-leaf per stem (plus or minus standard error) and percentage of flowering in Trillium species studied from 2002 to 2010.

[The difference row is mean height in exclosure minus that in the control plot. All values are based on individual stems rather than mean per plot. Symbols: \% flower, percent flowering; C, control; E, exclosure]

\begin{tabular}{|c|c|c|c|c|c|c|c|c|c|c|}
\hline \multicolumn{2}{|c|}{ Declined trillium } & \multirow{2}{*}{$\begin{array}{c}2002 \\
44 / 25\end{array}$} & \multirow{2}{*}{$\begin{array}{c}2003 \\
34 / 28\end{array}$} & \multirow{2}{*}{$\begin{array}{c}2004 \\
52 / 31\end{array}$} & \multirow{2}{*}{$\begin{array}{c}2005 \\
24 / 26\end{array}$} & \multirow{2}{*}{$\begin{array}{c}2006 \\
37 / 26\end{array}$} & \multirow{2}{*}{$\begin{array}{c}2007 \\
34 / 32\end{array}$} & \multirow{2}{*}{$\begin{array}{c}2008 \\
11 / 23\end{array}$} & \multirow{2}{*}{$\frac{2009}{25 / 29}$} & \multirow{2}{*}{$\begin{array}{l}2010 \\
9 / 21\end{array}$} \\
\hline & $\mathrm{N}(\mathrm{C} / \mathrm{E})$ & & & & & & & & & \\
\hline Control & Mean height & $20.5 \pm 1.2$ & $18.1 \pm 1.2$ & $20.1 \pm 0.7$ & $17.6 \pm 1.1$ & $17.3 \pm 0.7$ & $12 \pm 0.6$ & $11.4 \pm 1.3$ & $10.6 \pm 0.6$ & $7.3 \pm 0.8$ \\
\hline \multirow[t]{2}{*}{ Exclosure } & Mean height & $19.5 \pm 1.1$ & $24.8 \pm 1$ & $31.4 \pm 1.1$ & $29.5 \pm 1.8$ & $32.7 \pm 1.7$ & $22 \pm 1.8$ & $34.9 \pm 1.9$ & $24.6 \pm 2.5$ & $37.9 \pm 1.8$ \\
\hline & Difference & -1 & 6.7 & 11.3 & 11.9 & 15.4 & 10 & 23.9 & 14 & 30.6 \\
\hline Control & $\%$ flower & 25 & 0 & 1.9 & 0 & 0 & 0 & 0 & 0 & 0 \\
\hline \multirow[t]{2}{*}{ Exclosure } & $\%$ flower & 8 & 50 & 67.7 & 57.7 & 61.5 & 71.9 & 60.9 & 27.6 & 52.4 \\
\hline & Difference & -17 & 50 & 65.8 & 57.7 & 61.5 & 71.9 & 60.9 & 27.6 & 52.4 \\
\hline \multicolumn{2}{|c|}{ White trillium } & 2002 & 2003 & 2004 & 2005 & 2006 & 2007 & 2008 & 2009 & 2010 \\
\hline & $\mathrm{N}(\mathrm{C} / \mathrm{E})$ & $11 / 22$ & $21 / 23$ & $14 / 26$ & $13 / 40$ & $26 / 60$ & $10 / 14$ & $28 / 25$ & $29 / 27$ & $9 / 31$ \\
\hline Control & Mean height & $21.8 \pm 1.4$ & $16.6 \pm 1.0$ & $19.9 \pm 1.0$ & $18.2 \pm 0.9$ & $14.1 \pm 1.0$ & $11.8 \pm 0.9$ & $11.6 \pm 0.9$ & $9.7 \pm 0.7$ & $7 \pm 1$ \\
\hline \multirow[t]{2}{*}{ Exclosure } & Mean height & $19.0 \pm 0.9$ & $24.7 \pm 0.9$ & $29.9 \pm 1.0$ & $27.5 \pm 0.9$ & $28.0 \pm 1.2$ & $15.6 \pm 1.3$ & $24.8 \pm 1.5$ & $26.5 \pm 1.6$ & $26.2 \pm 1.5$ \\
\hline & Difference & -2.8 & 8.2 & 10.0 & 9.3 & 13.9 & 3.8 & 13.2 & 16.8 & 19.2 \\
\hline Control & $\%$ flower & 34.4 & 0 & 14.7 & 0 & 2.6 & 0 & 0 & 0 & 0 \\
\hline \multirow[t]{2}{*}{ Exclosure } & $\%$ flower & 41.9 & 78.1 & 80.6 & 70.8 & 61.8 & 26.1 & 72 & 81.5 & 77.4 \\
\hline & Difference & 7.5 & 78.1 & 65.9 & 70.8 & 59.2 & 26.1 & 72 & 81.5 & 77.4 \\
\hline \multicolumn{2}{|c|}{ Red trillium } & Difference & 2003 & 2004 & 2005 & 2006 & 2007 & 2008 & 2009 & 2010 \\
\hline & $\mathrm{N}(\mathrm{C} / \mathrm{E})$ & $119 / 185$ & $125 / 204$ & $114 / 160$ & $142 / 236$ & $305 / 295$ & $355 / 445$ & $537 / 715$ & $535 / 715$ & $263 / 310$ \\
\hline Control & Mean height & $13.9 \pm 0.8$ & $13.5 \pm 0.7$ & $13 \pm 0.8$ & $13.6 \pm 0.6$ & $11.7 \pm 0.4$ & $8.5 \pm 0.2$ & $8.3 \pm 0.1$ & $8 \pm 0.1$ & $6.1 \pm 0.2$ \\
\hline \multirow[t]{2}{*}{ Exclosure } & Mean height & $14.7 \pm 0.6$ & $13.8 \pm 0.5$ & $19.2 \pm 0.8$ & $19.3 \pm 0.6$ & $18.4 \pm 0.6$ & $14.4 \pm 0.5$ & $15.3 \pm 0.3$ & $13.2 \pm 0.3$ & $13.1 \pm 0.5$ \\
\hline & Difference & 0.8 & 0.3 & 6.2 & 5.7 & 6.7 & 5.9 & 7 & 5.2 & 7 \\
\hline Control & $\%$ flower & 20.2 & 27.2 & 19.3 & 9.2 & 19.3 & 2.5 & 1.1 & 1.5 & 4.2 \\
\hline \multirow[t]{2}{*}{ Exclosure } & $\%$ flower & 10.8 & 37.7 & 46.3 & 44.1 & 35.3 & 33 & 21.1 & 21.8 & 38.1 \\
\hline & Difference & -9.4 & 10.5 & 27.0 & 34.9 & 16 & 30.5 & 20 & 20.3 & 33.9 \\
\hline
\end{tabular}


Table 3. Comparison of large-flowered trillium (Trillium grandiflorum) percentage flowering and height-to-leaf (plus or minus standard error) between treatments, by year and duration, based on paired t-tests.

[ns, not significant; *, $\mathrm{P}<0.05$ and $>0.01$. For year, $\mathrm{n}=2$ except for $\mathrm{n}=3$ in 2006. For duration, $\mathrm{n}=3$ ]

\begin{tabular}{|c|c|c|c|c|c|c|}
\hline \multirow{2}{*}{\multicolumn{2}{|c|}{ Year }} & \multicolumn{2}{|c|}{ Height to leaf } & & \multicolumn{2}{|c|}{ Percent flowering } \\
\hline & & \multirow{2}{*}{$\begin{array}{c}\text { Control } \\
20.6 \pm 3.8\end{array}$} & \multirow{2}{*}{$\begin{array}{l}\text { Exclosure } \\
18.8 \pm 0.5\end{array}$} & & \multirow{2}{*}{$\begin{array}{c}\text { Control } \\
32.7 \pm 5.4\end{array}$} & \multirow{2}{*}{$\begin{array}{l}\text { Exclosure } \\
36.1 \pm 13.9\end{array}$} \\
\hline 2002 & ns & & & ns & & \\
\hline 2004 & ns & $19.5 \pm 2.3$ & $29.4 \pm 1.1$ & ns & $16.8 \pm 11.8$ & $83.5 \pm 6.5$ \\
\hline 2005 & ns & $18 \pm 1.7$ & $26 \pm 2.2$ & ns & $0 \pm 0$ & $62.5 \pm 12.5$ \\
\hline 2008 & ns & $10.6 \pm 3.6$ & $23.7 \pm 5.4$ & ns & $0 \pm 0$ & $65 \pm 35$ \\
\hline 2009 & ns & $8.7 \pm 2.6$ & $26.7 \pm 6$ & ns & $0 \pm 0$ & $81.9 \pm 10.4$ \\
\hline 2010 & ns & $8.4 \pm 2.6$ & $26.1 \pm 4.2$ & $*$ & $0 \pm 0$ & $77.3 \pm 4$ \\
\hline \multicolumn{2}{|c|}{ Duration } & \multicolumn{2}{|c|}{ Height to leaf } & & \multicolumn{2}{|c|}{ Percent flowering } \\
\hline 2 & $*$ & $15.3 \pm 4.4$ & $25.7 \pm 3.8$ & & $11.2 \pm 8.8$ & $65.6 \pm 18.2$ \\
\hline 3 & ns & $14 \pm 4.1$ & $24.2 \pm 2.2$ & & $0 \pm 0$ & $65.5 \pm 7.8$ \\
\hline 4 & $*$ & $13.8 \pm 4$ & $26.3 \pm 2.9$ & & $2.8 \pm 2.8$ & $60 \pm 17.7$ \\
\hline
\end{tabular}

\section{Red Trillium (Trillium recurvatum)-}

Red trillium is the most abundant Trillium species in the park because it can live and reproduce in a diversity of habitats ranging from oak savanna to oak woods and mesophytic forests. On average, the mean height-to-leaf of red trillium decreased by $7.8 \mathrm{~cm}$ outside the exclosures from 2002 to 2010, whereas the mean height-to-leaf increased from 14.7 to 19.3 $\mathrm{cm}$ and then decreased to the beginning height-to-leaf (13.1) in the exclosures over the same period (table 2). Plants in the exclosure were on average 5 to $7 \mathrm{~cm}$ taller compared to those growing outside the exclosure. This pattern is demonstrated by the increasing difference in values over the 9 years. The net difference in height is thus the result of both plants unexposed to browsing growing larger and plants exposed to browsing decreasing in size. Percentage of flowering plants increased in the exclosures while decreasing in the exclosures resulting in range of flowering from 1 to 27 percent outside the exclosure and 11 to 46 percent inside the exclosure. The difference in percent flowering ranged from -9 to 35 percent.

Several state variables would be expected to influence Trillium height-to-leaf. Although flowering plants would be expected to be taller, height-to-leaf probably influences flowering rather than flowering being an influence on greater height-to-leaf. Plants that have been protected longer from deer browsing would be expected to be larger and flower more readily, as confirmed in the previous analyses; thus, we would expect an interaction between duration and flowering to influence plant height. Flowering plants might be the tallest plants exposed to deer browsing if deer browsing takes only the leaves and not part of the stem. But because the tallest plants would be the most easily browsed and because deer might take part of the stem as well, we could expect an interaction between flowering and browsing to influence height to stem. In conclusion, one would expect an interaction between both flowering and duration, and between flowering and browsing to influence plant height. Leaning would not be expected to interact with flowering or duration, but it might be a random effect to be tested separately.

Over the 8 years of study, the percentage of blooming plants varied over time and was consistently lower in the control plots on average than in the exclosure plots except in 2002, the year the exclosure was installed (fig. 10A and table 2). The frequency of browsed plants was not significantly different between the control and exclosed plants except in 2005 and 2009, when the frequency of browsed plants exposed to deer was significantly higher (fig. 10B). The percentage of leaning plants varied among years but did not differ between the treatments (fig. 10C). Senescent plants were present only in 2002, and the percentage of their occurrence did not differ among the treatments. (fig. 10D). 
$A$

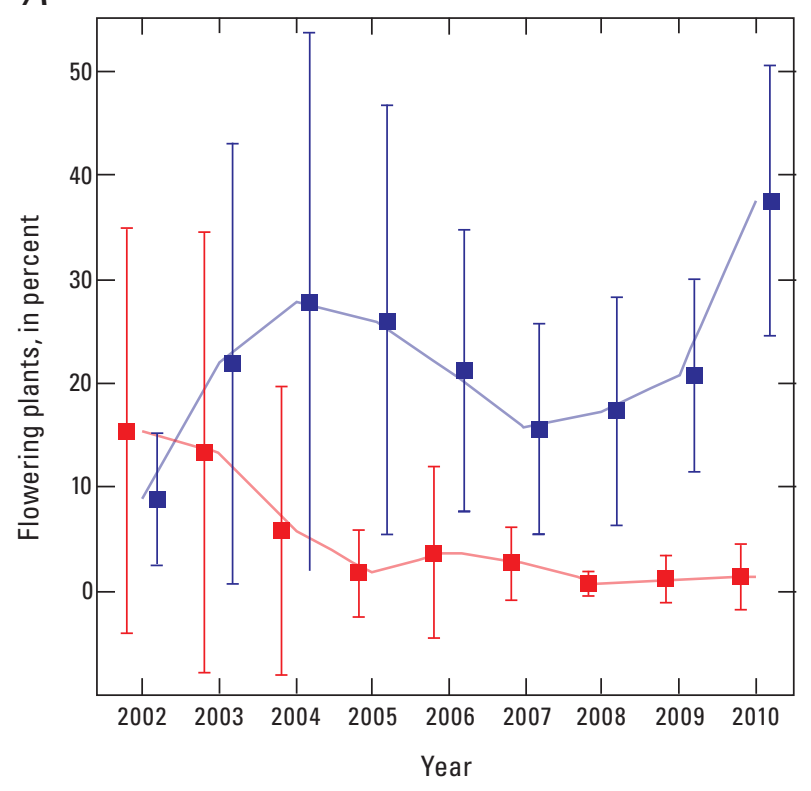

\section{C}

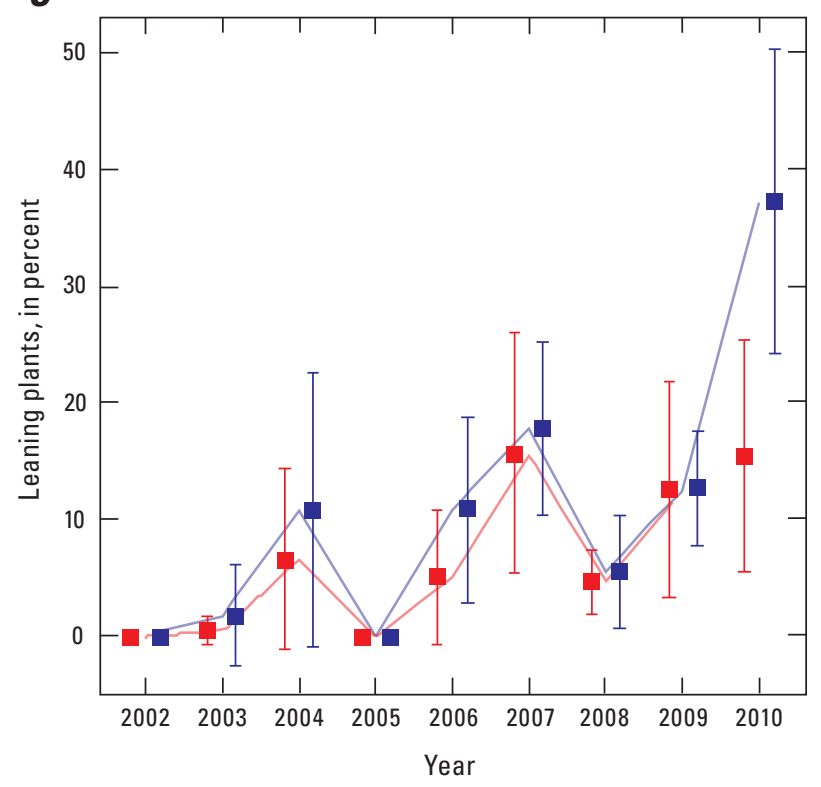

B

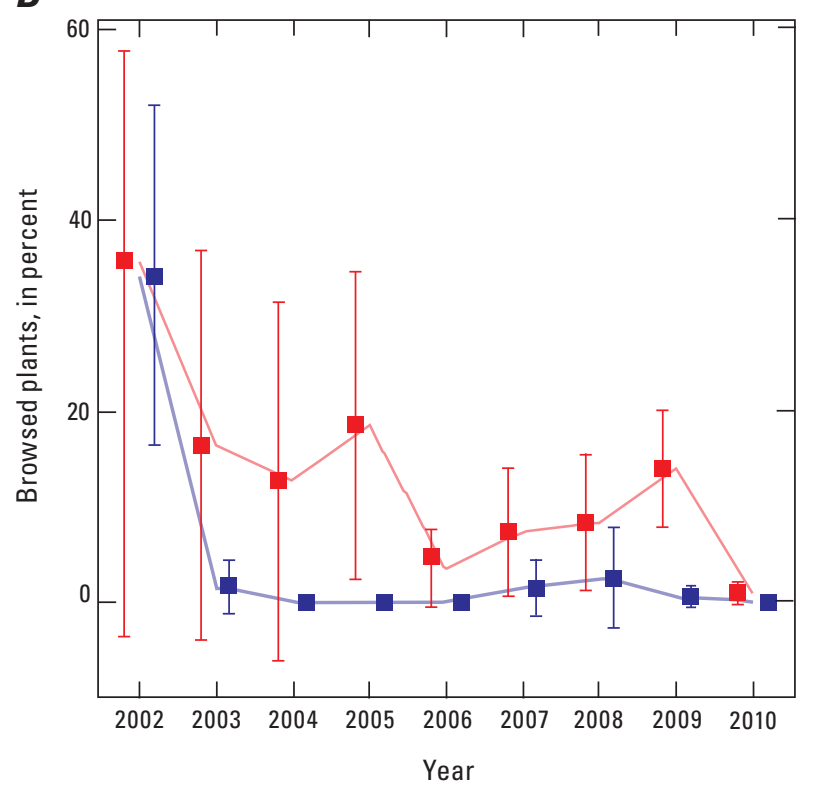

$D$

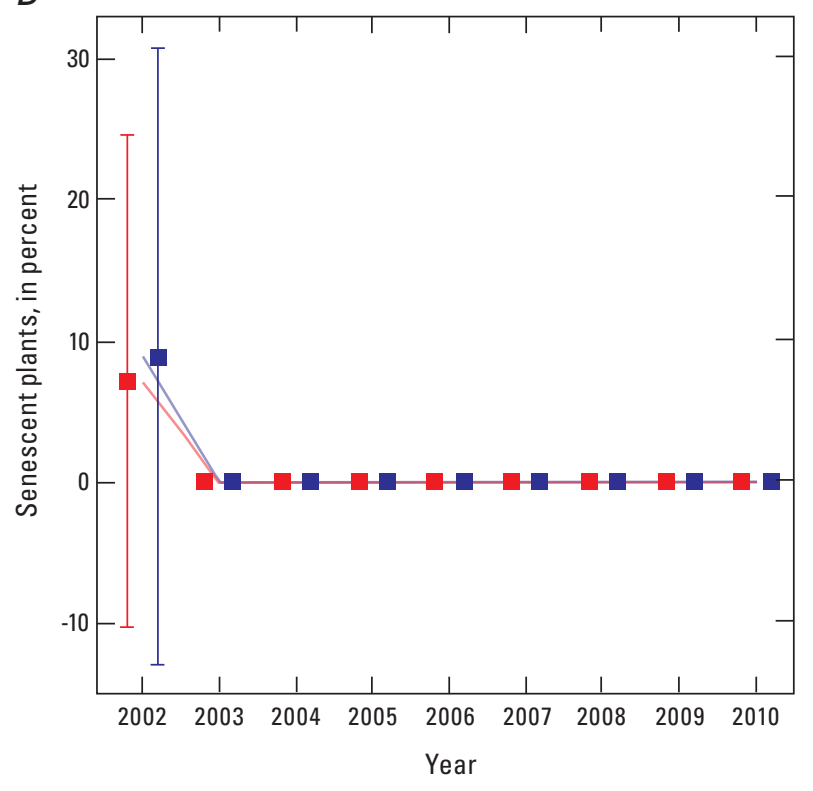

Figure 10. Temporal trends in red trillium (Trillium recurvatum): $A$, Percent flowering. $B$, Browsed plants. $C$, Leaning plants. $D$, Senescent plants. 


\section{Analysis of Flowering Individual Stems in 2009}

Flowering plants in 2009 were significantly taller $(6 \mathrm{~cm})$ on the moraine soils compared to the sand dune soils: $20.7 \pm$ $1.2 \mathrm{~cm}$ versus $27.2 \pm 0.8 \mathrm{~cm}(\mathrm{~F} 1,162=20, \mathrm{P}=0.004)$. Nevertheless, the smallest flowering red trillium on sand was $4 \mathrm{~cm}$ tall and on moraine soils was $3.5 \mathrm{~cm}$ tall. The largest flowering plants were $37 \mathrm{~cm}$ tall on sand and $43 \mathrm{~cm}$ tall on moraine soils. Nonflowering plants had an average height of $9.7 \pm 0.2$ $\mathrm{cm}$ and did not differ significantly among soil types (F 1,557 = $1.1, \mathrm{P}=0.293)$.
The most parsimonious model for flowering probability had both substrate and height-to-leaf (ln) as variables (AIC $=360.73$, McFadden's rho $=0.542$, Naglekerke's R2 $=0.67$, ROC $=0.92$, correct classification $=92.5$ percent; table 4 , fig. 11). The 50 percent probability of flowering is approximately $18 \mathrm{~cm}$ on sand and $20 \mathrm{~cm}$ on the moraine; the height-to-leaf at 33 percent probability of flowering is, respectively, 14 and 16 $\mathrm{cm}$, and the height-to-leaf at 25 percent probability of flowering is, respectively, 12 and $14 \mathrm{~cm}$.
Figure 11. Sigmoidal model of flowering probability of red trillium (Trillium recurvatum), by height-to-leaf and substrate.

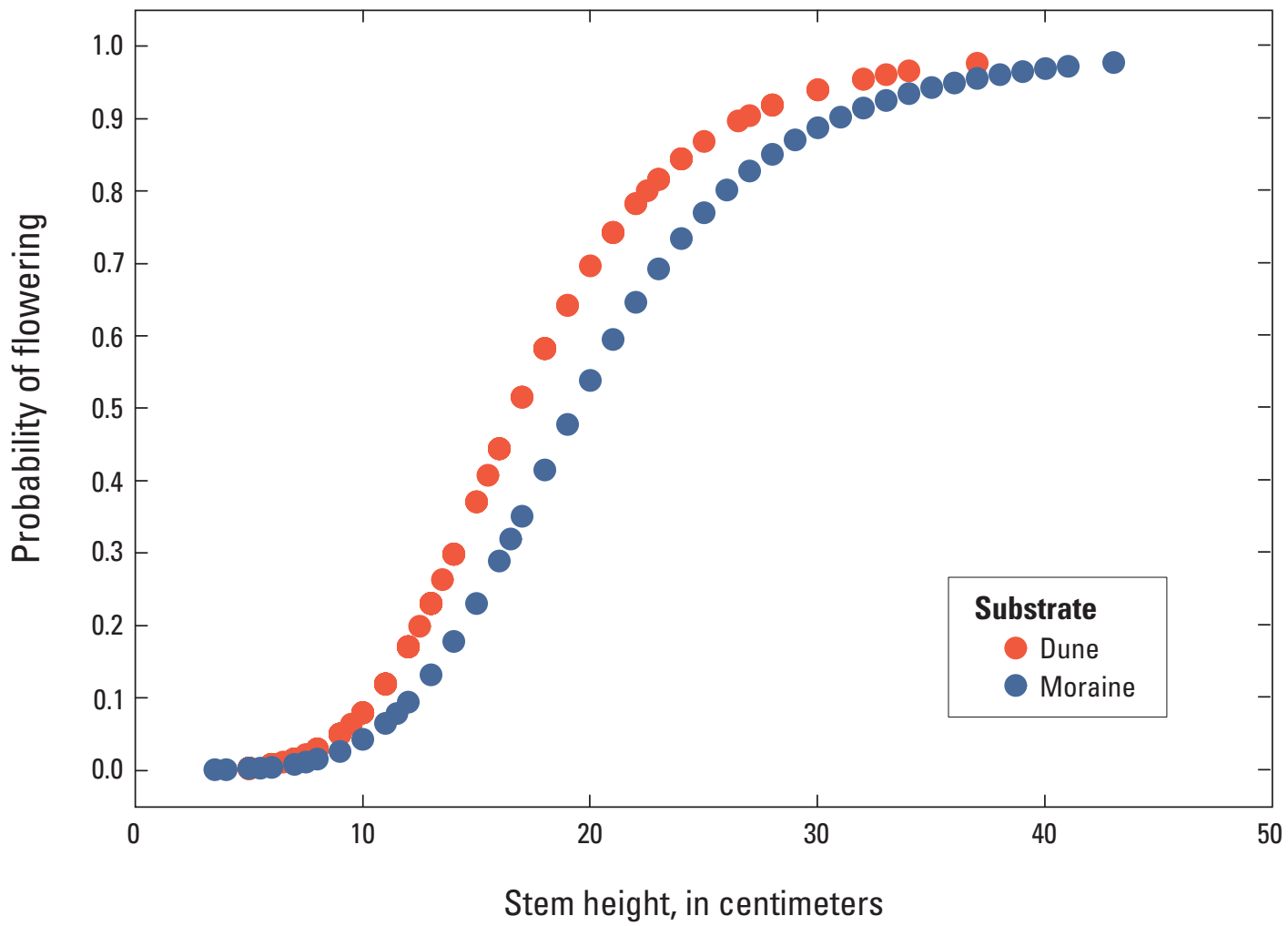

Table 4. Statistics for models of red trillium flowering probability (logistic regression) and proportion of plants flowering (GLM regression).

\begin{tabular}{lccc}
\hline \multicolumn{1}{c}{ Flowering percentage } & Coefficients & Standard errors & $\mathbf{z}$ \\
\hline Intercept & -13.32 & 0.97 & $-13.782 * * *$ \\
Height to leaf $(\ln )$ & 4.724 & 0.35 & $13.382^{* * *}$ \\
Substrate [Moraine $=1]$ & -0.68 & 0.29 & $-2.314 *$ \\
\hline \multicolumn{1}{c}{ Flowering percentage } & Coefficients & Standard errors & $\mathbf{z}$ \\
\hline Intercept & -91.04 & 7.89 & $-11.53 * * *$ \\
Height to leaf $(\ln )$ & 45.97 & 3.3 & $13.936 * *$ \\
Rainfall deviation & -0.48 & 0.15 & $-3.24 * *$ \\
Duration & 1.32 & 0.54 & \\
\hline
\end{tabular}




\section{Proportion of Flowering Plants by Plot, Year, and Duration}

The percentage of flowering red trillium plants was not significantly different between treatments in 2002 and 2003, but thereafter, the proportion of flowering plants was higher in the exclosures compared to the control plots (table 5). However, analysis by duration is the more logical classification because it relativizes treatments to the time that has elapsed since the installation of the exclosure or how long deer have been excluded. By duration, there were no significant differences in proportion of flowering the year of the setup of the exclosures; thereafter, 28 percent flowered in exclosures and 3 percent flowered in control plots (table 5). Percent flowering increased in the exclosures while decreasing in the control plots, resulting in ranges of 11 to 46 percent and 1 to 27 percent, respectively. Of the 23 control plots, only 1 had flowering red trillium for the whole duration (HR1), whereas one only had flowering at duration 0 (TR2), at duration 0 to 1 (TR1), at duration 1 to 3 (Mnoke1), and at duration 5 (BS1); thus, 18 control plots ( 78 percent) had no flowering individuals during the course of the entire study. Standard deviations of percent flowering were not significantly different between treatments during the first year and thereafter was equally significantly greater or not in the control compared to the exclosure (table 6).

At the Dunewood DMZ, there were significantly greater number of plants flowering in the enclosures that were in place from 2 to 5 years' duration (table 7). There were no significantly different flowering proportions between treatments in the Little Calumet DMZ (table 7).

At the Riverine DMZ (Little Calumet plus Heron Rookery DMZ), significant differences were found in the percentage of plants flowering in second year of protection (table 8). In the East Unit DMZ (Cowles Dunes, Dune Ridge, and Dune Wood combined), percent flowering was significantly different for most durations, except towards longer durations when the sample sizes were decreasing.

Proportion of Trillium recurvatum stems flowering was significantly related to height-to-leaf $(\ln )$, rainfall deviation, and duration (table 4, fig. 12). As shown in figure 11, the probability of 50 percent flowering occurs at approximately $20 \mathrm{~cm}$ mean height-to-leaf.

\section{Mean Red Trillium Height-to-Leaf, Paired Comparisons}

The mean height of red trillium plants was not significantly different between treatments in 2002 and 2003; however, after that, mean height was always significantly greater in the exclosure (table 9). The mean height-to-leaf of the plants was not significantly different when the plots were set up, but by the second season (duration $=1$ ), the heights diverged and were significantly different from each other (table 9). By the fourth and sixth year after being fenced, mean height-to-leaf reached a peak between 14 and $15 \mathrm{~cm}$ in exclosures compared to fluctuating between 6 and $8 \mathrm{~cm}$ in control plots. On average, control plants were $5.7 \mathrm{~cm}$ shorter than exclusion plants (paired t $8=-7.7, \mathrm{P}<0.001$, respectively, 7.5 and $13.3 \mathrm{~cm}$ ) (table 9). In addition, the standard deviation of height increased significantly in exclosures compared to control plots (table 6). Mean height (ln) varied with red trillium density and treatment by duration, despite consisting of aggregate data among all pairs (table 10). Height-to-leaf increased at a greater rate with increasing duration in the exclosures, whereas it decreased slightly in the control plots (fig. 13).

When paired t-tests were done by DMZ and duration, results for most DMZs with five or fewer replicates were statistically insignificant. Rather than indicating the deer were not having an impact on height-to-leaf, these results are a function of small sample size (note decreasing significance as sample size decreases in tables 11 and 12). Only in the Dune Wood and Little Calumet DMZs, where sample sizes were 6, were there significant differences in height-to-leaf (table 11).

In a followup analysis on DMZs that had small sample sizes (table 11), we combined the Dune Wood, Dune Ridge, and Cowles Dunes DMZs into one unit called East Unit and analyzed it separately (table 13). In that analysis, mean heightto-leaf became statistically significant when duration increased beyond the initial installation of the exclosure, showing that red trillium will grow taller in the absence of deer throughout the East Unit. 
Table 5. Mean percent flowering plants per paired control and exclosure plots for red trillium (Trillium recurvatum).

[Significance assessed by use of paired t-test. Symbols: ns, not significant; *, $0.01>\mathrm{P}<0.05 ; * *, \mathrm{P}<0.01$; ***, $\mathrm{P}<0.001$ ]

\begin{tabular}{|c|c|c|c|c|c|c|c|}
\hline Year & $\mathbf{N}$ & Control & Exclosure & Duration & $\mathbf{N}$ & Control & Exclosure \\
\hline $2002 \mathrm{~ns}$ & 7 & $15.4 \pm 8$ & $8.9 \pm 2.6$ & $0 \mathrm{~ns}$ & 23 & $4.7 \pm 2.8$ & $7.4 \pm 3.2$ \\
\hline $2003 \mathrm{~ns}$ & 7 & $15.5 \pm 9.8$ & $25.6 \pm 9.3$ & $1 *$ & 19 & $5.1 \pm 3.2$ & $21.5 \pm 6.4$ \\
\hline $2005 *$ & 9 & $1.8 \pm 1.8$ & $26.1 \pm 8.9$ & $3 * * *$ & 16 & $2.4 \pm 1.6$ & $25.8 \pm 5.4$ \\
\hline $2006 * *$ & 12 & $3.8 \pm 3.8$ & $21.2 \pm 6.2$ & $4 * *$ & 11 & $4.1 \pm 4.1$ & $29 \pm 6.3$ \\
\hline $2009 * * *$ & 21 & $1.2 \pm 1$ & $21.3 \pm 4.8$ & $7 *$ & 5 & $0.5 \pm 0.5$ & $29.7 \pm 7.9$ \\
\hline $2010 * * *$ & 17 & $1.6 \pm 1.6$ & $40 \pm 6.7$ & $8 * *$ & 5 & $5.4 \pm 5.4$ & $53.8 \pm 12$ \\
\hline Total $* * *$ & 114 & $3.6 \pm 1$ & $23.2 \pm 2.3$ & Total $* * *$ & 114 & $3.3 \pm 0.6$ & $25.6 \pm 3.2$ \\
\hline
\end{tabular}

Table 6. Mean standard deviation of height-to-leaf (SD height) and percent browsed individuals of red trillium (Trillium recurvatum) per paired control and exclosure plots.

[Significance assessed by use of paired t-test. Symbols: ns, not significant; *, $0.01>\mathrm{P}<0.05$; **, $\mathrm{P}<0.01$; *** $\mathrm{P}<0.001$; N, number of plot pairs]

\begin{tabular}{|c|c|c|c|c|c|}
\hline \multirow{2}{*}{ Duration } & \multirow{2}{*}{$\mathbf{N}$} & \multicolumn{2}{|c|}{ Percent browsed } & \multicolumn{2}{|c|}{ SD height } \\
\hline & & Control & Exclosure & Control & Exclosure \\
\hline 0 & 23 & $16 \pm 4 \mathrm{~ns}$ & $14 \pm 4$ & $2.7 \pm 0.4 \mathrm{~ns}$ & $3.2 \pm 0.5$ \\
\hline 2 & 18 & $10 \pm 4^{*}$ & $0 \pm 0$ & $2.0 \pm 0.3 * * *$ & $5.0 \pm 0.6$ \\
\hline 3 & 16 & $12 \pm 4 * *$ & $0 \pm 0$ & $2.4 \pm 0.5^{* *}$ & $5.6 \pm 0.9$ \\
\hline 5 & 9 & $11 \pm 4^{*}$ & $0 \pm 0$ & $1.9 \pm 0.6^{*}$ & $5.8 \pm 1.2$ \\
\hline 6 & 8 & $2 \pm 1 \mathrm{~ns}$ & $0 \pm 0$ & $1.9 \pm 0.4^{* *}$ & $6.9 \pm 1.4$ \\
\hline 7 & 5 & $15 \pm 7 \mathrm{~ns}$ & $0 \pm 0$ & $1.9 \pm 0.3 * *$ & $7.9 \pm 1.1$ \\
\hline 8 & 5 & $0 \pm 0 \mathrm{~ns}$ & $0 \pm 0$ & $2.3 \pm 0.5 * * *$ & $9.8 \pm 0.3$ \\
\hline Mean & 9 & $9 \pm 2 * *$ & $2 \pm 2$ & $2.7 \pm 0.3 * * *$ & $5.0 \pm 0.3$ \\
\hline
\end{tabular}

Table 7. Mean percent flowering plants per paired control and exclosure plots, by deer management zones (Dune Wood and Little Calumet), for red trillium (Trillium recurvatum).

[Significance assessed by use of paired t-test. Symbols: ns, not significant; *, $0.01>\mathrm{P}<0.05$; **, P $<0.01$; ***, P $<0.001$; N, number of plot pairs]

\begin{tabular}{|c|c|c|c|c|c|c|}
\hline \multirow[b]{2}{*}{ Duration } & \multicolumn{3}{|c|}{ Dune Wood DMZ } & \multicolumn{3}{|c|}{ Little Calumet DMZ } \\
\hline & $\mathbf{N}$ & Control & Exclosure & $\mathbf{N}$ & Control & Exclosure \\
\hline 0 & $6 \mathrm{~ns}$ & $11.7 \pm 8.3$ & $5.9 \pm 3.0$ & $6 \mathrm{~ns}$ & $0 \pm 0$ & $2.7 \pm 2.7$ \\
\hline 2 & $6 *$ & $0 \pm 0$ & $35.4 \pm 10$ & $6 \mathrm{~ns}$ & $1.5 \pm 1.5$ & $12.1 \pm 4.4$ \\
\hline 3 & $6 * *$ & $0 \pm 0$ & $41.7 \pm 7.1$ & $5 \mathrm{~ns}$ & $4.3 \pm 4.3$ & $18.2 \pm 7.3$ \\
\hline 5 & $4 *$ & $0 \pm 0$ & $36.1 \pm 7.9$ & & & \\
\hline 6 & $4 \mathrm{~ns}$ & $0 \pm 0$ & $43.7 \pm 16.2$ & & & \\
\hline 7 & $3 \mathrm{~ns}$ & $0 \pm 0$ & $34.7 \pm 10.7$ & & & \\
\hline 8 & $2 \mathrm{~ns}$ & $0 \pm 0$ & $52.7 \pm 19.7$ & & & \\
\hline
\end{tabular}


Table 8. Mean percent flowering plants per paired control and exclosure plots for red trillium (Trillium recurvatum) for the Riverine and East Unit deer management zones (DMZs).

[Significance assessed by use of paired t-test. Symbols: ns, not significant; *, $0.01>\mathrm{P}<0.05 ; * *, \mathrm{P}<0.01$; ***, $\mathrm{P}<0.001$; N, number of plot pairs]

\begin{tabular}{|c|c|c|c|c|c|c|}
\hline \multirow[b]{2}{*}{ Duration } & \multicolumn{3}{|c|}{ Riverine DMZ } & \multicolumn{3}{|c|}{ East Unit DMZ } \\
\hline & $\mathbf{N}$ & Control & Exclosure & $\mathbf{N}$ & Control & Exclosure \\
\hline 0 & $8 \mathrm{~ns}$ & $4.8 \pm 4.8$ & $12.7 \pm 8.7$ & $15 \mathrm{~ns}$ & $4.7 \pm 3.5$ & $4.6 \pm 1.6$ \\
\hline 2 & $7 *$ & $8.0 \pm 6.6$ & $22.4 \pm 10.9$ & $11 * *$ & $0 \pm 0$ & $16.4 \pm 6.7$ \\
\hline 3 & $6 \mathrm{~ns}$ & $6.3 \pm 4.1$ & $24 \pm 8.3$ & $10 * *$ & $0 \pm 0$ & $26.8 \pm 7.4$ \\
\hline 5 & & & & $8 \mathrm{~ns}$ & $3.1 \pm 3.1$ & $19.5 \pm 7.4$ \\
\hline 6 & & & & $7 *$ & $0 \pm 0$ & $31.3 \pm 10.9$ \\
\hline 7 & & & & $4 \mathrm{~ns}$ & $0 \pm 0$ & $28.1 \pm 10$ \\
\hline 8 & & & & $4 *$ & $0 \pm 0$ & $44.2 \pm 9.2$ \\
\hline
\end{tabular}

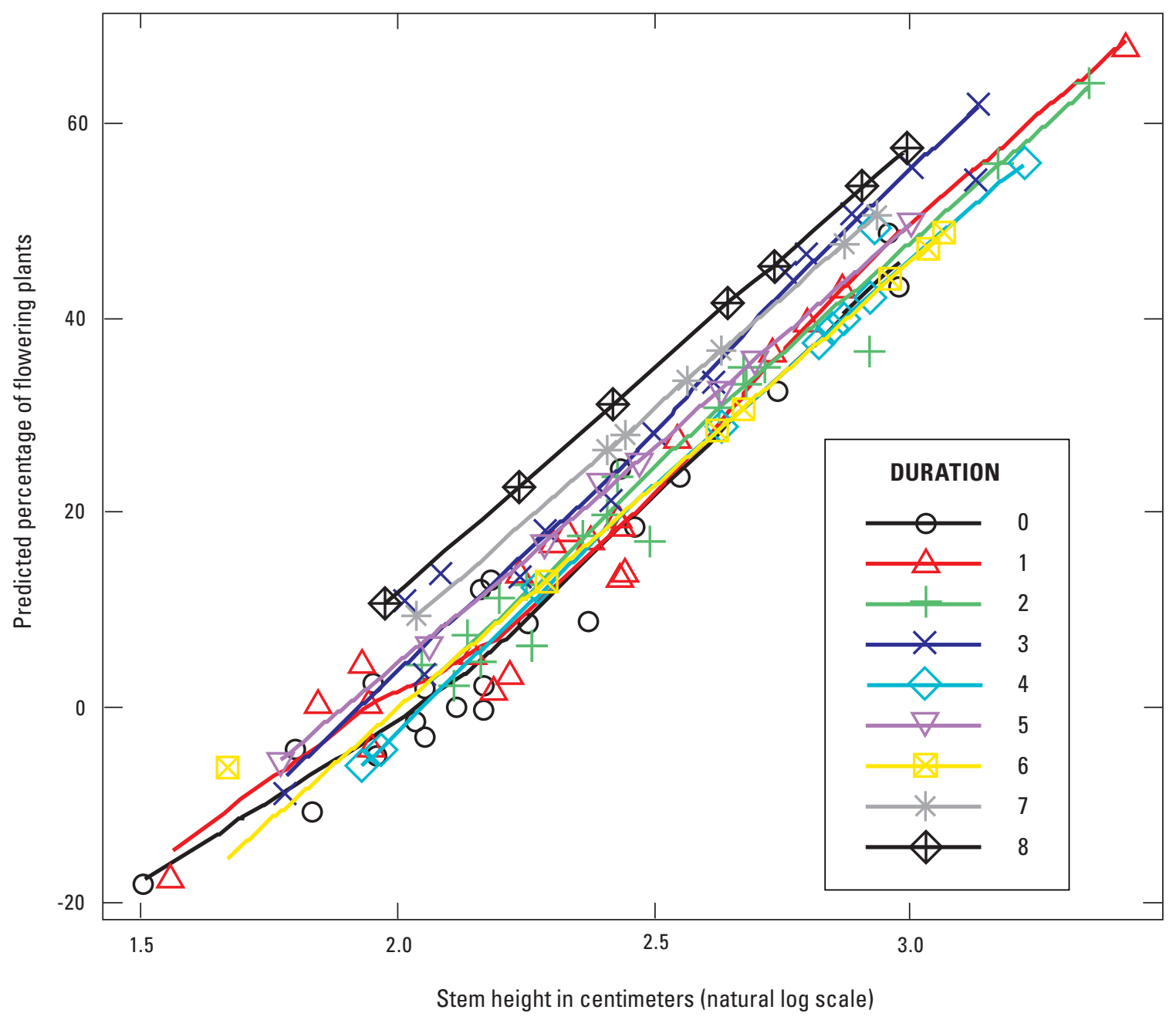

Figure 12. Predicted mean percentage of flowering by height of stem and duration of protection for red trillium (Trillium recurvatum). Upper black line is for duration $=8$ years. 
Table 9. Mean height-to-leaf of red trillium (Trillium recurvatum) plants, by year and duration.

[Significance assessed by use of paired t-test. Symbols: ns, not significant; *, $0.01>\mathrm{P}<0.05$; **, $\mathrm{P}<0.01$; ***, $\mathrm{P}<0.001$; N, number of plot pairs]

\begin{tabular}{|c|c|c|c|c|c|c|c|}
\hline Year & $\mathbf{N}$ & Control & Exclosure & Duration & $\mathbf{N}$ & Control & Exclosure \\
\hline $2002 \mathrm{~ns}$ & 7 & $10.2 \pm 1.9$ & $9.4 \pm 1.8$ & $0 \mathrm{~ns}$ & 23 & $8.8 \pm 0.7$ & $10 \pm 0.8$ \\
\hline $2003 \mathrm{~ns}$ & 6 & $8.5 \pm 1.9$ & $11.4 \pm 2$ & $1 * *$ & 19 & $7.9 \pm 0.7$ & $11.5 \pm 1.2$ \\
\hline $2005 *$ & 9 & $9.1 \pm 1.1$ & $13.5 \pm 2.1$ & $3 * * *$ & 16 & $7.9 \pm 0.8$ & $13.2 \pm 1.4$ \\
\hline $2006 * *$ & 12 & $8.4 \pm 0.8$ & $13.4 \pm 1.6$ & $4 * *$ & 11 & $7.7 \pm 1$ & $14.5 \pm 1.8$ \\
\hline $2008 * * *$ & 19 & $8.2 \pm 0.5$ & $12.6 \pm 1$ & $6 * * *$ & 8 & $7.4 \pm 0.8$ & $14.8 \pm 2$ \\
\hline $2009 * * *$ & 21 & $7.6 \pm 0.4$ & $12.5 \pm 0.9$ & $7 * * *$ & 5 & $8.2 \pm 0.5$ & $14.6 \pm 1.6$ \\
\hline $2010 * * *$ & 17 & $5.9 \pm 0.3$ & $13.9 \pm 1.4$ & $8 * *$ & 5 & $6.2 \pm 0.8$ & $15 \pm 2.2$ \\
\hline Total $* * *$ & 115 & $7.9 \pm 0.3$ & $12.6 \pm 0.5$ & Mean *** & 9 & $7.6 \pm 0.3$ & $12.9 \pm 0.5$ \\
\hline
\end{tabular}

Table 10. Parameters for model of red trillium (Trillium recurvatum) height-to-leaf and change in height to leaf between years.

[P-values in bold print indicate statistically significant differences]

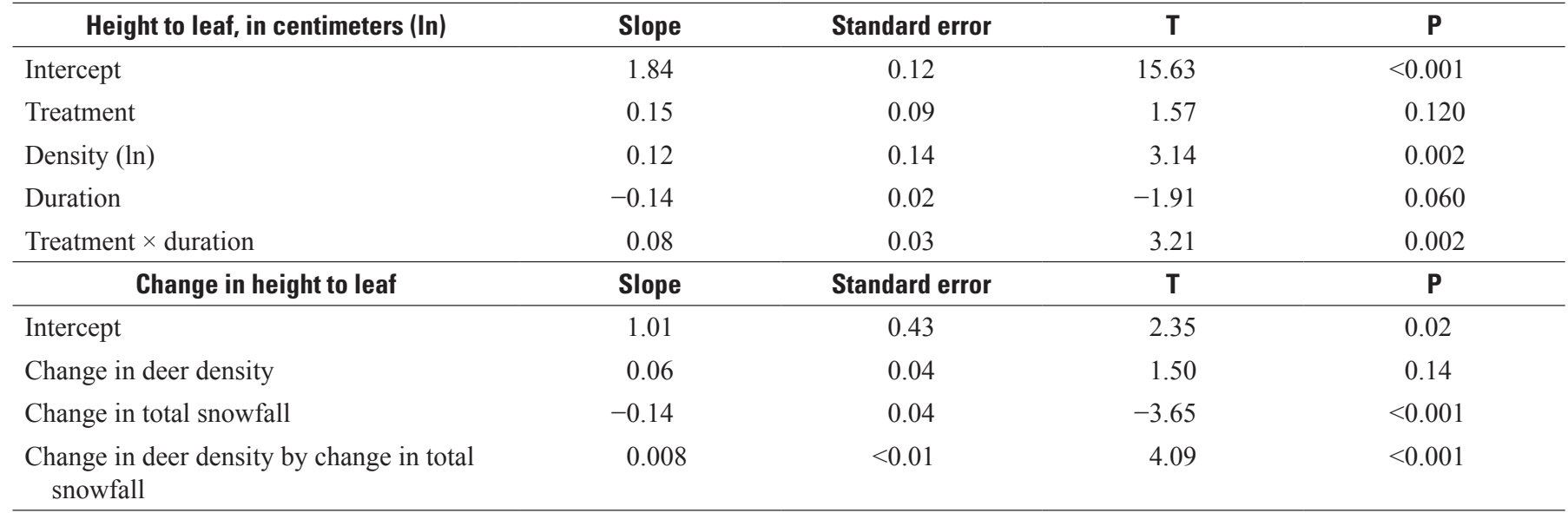

Figure 13. Height-to-leaf, by treatment and duration.

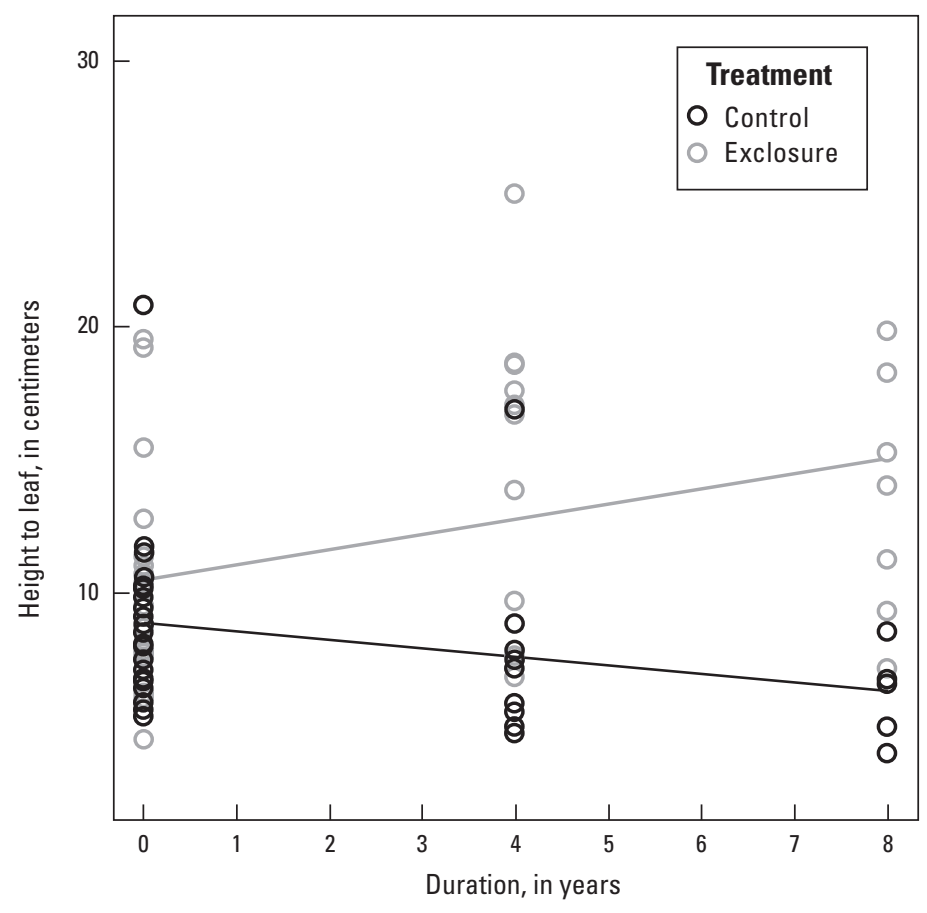


Table 11. Mean red trillium (Trillium recurvatum) height-to-leaf with paired t-test sample size, by treatment by duration of exclosure.

[Significance assessed by use of paired t-test. Symbols: ns, not significant; *, $0.01>\mathrm{P}<0.05 ; * *, \mathrm{P}<0.01$; ***, $\mathrm{P}<0.001$; N, number of plot pairs]

\begin{tabular}{|c|c|c|c|c|c|c|}
\hline \multirow[b]{2}{*}{ Duration (years) } & \multicolumn{3}{|c|}{ Dune Wood DMZ } & \multicolumn{3}{|c|}{ Little Calumet DMZ } \\
\hline & $\mathbf{N}$ & Control & Exclosure & $\mathbf{N}$ & Control & Exclosure \\
\hline 0 & $6 \mathrm{~ns}$ & $9.1 \pm 1.9$ & $8.8 \pm 1.4$ & $6 \mathrm{~ns}$ & $8.6 \pm 1.0$ & $8.3 \pm 0.8$ \\
\hline 2 & $6 * *$ & $6.9 \pm 0.8$ & $15.9 \pm 4.8$ & $6 *$ & $8.1 \pm 0.7$ & $10.3 \pm 0.5$ \\
\hline 3 & $6 * *$ & $7.7 \pm 1.7$ & $17 \pm 4.5$ & $5 *$ & $7.2 \pm 1.2$ & $11.3 \pm 0.7$ \\
\hline 6 & $4 *$ & $8.0 \pm 0.8$ & $17 \pm 3.9$ & & & \\
\hline 7 & $3 \mathrm{~ns}$ & $7.8 \pm 0.8$ & $14.2 \pm 3.3$ & & & \\
\hline 8 & $2 \mathrm{~ns}$ & $6.7 \pm 0.1$ & $16.2 \pm 3.0$ & & & \\
\hline
\end{tabular}

Table 12. Mean red trillium (Trillium recurvatum) height-to-leaf with paired t-test sample size, by treatment by duration of exclosure.

[Significance assessed by use of paired t-test. Symbols: ns, not significant; *, $0.01>\mathrm{P}<0.05 ; * *, \mathrm{P}<0.01 ; * * *, \mathrm{P}<0.001$; N, number of plot pairs]

\begin{tabular}{|c|c|c|c|c|c|c|}
\hline \multirow[b]{2}{*}{ Duration (years) } & \multicolumn{3}{|c|}{ Dune Ridge } & \multicolumn{3}{|c|}{ Heron Rookery DNZ } \\
\hline & $\mathbf{N}$ & Control & Exclosure & $\mathbf{N}$ & Control & Exclosure \\
\hline 0 & $5 \mathrm{~ns}$ & $7.2 \pm 0.5$ & $9 \pm 2$ & $2 \mathrm{~ns}$ & $13.8 \pm 7$ & $19.4 \pm 0.2$ \\
\hline 2 & $3 / 4 \mathrm{~ns}$ & $7.4 \pm 0.7$ & $8.4 \pm 0.3$ & $1 \mathrm{~ns}$ & 21 & 28.4 \\
\hline 3 & $4 \mathrm{~ns}$ & $6.9 \pm 0.2$ & $7.3 \pm 0.5$ & $1 \mathrm{~ns}$ & 17.5 & 22.9 \\
\hline 5 & $4 \mathrm{~ns}$ & $5.8 \pm 1.3$ & $8.6 \pm 1.1$ & $1 \mathrm{~ns}$ & 12.5 & 20.1 \\
\hline 6 & $4 / 3 \mathrm{~ns}$ & $5.5 \pm 1.2$ & $9.9 \pm 2.7$ & $1 \mathrm{~ns}$ & 10 & 20.7 \\
\hline 7 & $1 / 2 \mathrm{~ns}$ & 7.5 & $9.6 \pm 1.9$ & $1 \mathrm{~ns}$ & 10.1 & 18.8 \\
\hline \multirow[t]{2}{*}{8} & $2 \mathrm{~ns}$ & $4.5 \pm 0.5$ & $11.3 \pm 4.1$ & $1 \mathrm{~ns}$ & 8.5 & 19.9 \\
\hline & \multicolumn{3}{|c|}{ Cowles Dunes } & & & \\
\hline 2 & $2 \mathrm{~ns}$ & $5.5 \pm 0.8$ & $12.9 \pm 1.6$ & & & \\
\hline
\end{tabular}

Table 13. Mean height-to-leaf, by treatment, for each level of duration for the East Unit.

\begin{tabular}{cccc}
\hline $\begin{array}{c}\text { Duration } \\
\text { (years) }\end{array}$ & $\mathbf{N}$ & Control & Exclosure \\
\hline 0 & $15 \mathrm{~ns}$ & $8.2 \pm 0.4$ & $9.4 \pm 0.7$ \\
1 & $12 * *$ & $6.9 \pm 0.4$ & $10.2 \pm 1.1$ \\
2 & $11 * * *$ & $6.8 \pm 0.3$ & $13.3 \pm 1.5$ \\
3 & $10 *$ & $7.3 \pm 0.4$ & $13.1 \pm 1.9$ \\
4 & $10 * *$ & $6.7 \pm 0.4$ & $13.4 \pm 1.6$ \\
5 & $8 * *$ & $6.3 \pm 0.7$ & $11.9 \pm 1.5$ \\
6 & $7 * *$ & $7.1 \pm 0.8$ & $14 \pm 2$ \\
7 & $4 *$ & $7.8 \pm 0.7$ & $13.5 \pm 1.5$ \\
8 & $4 *$ & $5.6 \pm 0.7$ & $13.7 \pm 2.3$ \\
\hline
\end{tabular}




\section{Model With Deer Density}

Deer densities from 2002 to 2006 at Dune Wood and Dune Ridge DMZ ranged from 7 to 31 deer $\mathrm{km}^{-2}$. There were significantly higher deer densities at Dune Ridge compared to Dune Wood except in 2005 and 2006 (fig. 14) (Underwood and Knutson, 2011). Across all plots, the mean change in red trillium height was $-0.9 \pm 0.2 \mathrm{~cm} \mathrm{yr}^{-1}$ in the control plots and $1.5 \pm 0.3 \mathrm{~cm} \mathrm{yr}^{-1}$ in the exclosures; however, there was a significant treatment-by-duration interaction (fig. 15). The significant model for change in height to stem included change in deer density, change in total snowfall, and interaction of change in deer density by change in snow cover (table 14 , fig. 15 , $\mathrm{AIC}=183$, deviance $137=166$ ). When snowfall was less than the previous year $(\Delta$ snow $=-36)$, deer density increased relative to the previous year. This increase in deer density resulted in more browsing, and red trillium height-toleaf became shorter than in the previous year (fig. 15, point A, $\Delta$ deer density $=26)$. When snowfall changed little from previous year $(\Delta$ snow $=-5)$ and deer density decreased, then red trilliums became taller than the previous year (fig. 15, point $\mathrm{B}, \Delta$ deer density $=-15$ ). However, when there was little change in snowfall and deer density from the previous year, the change in height-to-leaf was variable, either an increase or a decrease (fig. 15, line $\mathrm{C}, \Delta$ deer density $=5$ ).

There was a strong negative correlation between change in snowfall and change in deer density $(\mathrm{r}=-0.708, \mathrm{P}<0.001)$, demonstrating that when snowfall was less than in the previous year, deer density increased and when snowfall was more than the previous year, deer density decreased (fig. 16). This pattern is well established in literature (Patterson and Power, 2002; Potvin and Huot, 1983). The correlation between change in deer density and change in red trillium height-to-leaf was also negative but not statistically significant $(\mathrm{r}=-0.219$, $\mathrm{P}=0.174)$. Whether or not the relation would be significant with data from more years, the trend is what would be expected: when deer densities are less than in the previous year, red trilliums grow taller; and when deer densities are greater than in the previous year, red trilliums are shorter.

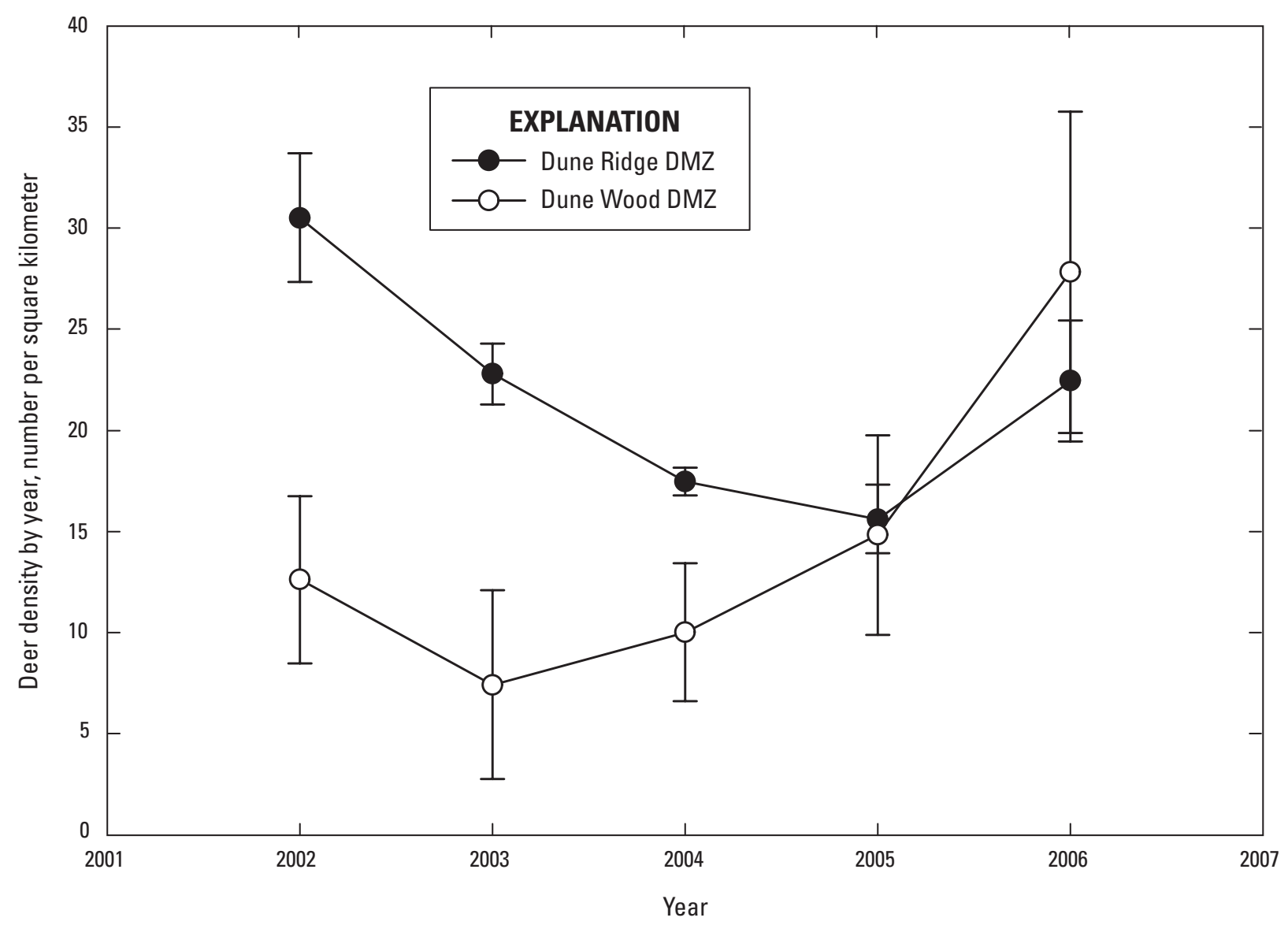

Figure 14. Changes in estimated deer densities for the Dune Ridge and Wood deer management zones (DMZs) based on spotlight surveys and distance sampling (Underwood and Knutson, 2011). 
Figure 15. Interaction between change in snowfall and change in deer density in relation to height-to-leaf (in centimeters) in red trillium (Trillium recurvatum).
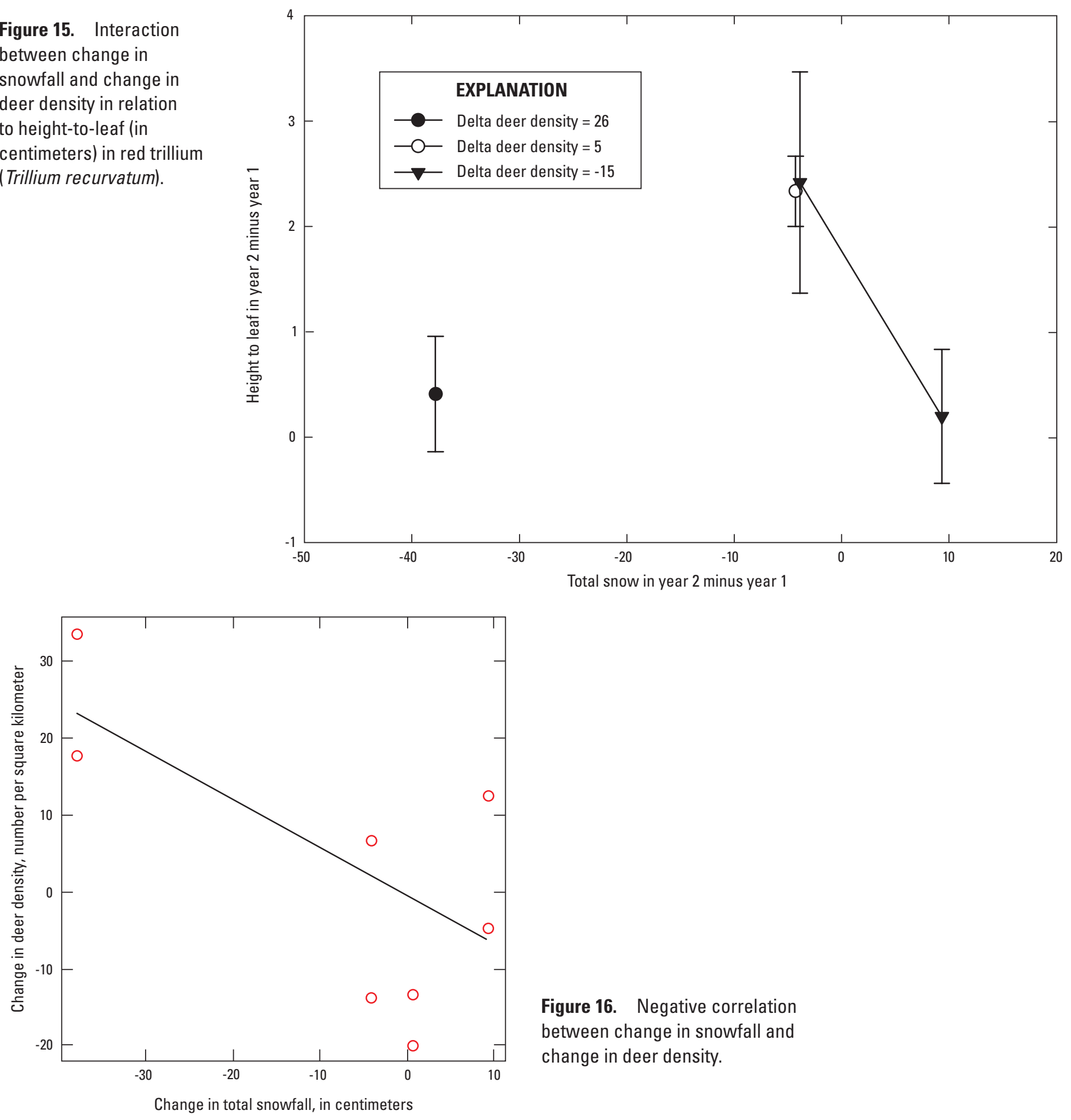

Figure 16. Negative correlation between change in snowfall and change in deer density.

Table 14. Results of general linear model regression of change in height-to-leaf versus change in total snowfall and change in deer density.

[P-values in bold print indicate statistically significant differences]

\begin{tabular}{lcccc}
\hline \multicolumn{1}{c}{ Independent variables } & Slope & Standard error & T & P \\
\hline Intercept & 1.01 & 0.43 & 2.35 & 0.02 \\
Change in deer density & 0.06 & 0.04 & 0.14 & $<0$ \\
Change in total snowfall & -0.14 & 0.04 & -3.65 & 4.09 \\
Change in deer density by change in total snowfall & 0.008 & $<0.01$ & $<0.001$ \\
\hline
\end{tabular}




\section{Discussion}

Impacts of white-tailed deer browsing on red trillium have been demonstrated by decreases in height and percent flowering in control plots while these two variables increase in exclosures (figs. 7 and 10). In addition, the change in height from year to year is best explained by an interaction between change in snow depth and change in deer density (fig. 12). Our results confirm that deer consume red trillium in preference to other vegetation present at three sites, as Anderson (1994) also found. We observed that large-flowered trillium flowers were rarely observed at INDU after 1991, whereas red trillium continued to flower until recently (Noel Pavlovic, personal observations), suggesting that red trillium might be less preferred than large-flowered trillium by white-tailed deer. Thus, from this study and studies by Anderson (1994) and Frankland and Nelson (2003), it is clear that deer are affecting the populations of red trillium.

\section{Flowering Probability}

The premise of this research was that red trillium would be similar to large-flowered trillium in response to browsing and that height would be a good measure to assess potential deer impacts (Anderson, 1994). Although leaf area, rhizome volume, and biomass have been used by other researchers to predict reproductive output in Trillium species (Kawano and others, 1986; Hanzawa and Kalisz, 1993), we found a strong relationship between height and flowering probability on a stem and plot basis, as has been shown for large-flowered trillium (Rooney and Waller, 2001). Probability of flowering curves are similar to those of Jenkins and others (2007) and Webster and others (2005) for bashful wakerobin (T. catesbaei Elliot), except that the red trillium curve was shifted to the left towards lower heights to leaf. Webster and Jenkins (2008) found that the 50 percent flowering probability in largeflowered trillium, Vasey's trillium (T. vaseyi Harbison), and illscented trillium (T. erectum L.) corresponded respectively to plant minimum ages of 12,13 , and 16 years. Thus, height-toleaf is a reliable metric for predicting probability of flowering for red trillium.

We demonstrated that this threshold based on height-toleaf is greater for plants on moraine substrate than on sand. Given the greater nutrient sources in moraine soils compared to sand, we might expect plants to flower at a smaller size on the moraine. It may be that the Trillium plants grow taller on the moraine in response to greater interspecific competition that could result from a direct effect of higher nutrient levels producing more competition. Alternatively, it may be that flowering probability has a stronger relationship with leaf area rather than height-to-leaf, but leaf area was not measured in this study.

Probability of flowering based on all the plants in the 1- $\mathrm{m}^{2}$ plots was comparable to that based on individual stems; 50 percent probability of flowering on individual stems occurred at $19 \mathrm{~cm}$ (mean of 18 and 20) compared to $20 \mathrm{~cm}$ on the plot basis. Hence, both data types provide a consistent basis to evaluate deer browsing pressure on red trillium flowering.

The impacts of deer on red trillium are demonstrated by the finding that 78 percent of control plots were without flowering plants during 8 years. Plants in exclosures recovered by showing a ninefold increase in flowering and a 6-cm increase in height over 8 years. Similarly, Frankland and Nelson (2003) found that flowering in red trillium increased by 17 percent and that height increased by $5 \mathrm{~cm}$ when deer were excluded from sites in southern Illinois. These values are similar to those from a study of red trillium in Quebec, where there was a fivefold increase in flowering and plants were $10 \mathrm{~cm}$ taller in exclosures compared to control plots over an 8-year period (Collard and others, 2010). In Pennsylvania, Trillium species were more than twice as likely to flower and were 45-56 percent taller after deer reductions (Royo and others, 2010). Another indication of population recovery in our study was the increasing standard deviation of height in exclosures as the duration increased (table 6). This pattern was opposite to that of browsing impacts on large-flowered trillium, where flowering plants become shorter, smaller, and nonreproductive; retain three leaves, and collectively show no correlation between size and age (Knight and others, 2009a; Koh and others, 2010).

\section{Implications for Deer Management}

When considering the results of this study and their implication for deer management, readers must recognize that the experimental approach is extreme because the exclosures completely eliminate deer browsing. In presettlement times, when deer densities were lower than now and Trillium was more abundant on the landscape, deer browsing of Trillium no doubt occurred, but at a lower rate than today. So, some low level of browsing would be normal. Nevertheless, our experimental approach shows how significant the deer impact is on red trillium height-to-leaf and flowering.

\section{Trillium Monitoring Issues}

One of the variables that is measured in the monitoring program is plant quality status. In this context, a better classification of leaf damage, which was not analyzed in our study because of ambiguities, would assist in the development of the program. All trillium individuals with less than three leaflets were scored as incomplete, whereas a distinction between leaflet number and evidence of browsing would be helpful (table 15). For example, it would be useful to be able to distinguish a plant that has one leaflet because it is young versus one that had three leaflets but lost two of them to browsing, resulting in a plant with one leaflet plus torn tissue. The same would be true for two-leaflet plants. 
Table 15. Growth stages of Trillium and implications of browsing on plant and monitoring.

\begin{tabular}{lllll}
\hline \multicolumn{1}{c}{ Plant stage } & Browsed absent & Browsed present & Ecological implications & Monitoring Implications \\
\hline $\begin{array}{l}\text { Cotyledons } \\
\text { 1-leaf stage }\end{array}$ & $\begin{array}{l}\text { Seedling } \\
\text { Juvenile }\end{array}$ & Little stump & Probable death & Difficult to find \\
3 leaflets, nonflowering & & $\begin{array}{c}\text { Growth delayed to next year and } \\
\text { reserves depleted } \\
\text { Growth delayed to next year and } \\
\text { reserves depleted }\end{array}$ & Easy to miss if not tagged \\
3 leaflets, flowering & Flowering & Largest stump & Reproduction delayed & Easy to miss if not tagged \\
\hline
\end{tabular}

In addition, we could not document the fate of plants in the year or years after they flower because individuals were not uniquely identified. The only exception to this was when there was only one plant in the plot. For instance, the plant height might decrease the year after flowering as a result of the investment of carbohydrate into flower and fruit production, depending on the local light environment (Ida and Kudo, 2008). In addition, we do not know whether a plant flowers repeatedly year after year once a it reaches a certain size. This question, though not directly related to using Trillium as a deer pressure index, is relevant in determining how the species behaves without deer browsing pressure and might be relevant to determining action thresholds.

\section{Replication}

Replication of plots for large-flowered trillium and nodding trillium comparable to the plots we used for red trillium would be the only way to statistically test for deer impacts across all three species. Given that the large-flowered trillium and nodding trillium are now quite rare, finding additional plots might be difficult. If deer populations are reduced, perhaps some of the former populations might reappear and then could be used in the monitoring program. Replication with large-flowered trillium might be possible by using the population that still remains south of South State Park Road between Tremont Road and Indiana State Road 49. For nodding trillium, a control plot that Marlin Bowles and Noel Pavlovic installed in 1988 should be included into the study; perhaps a replicate set can be found for this species. Given the relative abundance of declined trillium at the Heron Rookery, additional plots distant from the existing one are recommended.

Deer management zones where additional plot pairs are needed to allow for statistical comparison are Cowles Dune and Heron Rookery. Establishing plot pairs should be easy for the Heron Rookery but difficult in the Cowles Dunes region because the latter is more savanna than woodland, and Trillium species and plants appear to be rarer the further west within INDU.

Leaning versus nonleaning plants did not differ in probability of flowering. On the basis of first principles, stem length rather than height-to-leaf would be expected to have a stronger relationship with probability of flowering. Nevertheless, height-to-leaf was a good predictor of leaf area and thus plant size in large-flowered trillium (Anderson, 1994). The
Trillium plant, whether leaning or not, responds to leaf area and height-to-leaf for flowering. Stem length is a more proximate variable to reproduction probability. Thus, the sampling category of leaning plant can be removed from the sampling protocol and height-to-leaf retained as the appropriate variable to be measured.

\section{Estimating Deer Densities}

Because the deer management zones are important for the monitoring program, we would encourage that deer spotlighting surveys be established at the Heron Rookery especially, because this unit is the most Trillium species-rich in the park and because it has healthy populations of most of the Trillium species present. The data from the Heron Rookery suggests that deer are having an impact as urbanization increases surrounding the area, but low samples sizes prevent any statistical detection of a treatment effect (fig. 17 and 18). Trillium heights are not only variable within years but also among years.

\section{Defining a Threshold for Deer Management}

We have strong evidence that deer are affecting the growth and flowering of red trillium and have weaker evidence for deer impacts on large-flowered, nodding, and declined trilliums. What standard should be selected to decide whether to reduce the deer population? There is no hard and fast rule because the selection of a particular height might depend on the management goals of the site (Anderson, 1994). Although height might be a reasonable threshold value to have healthy reproducing populations of Trillium, a better threshold would be probability of flowering. Using the relationship between height-to-leaf and probability of flowering in red trillium as a basis, we might select a certain flowering threshold. With regard to probability of flowering, if red trillium reaches a size of $18 \mathrm{~cm}$ or less on the moraine and $16 \mathrm{~cm}$ or less on the dunes, then there is less than a 50 percent chance of flowering (fig. 8). With data from two DMZs, we found a negative relationship between height-to-leaf and browsing $(\mathrm{r}=-0.156$, $\mathrm{P}<0.01)$ and between height-to-leaf and estimated deer density $(\mathrm{r}=-0.148, \mathrm{P}=0.21)$, but the latter was not significant. The former correlation suggests that height could be a useful indicator, similar to that for large-flowered trillium (Anderson, 1994). In addition, percentage of flowering plants was strongly correlated with height-to-leaf (fig. 9). 
To use Trillium height to decide when deer populations need to be reduced, we need the answers to two questions: What is the expected height distribution for a healthy reproducing red trillium population, and what height is reasonable given the overabundant deer? For example, if the height threshold to decide whether to cull deer was chosen to be a 50 percent probability of flowering, then a decision height at $18 \mathrm{~cm}$ on the moraine would be selected. The difficulty arises when the $18-\mathrm{cm}$ value is applied to a patch of red trillium where plants typically are of varying heights. To which plant should the $18-\mathrm{cm}$ standard be applied? If the tallest plant in the plot is used, then, by definition, none are taller. If the tallest plant is less than the threshold, then the aggregate probability of flowering must be less than 50 percent because the other plants are less than $18 \mathrm{~cm}$ tall and thus have a lower probability of flowering. Culling the deer population would be the decision. When the tallest plant exceeded the threshold, culling of deer would cease until height-to-leaf declined again, while over that time interval most of the population would have been lower than the threshold height. The result would most likely be a Trillium population that fluctuated above and below the threshold but never exceeded the threshold by much. The population would probably never reach a flowering probability of 50 percent. Because most plants would have a probability of flowering of less than 50 percent, then the Trillium population might not be healthy and producing seed. Therefore, the danger with the tallest-plant approach is that the decision to cull would be subject to the weather and other events that might reduce plant size below the threshold independent of deer browsing pressure. For example, it would be useful to know whether a plant decreased in size the year after producing fruit.

If the smallest plant is chosen, then it is uncertain whether that minimum size is due to browsing or plant age. In this case, the decision would probably always be to reduce the deer population even though the small plant size is due to age (that is, seedling or small juvenile, stage and age relationships).
If there were seedlings in the populations, their size would have nothing to do with deer but everything to do with their life stage. Thus, the smallest-plant approach does not seem to be an acceptable threshold criterion either.

If the average height is used, then some plants would be greater than the threshold and likely to be flowering and others smaller than the threshold and not likely to be reproducing. Using the average size for any patch has advantages over the other two approaches. In any patch where the average-height approach is applied, there will be plants that are taller and have a greater probability of flowering than those at the threshold. Other plants would not be too small to be reproducing. For example, what if the selected threshold was $18 \mathrm{~cm}$, corresponding to a threshold of 50 percent flowering? If the mean dropped below $18 \mathrm{~cm}$, assuming multiple stems per plot, there would still be some plants that were likely to flower, but there would be an increasing reduction in probability of flowering over time assuming the same deer density. If it were decided then to reduce the deer density, then over time an increase in red trillium height and an increase in probability of flowering would be expected.

So what threshold should be used? One way to address this question is to examine the percentage of trillium plants in each species that are flowering. Unfortunately, such data for natural populations is meager at best. Augustine and Frelich (1998) found that declined and nodding trillium together, on average, flowered at a rate of 30.5 percent at low deer densities and 35 percent at another site with moderate deer densities. Meager data on percentage flowering, taken and calculated from the literature, reveals an average of 30 percent flowering (table 16). Thus, the threshold of about 33 percent might be an initial target that could be modified by using the principles of adaptive management. Under this concept, the height-to-leaf threshold would be $16 \mathrm{~cm}$ on sand and $18 \mathrm{~cm}$ on the moraine soils. The presence of seedlings would be a good indication that population has sufficient flowering densities.

Table 16. Proportion of population that flowers for Trillium species, as reported or estimated from the literature.

\begin{tabular}{lccc}
\hline \multicolumn{1}{c}{ Species } & Percent flowering & Deer browsing & Source \\
\hline T. grandiflorum & $21-34$ & Low deer impact & Anderson, 1994 \\
T. grandiflorum & $20^{*}$ & $?$ & Kawano and others, 1986 \\
T. catesbeai & $12^{*}$ & $?$ & Ohara and Utech, 1988 \\
T. vaseyi & $9^{*}$ & $?$ & Ohara and Utech, 1988 \\
T. flexipes & $21^{*}$ & $?$ & Ohara and Utech, 1988 \\
T. erectum & 35 & $?$ & Kawano and others, 1986 \\
T. undulatum & 35 & $?$ & Kawano and others, 1986 \\
T. sessile & 63 & $?$ & Kawano and others, 1986 \\
T. ovatum & 48 & $?$ & Jules, 1998 \\
Mean & $30 \pm 5$ & Heavy deer infestation, 60 years & Kirschbaum and Anacker, 2005 \\
T. species & 9 & & \\
\hline Total mean & $28 \pm 5$ & & \\
\hline
\end{tabular}


Because red trillium is self-incompatible (Sawyer, 2010), a greater height threshold might be chosen to ensure enough flowering plants for cross-pollination and, hence, periodic seed production and recruitment (Knight, 2003, 2004). Knight and others (2009a) showed with demographic models that large-flowered trillium populations could go extinct if browsing exceeded 15 percent for the larger size classes. Therefore, seed production and density of seedlings might be alternative variables to consider for deer management thresholds.

Another issue is the length of time it takes for a population to recover. How long should culling continue? Should it continue until the population mean to returns to above 18 and $20 \mathrm{~cm}$ ? This choice would make sense, but clearly it takes a population 6 or more years to return to such high values (fig. 10). Frankland and Nelson (2003) found a $2.7 \mathrm{~cm} \mathrm{yr}^{-1}$ increase in height compared to $1 \mathrm{~cm} \mathrm{yr}^{-1}$ outside exclosures. In addition, the rate of change in height increased from 1.3 $\mathrm{cm}$ the first year to 4.1 the second year. In contrast, we found in exclosures, on average, red trillium increased in height by $1.5 \mathrm{~cm}$ the first year and $1.6 \mathrm{~cm}$ the second year. In contrast, control plants decreased in height by $0.9 \mathrm{~cm}$ the first year and remained the same the second year. The rate of recovery will depend on duration and frequency of grazing, soil fertility, relative allocation to roots versus shoots, and legacy effects (Collard and others, 2010; LaPointe and others, 2010; Royo and others, 2010). From a practical standpoint, deer reductions would be required until the mean height reached or exceeded the selected threshold.

It would be possible to use proportion of plants that are blooming as a browsing-impact threshold. An advantage of this approach would be that deer management would continue longer because there might be a delay from the time that the plants grew above the height threshold to the time when the plants actually recommenced blooming.

\section{Application of a Threshold to Management}

To understand these possible thresholds, their application can be considered in relation to our historical trillium trends for the DMZ data (fig. 17 and 18). In only two instances-TR1 (Dune Wood DMZ) and HR1 (Heron Rookery DMZ) - were there any flowering red trilliums (fig. 17). In the exclosures, the proportion flowering tended to increase with time but were quite variable as to whether they exceeded the flowering threshold of 33 percent or the corresponding average-height threshold of $16 \mathrm{~cm}$ (fig. 17). Despite these impacts, a few individuals in control HR1 continued to flower over 8 years, suggesting that the rate of browsing had not reached the point where no plants were flowering, as was found for 78 percent of the sites.

Only red trillium at HR1 showed a gradual, but consistent, decrease in height-to-leaf with time in control plots, evidence that deer were having impacts on the individuals, especially after 2006 (fig. 18). This decrease was countered by the temporally variable but consistently high height to stem measurements in the exclosures (fig. 18). Thus, the exclosure experiment at this location demonstrated that deer negatively affected red trillium; unfortunately, deer density data are not available for that site to confirm the causation (fig. 18). In general, all paired plots in the East Unit of INDU failed to meet the height-to-leaf threshold, indicating that management action would be necessary to permit viable (that is, sexually reproducing) populations of this species to persist. Even though the thresholds were selected a priori and based on the relationship between height-to-leaf and probability of flowering, their application to the data collected at INDU seems to reflect well the transition between deer browsing pressure and response when browsing is prevented. 
$\boldsymbol{A}$
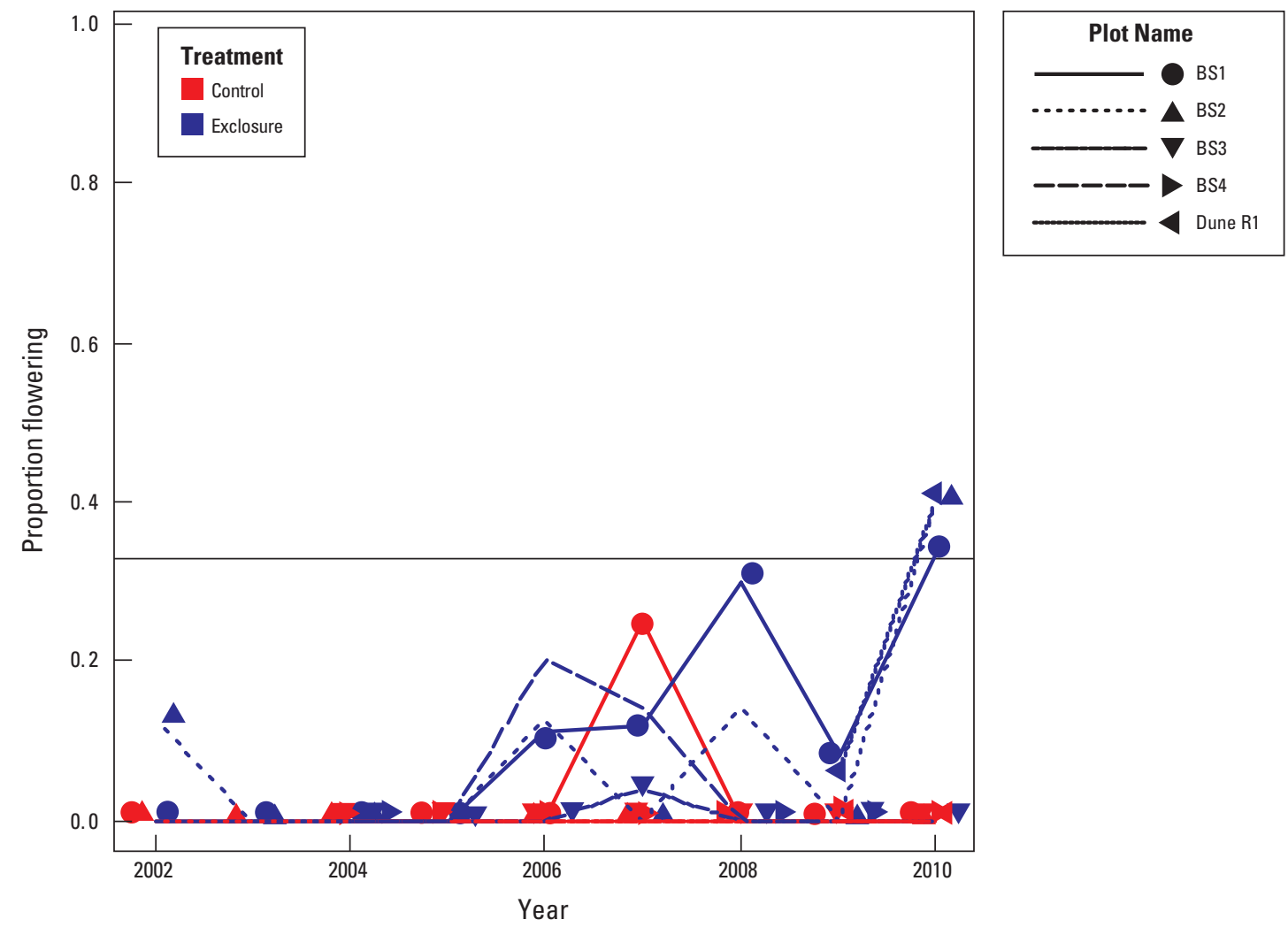

B
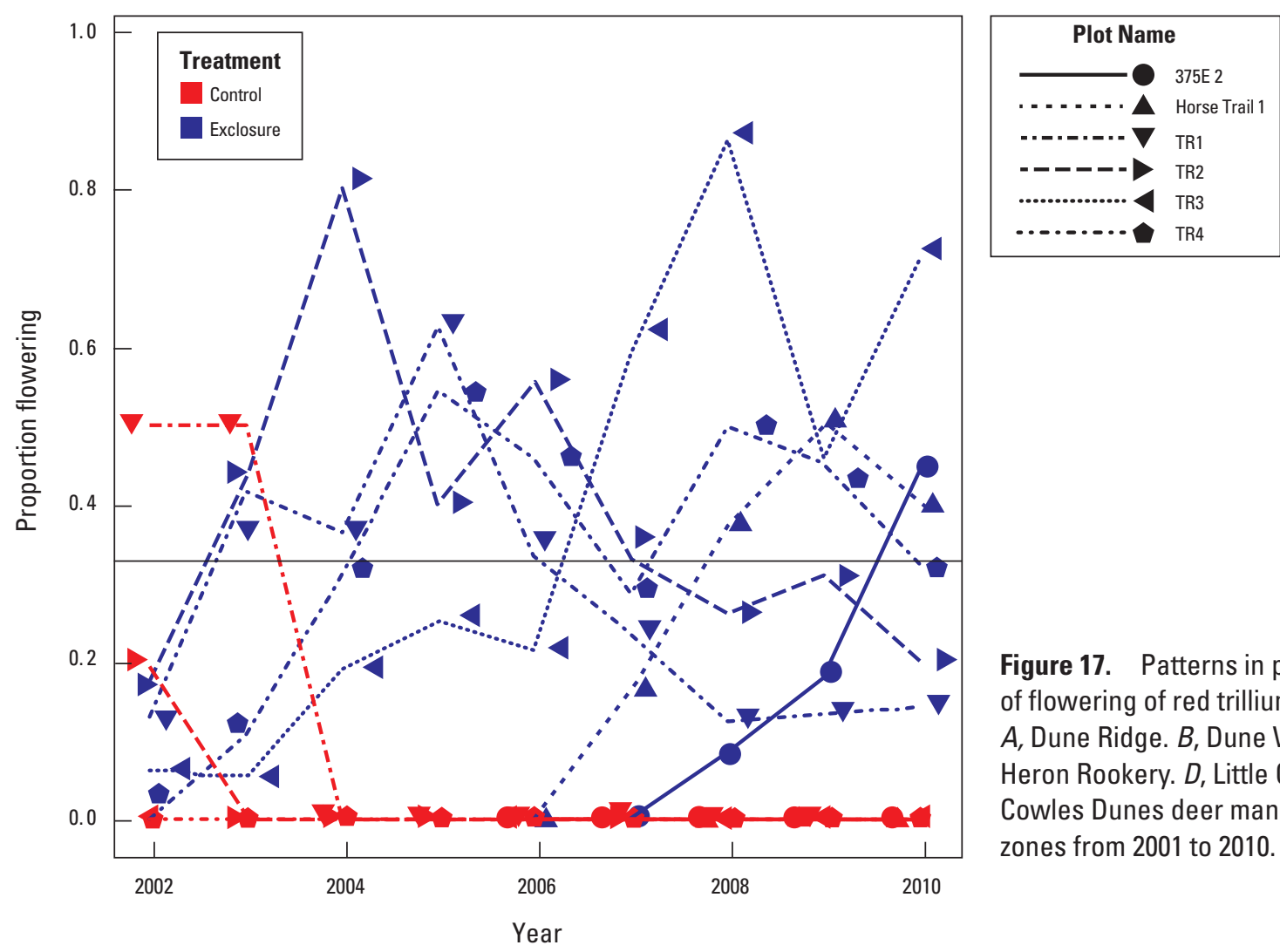

Figure 17. Patterns in proportion of flowering of red trillium in the $A$, Dune Ridge. $B$, Dune Wood. $C$, Heron Rookery. $D$, Little Calumet. $E$, Cowles Dunes deer management zones from 2001 to 2010. 
C

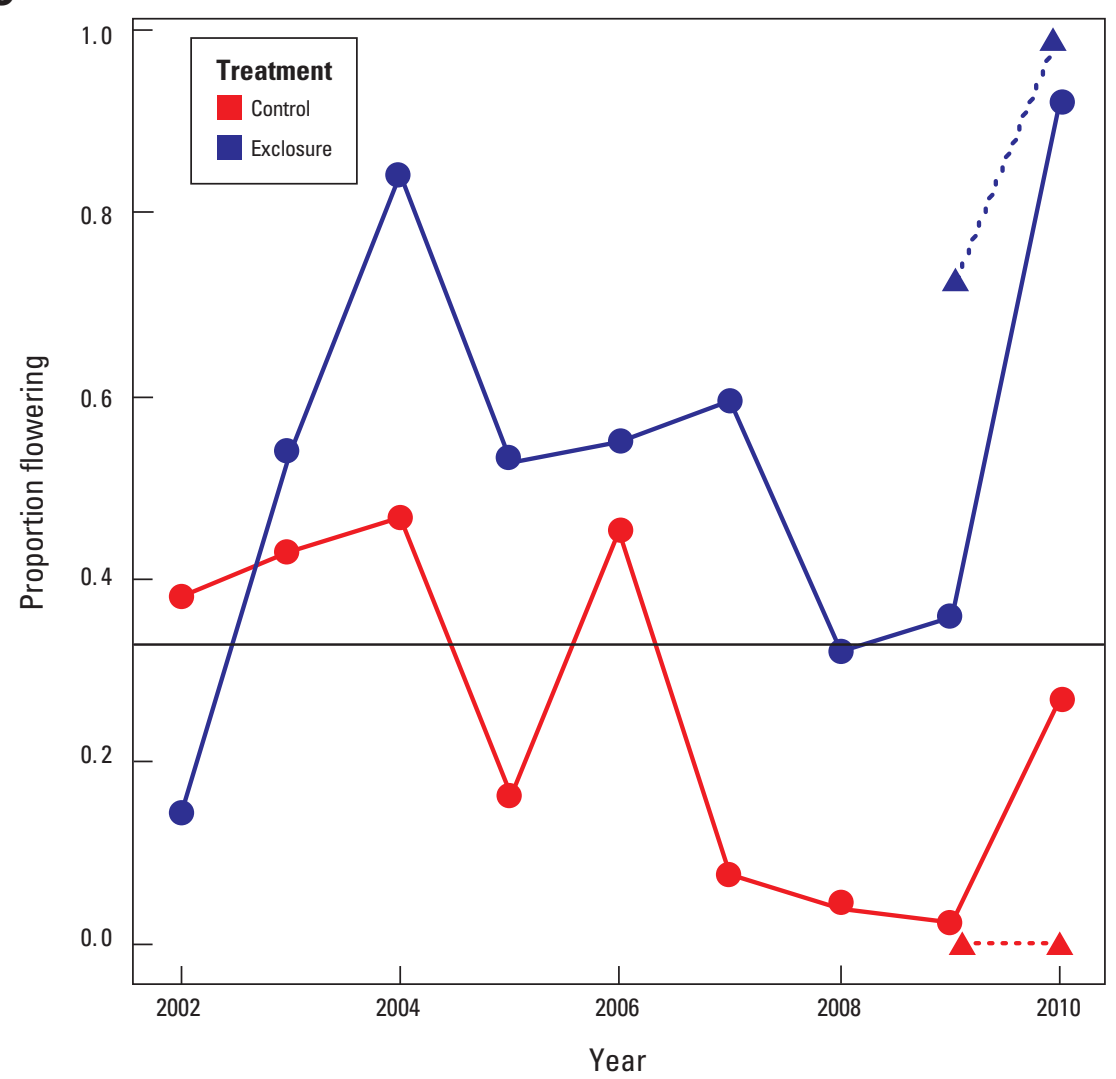

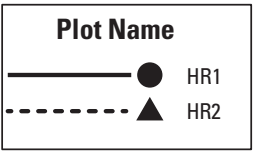

D

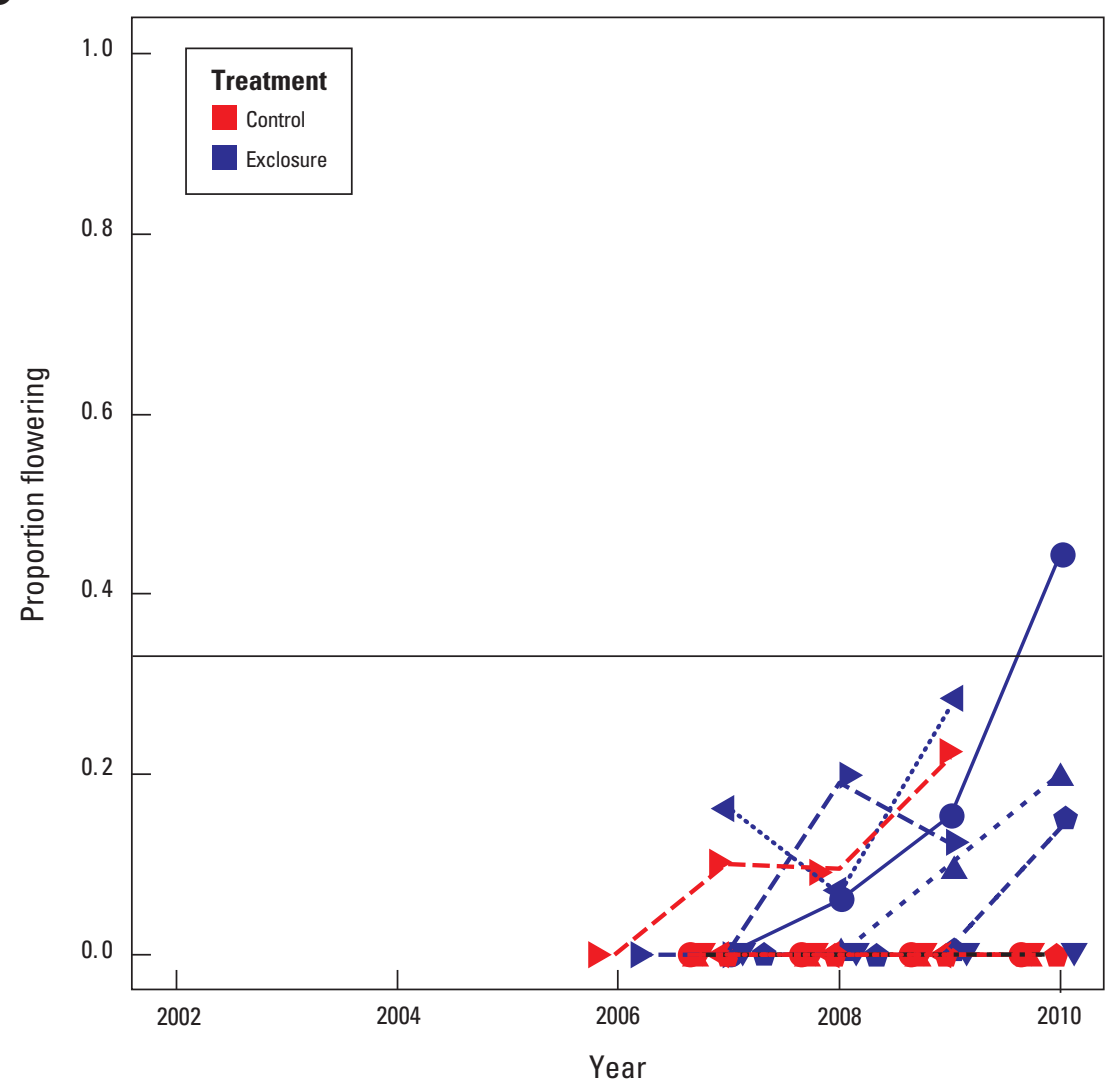

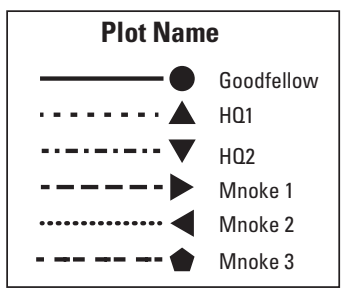

Figure 17, continued. Patterns in proportion of flowering of red trillium in the $A$, Dune Ridge. $B$, Dune Wood. $C$, Heron Rookery. D, Little Calumet. $E$, Cowles Dunes deer management zones from 2001 to 2010. 
E

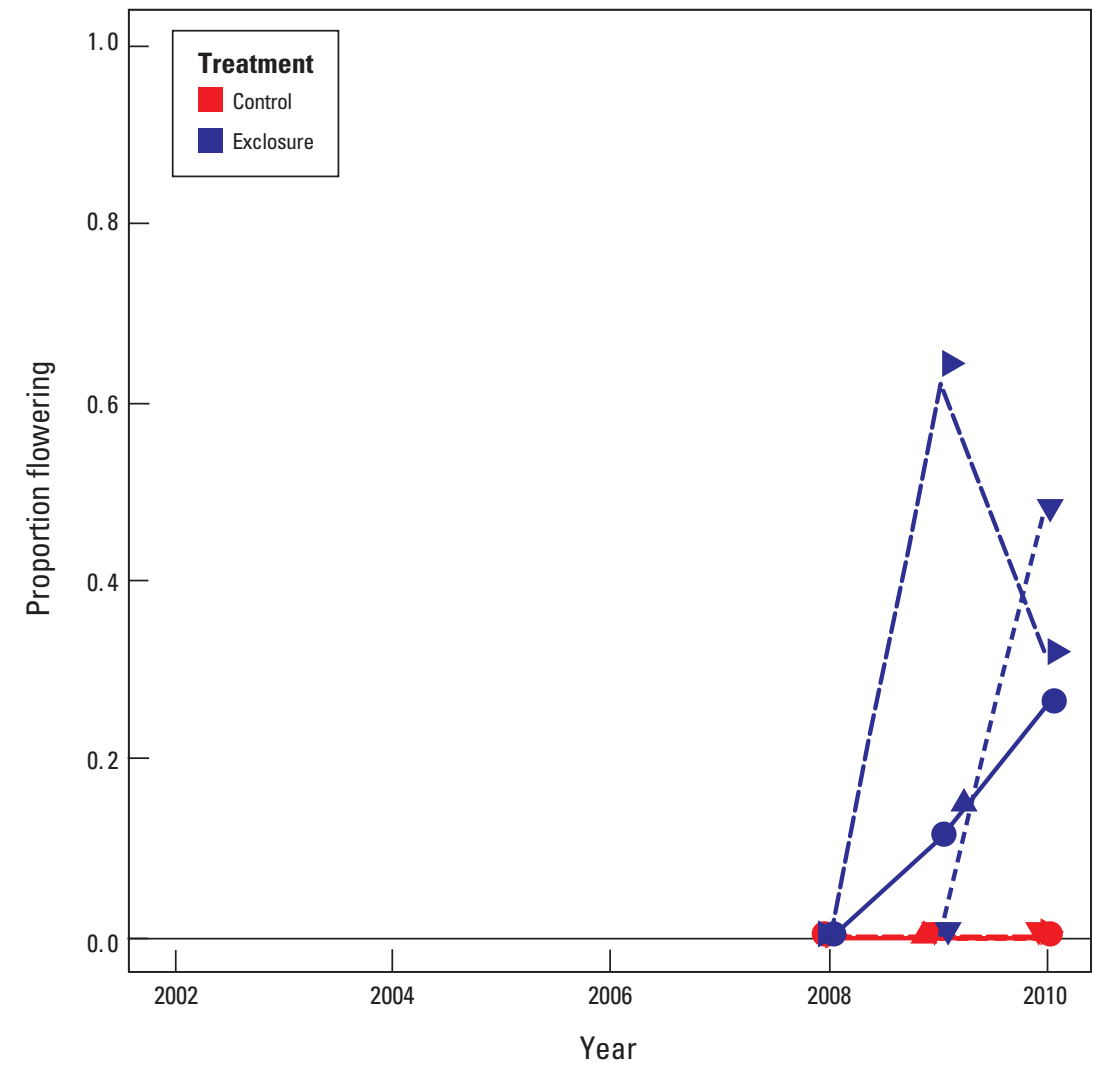

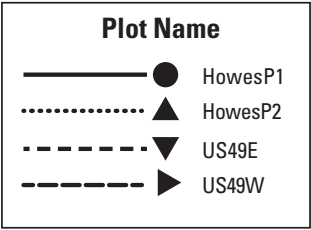

Figure 17, continued. Patterns in proportion of flowering of red trillium in the $A$, Dune Ridge. $B$, Dune Wood. $C$, Heron Rookery. $D$, Little Calumet. $E$, Cowles Dunes deer management zones from 2001 to 2010. 
$\boldsymbol{A}$
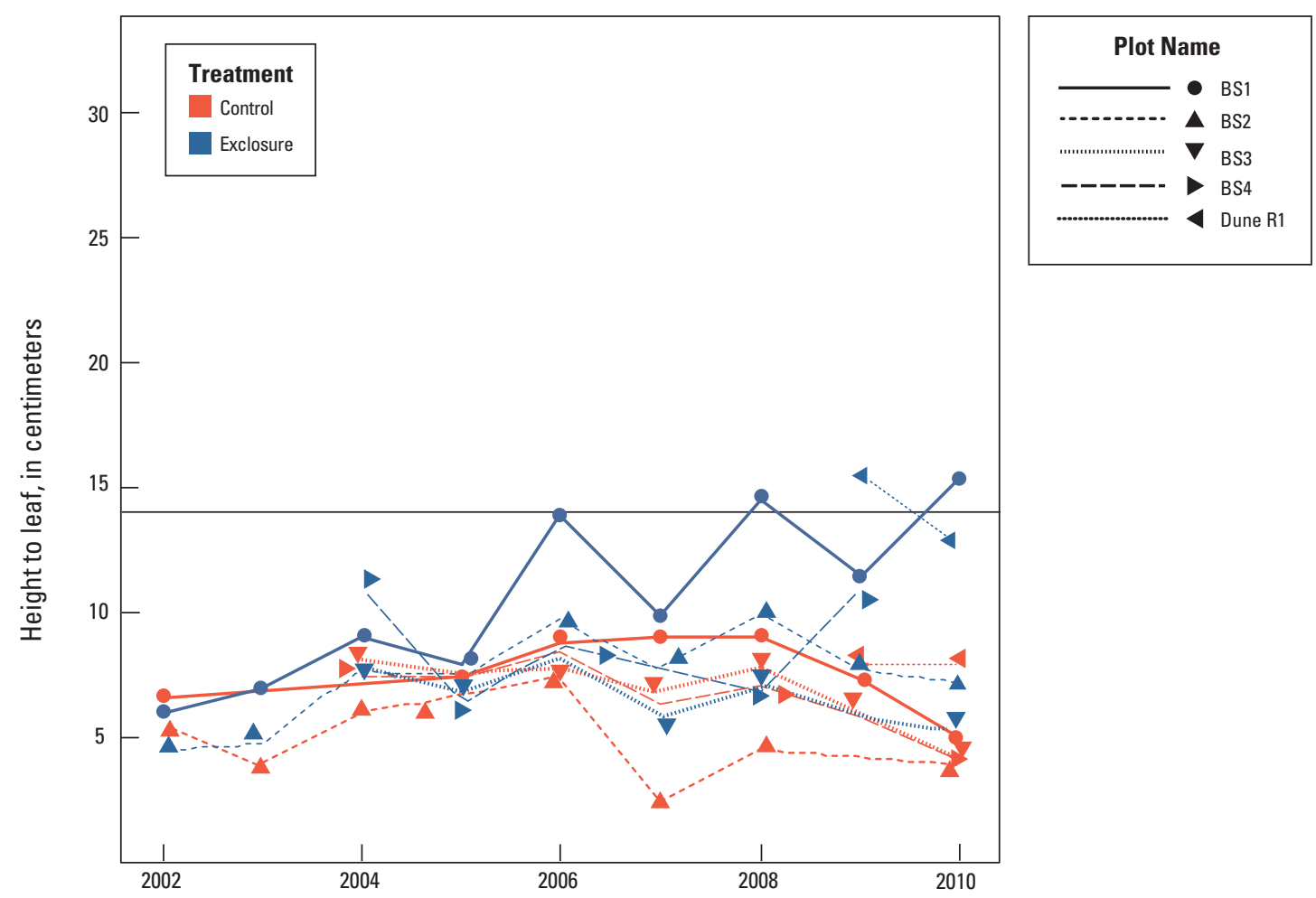

B

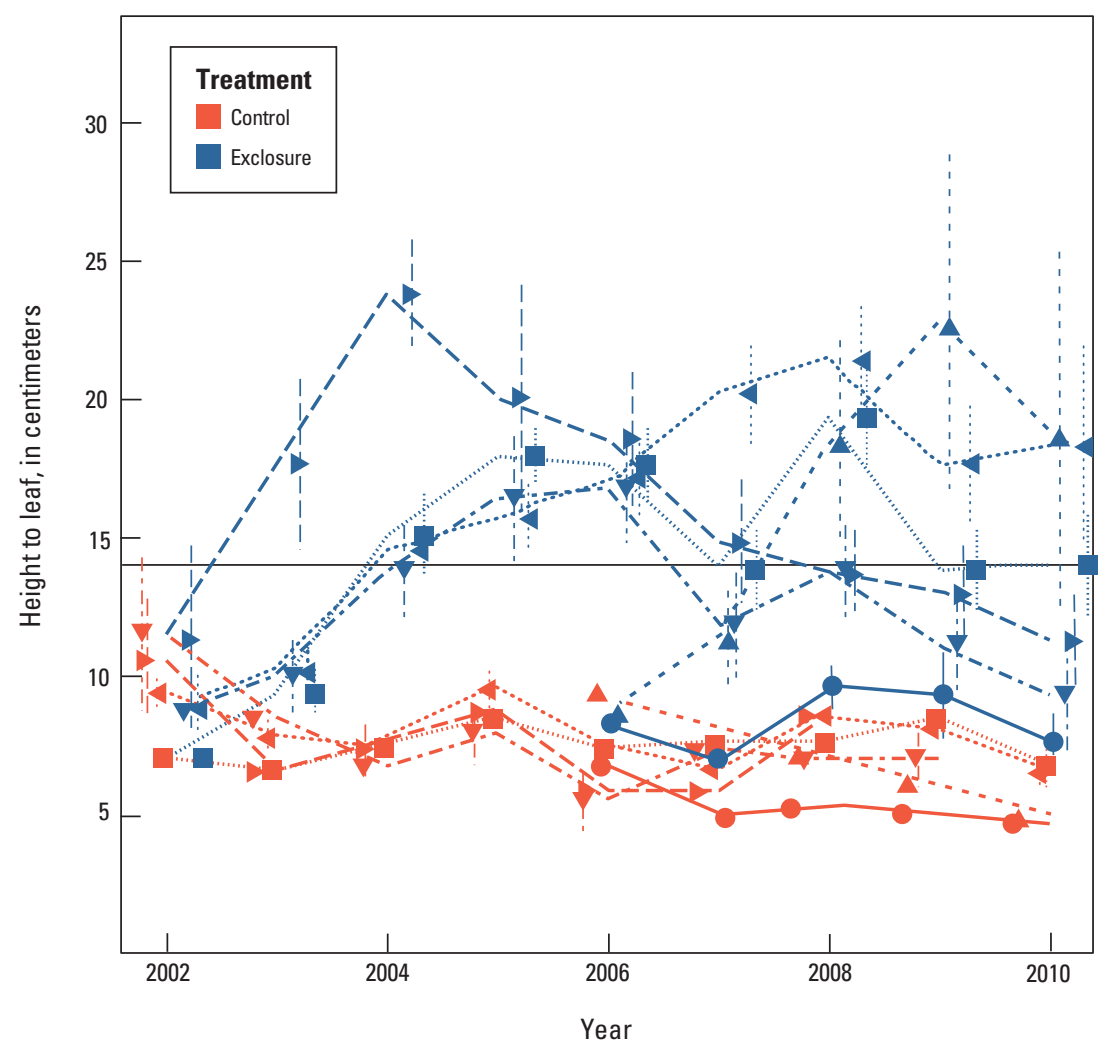

Figure 18. Patterns in change in height-to-leaf in red trillium in the $A$, Dune Ridge. B, Dune Wood. $C$, Heron Rookery. D, Little Calumet. E, Cowles Dunes deer management units from 200 to 2010. Possible thresholds are $16 \mathrm{~cm}$ on the moraine and $14 \mathrm{~cm}$ on the dunes. 
C

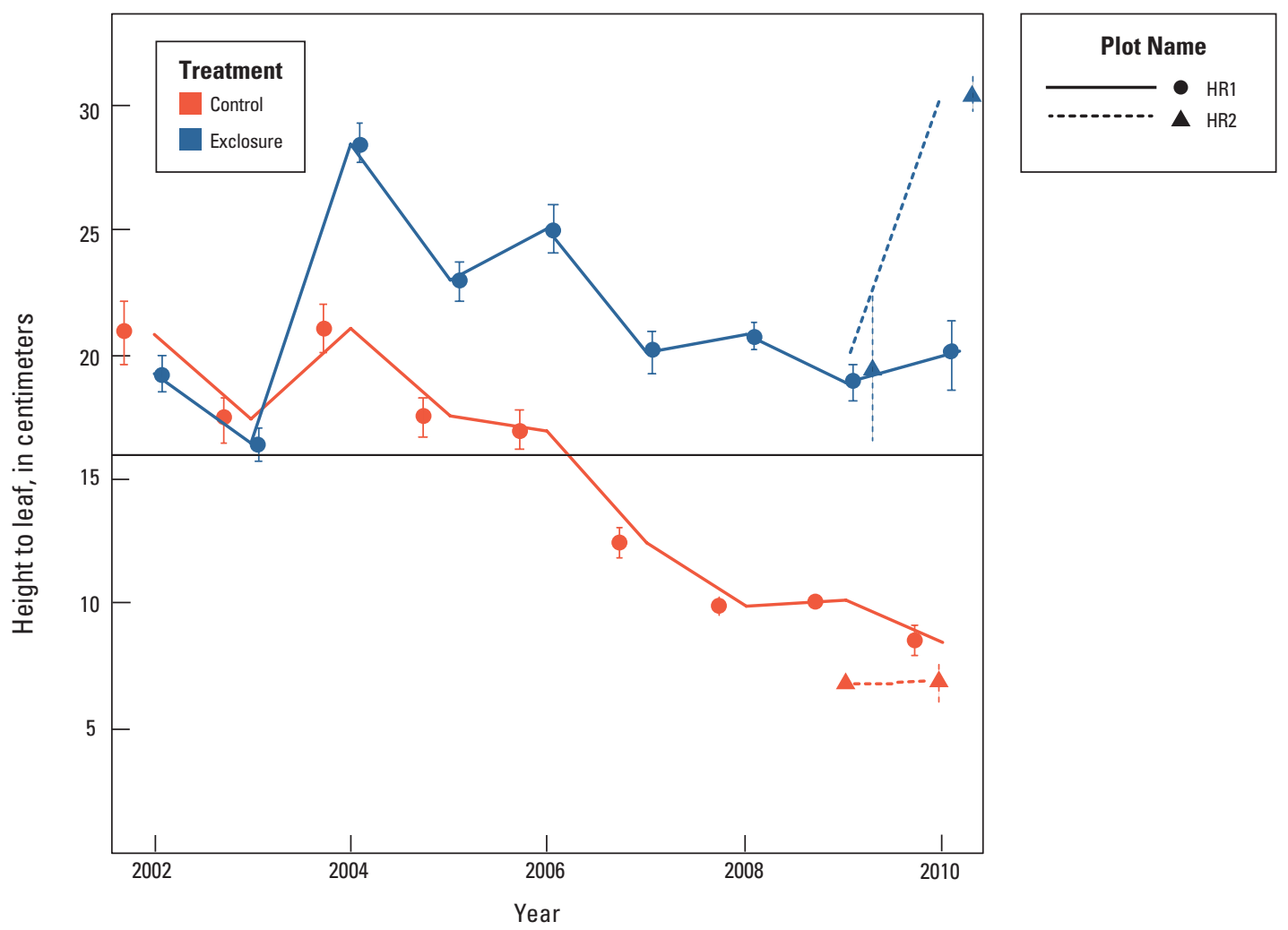

D

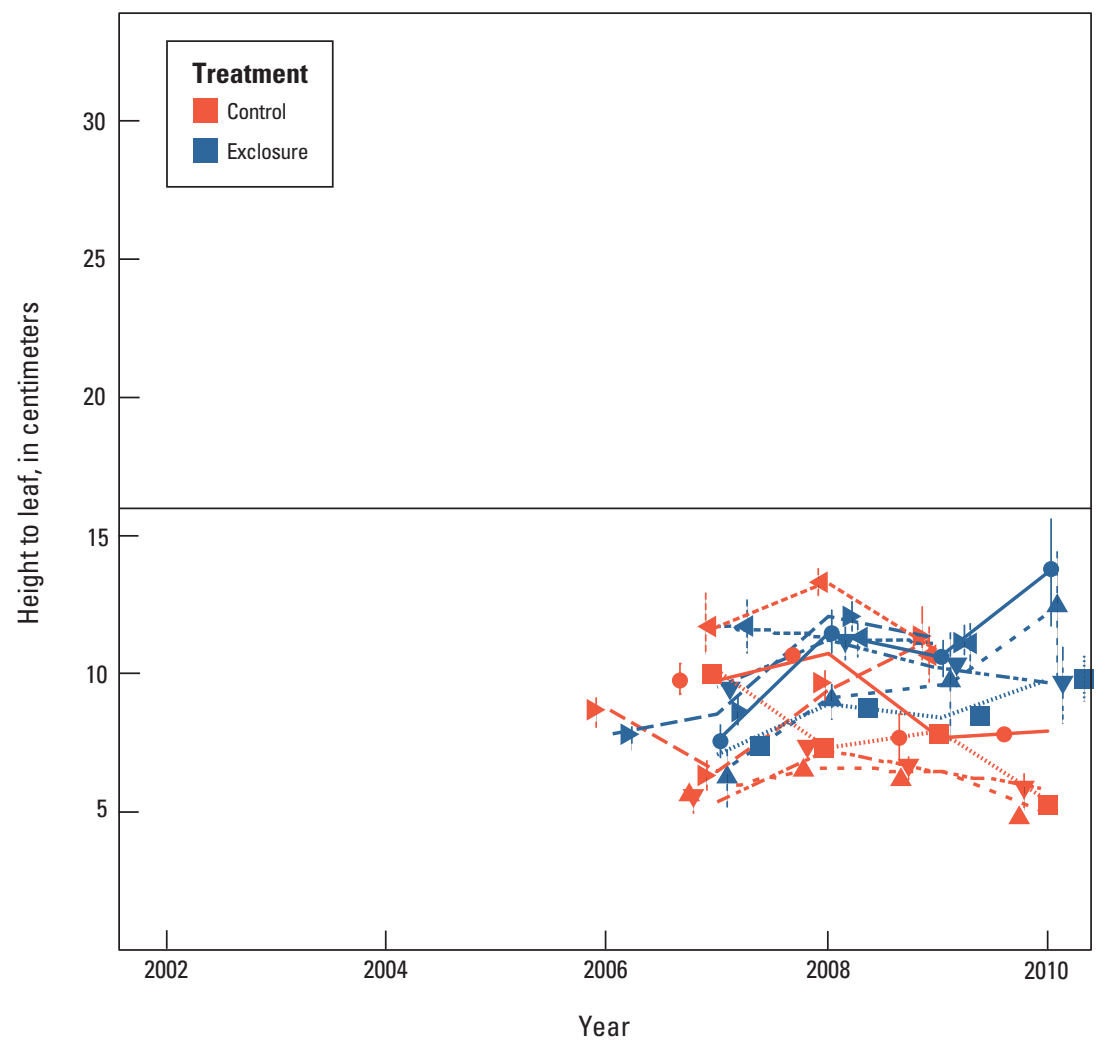

Figure 18, continued. Patterns in change in height-to-leaf in red trillium in the $A$, Dune Ridge. B, Dune Wood. $C$, Heron Rookery. D, Little Calumet. $E$, Cowles Dunes deer management units from 200 to 2010. Possible thresholds are $16 \mathrm{~cm}$ on the moraine and $14 \mathrm{~cm}$ on the dunes. 


\section{$\boldsymbol{E}$}

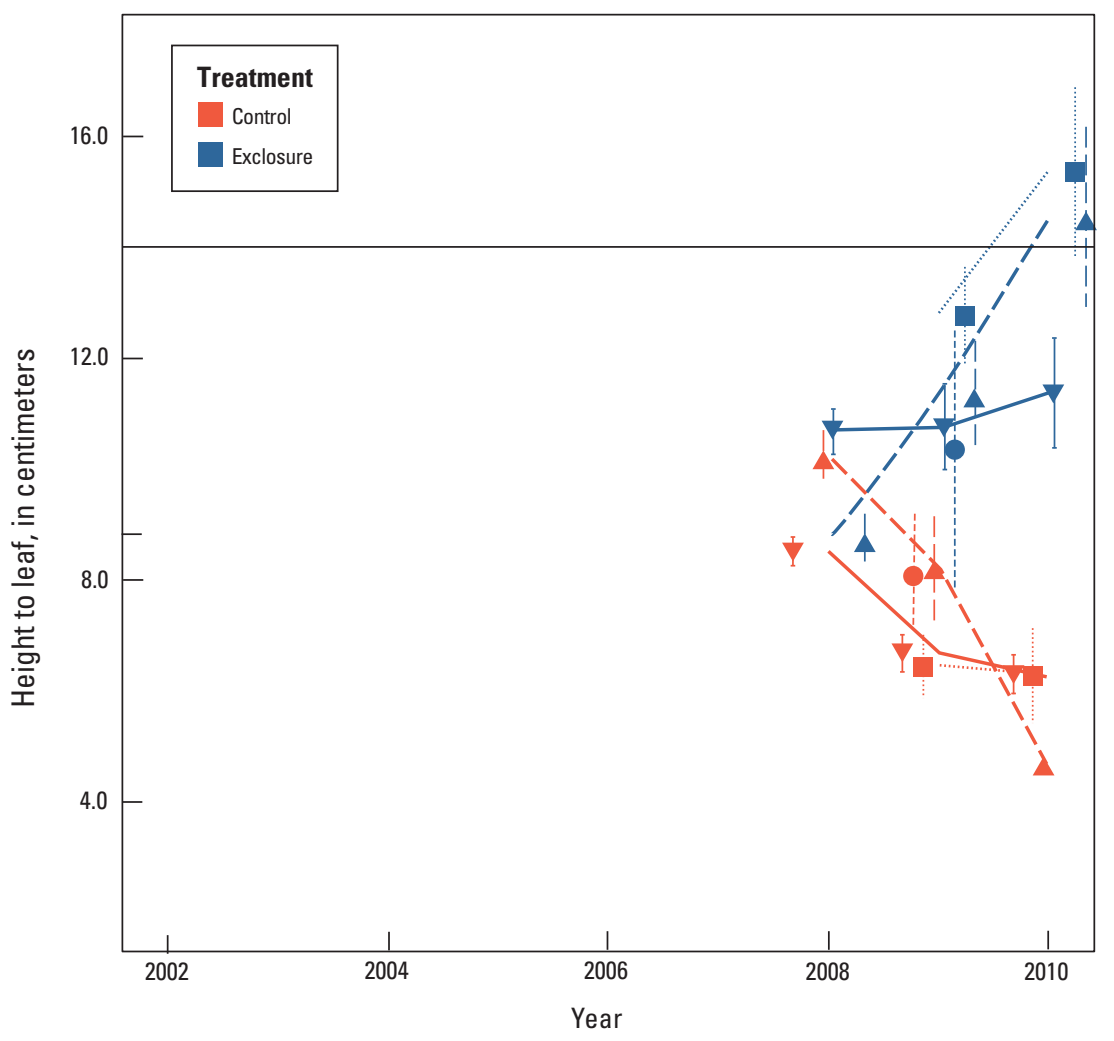

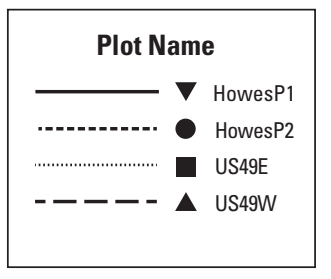

Figure 18, continued. Patterns in change in height-to-eaf in red trillium in the $A$, Dune Ridge. B, Dune Wood. $C$, Heron Rookery. $D$, Little Calumet. $E$, Cowles Dunes deer management units from 200 to 2010. Possible thresholds are $16 \mathrm{~cm}$ on the moraine and $14 \mathrm{~cm}$ on the dunes.

\section{Conclusions}

The fact that red trillium is the most abundant Trillium species at INDU stems from its presence in a wide diversity of habitats ranging from oak savanna to oak woods and mesophytic forests. On average, the mean height of red trillium exposed to deer browsing decreased from 2002 to 2010 , whereas the mean height increased steadily in the deer exclosures over the same duration (table 2). This pattern is demonstrated by the increasing difference values over the 9 years. Percentage of flowering plants increased in the exclosures while declining outside the exclosures. Flowering ranged from 1 to 27 percent outside the exclosure and 11 to 46 percent inside the exclosure.

Two deer management zones (DMZs) yielded evidence that changes in height from year to year were related to the interaction between change in total snow depth and change in deer density between years (fig. 4). Additional deer density data would clarify these relationships. Deer densities decreased after winters that produce higher snowfalls than the year before, consistent with results from other deer population research (Potvin and Huot, 1983; Patterson and Power, 2002). We were unable to demonstrate a significant negative correlation between increasing deer density and red trillium height, a pattern that was found for large-flowered trillium in Ontario (Koh and others, 2010). Nevertheless, the trend was what would be expected: when deer densities were less than the previous year, red trilliums tended to be taller; and when deer densities were greater than the previous year, red trilliums tended to be shorter. Spotlight-survey deer densities averaged $18 \pm 2$ deer $\mathrm{km}^{-2}$ ( 7 to 31 ) for two DMZs and in the East Unit from 1991 to 2006 and averaged $13 \pm 4$ deer $\mathrm{km}^{-2}$ (Underwood and Knutson, 2011). In the mature forests of the Great Lakes regions prior to European settlement, deer were probably at densities $<4$ deer km$~^{-2}$ (Alverson and others, 1988; McCabe and McCabe, 1997). Thus, densities of deer were great enough that their browsing could negatively affect growth and reproduction of red trillium.

For a plant species to be a phytoindicator of deer impacts on the landscape, it is best if it has a determinant growth form (LaPointe and others, 2010), is selected as food by deer (Anderson, 1994), is prevalent enough on the landscape (Kirschbaum and Anacker, 2005) to be useful across a broad range of conditions (Koh and others, 2010; Royo and others, 2010), and shows a qualitative or graded quantitative response to deer browsing. Red trillium has a determinant growth form and is selected by deer as food. At INDU, red trillium is present in all five DMZs, thus fitting the prevalence criterion (Kirschbaum and Anacker, 2005). We showed that white-tailed deer browsed red trillium and reduced its height-to-leaf and 
the proportion of flowering plants across the Indiana Dunes landscape in a quantitative fashion. Thus all four criteria have been met for a species to be a phytoindicator of deer impacts on the landscape. Based on these results, a height-toleaf threshold that translates into approximately $33 \%$ of the plants in bloom, might be used as an initial target for when to begin or cease culling of deer as a means of protecting red trillium populations. Additional data may further elucidate this threshold. These results add another species to the growing list of determinant flowering plants that can be used to assess the degree of deer browsing pressure. The list includes other Trillium species, white baneberry, bluebead (Clintonia borealis (Aiton) Raf.), Canada mayflower and false Solomon's seal (Maianthemum canadense Desf. and racemosum (L.) Link), sweet cicely, jack-in-the pulpit, and large-flower bellwort (Uvularia grandflora Sm.). Although single-species indicators do not address other issues of deer impacts on forest ecosystems, such as nutrient dynamics and community shifts from palatable to unpalatable species, red trillium will play an important role for managers in assessing deer browsing pressure, especially where large-flowered trillium has been extirpated.

\section{References Cited}

Alverson, W.S., Waller, D.M., and Solheim, S.L., 1988, Forests too deer-Edge effects in northern Wisconsin: Conservation Biology, v. 2, p. 348-358.

Anderson, R.C., 1994, Height of white-flowered trillium (Trillium grandiflorum) as an index of deer browsing: Ecological Applications, v. 4, p. 104-109.

Anderson, R.C., Nelson D., Anderson M.R., and Rickey M.A., 2005, White-tailed deer (Odocoileus virginianus Zimmerman) browsing effects on tallgrass prairie forbsDiversity and species abundances: Natural Areas Journal, v. 25, p. 19-25.

Asnani, K.M., Klips, R.A., and Curtis, P.S., 2006, Regeneration of woodland vegetation after deer browsing in Sharon Woods Metro Park, Franklin County, Ohio: Ohio Journal of Science, v. 106, p. 86-92.

Augustine, D.J., and DeCalesta, D., 2003, Defining deer overabundance and threats to forest communities-From individual plants to landscape structure: Ecoscience, v. 10, p. $472-486$.

Augustine, D.J., and Frelich, F.E., 1998, Effects of whitetailed deer on populations of an understory forb in fragmented deciduous forests: Conservation Biology, v. 12, p. 995-1004.
Begier, M.J., 1996, Factors affecting spotlight counts of whitetailed deer: Syracuse, N.Y., State University of New York, College of Environmental Science and Forestry, 74 p.

Beguin, J., Pothier, D., and Côté, S.D., 2011, Deer browsing and soil disturbance induce cascading effects on plant communities - A multilevel path analysis: Ecological Applications, v. 21, p. 439-451.

Burnham, K.W., and Anderson, D.R., Model selection and multimodel influence: New York, New York, SpringerVerlag, 488 p.

Case, F.W., and Case, R.B., 1997, Trilliums: Portland, Oreg., Timber Press, $285 \mathrm{p}$.

Chee, Y.E., and Wintle, B.A., 2010, Linking modelling, monitoring and management-An integrated approach to controlling overabundant wildlife: Journal of Applied Ecology, v. 47, p. 1169-1178.

Cohen, R.D., and McShane, S.G., 1998, Moonlight in duneland-The illustrated story of the Chicago South Shore and South Bend Railroad: Bloomington, Ind., Indiana University Press, 139 p.

Collard, A., Lapointe, L., Ouellet, J.-P., Crête, M., Lussier, A., Daigle, C., and Côté, S.D., 2010, Slow responses of understory plants of maple-dominated forests to white-tailed deer experimental exclusion: Forest Ecology and Management, v. 260 , p. 649-662.

Crawley, M.J., 2007, The R book: Chichester, England, John Wiley and Sons, 942 p.

Fernald, M.L., 1970, Gray's manual of botany-A handbook of the flowering plants and ferns of the central and northeastern United States and adjacent Canada: New York, D. Van Nostrand Company, 1,632 p.

Fletcher, J.D., McShea, W.J., Shipley, L.A., and Shumway, D., 2001, Use of common forest herbs to measure browsing pressure by white-tailed deer (Odocoileus virginianus Zimmerman) in Virginia, USA: Natural Areas Journal, v. 21 , p. $172-176$.

Frankland, F., and Nelson, T., 2003, Impacts of white-tailed deer on spring wildflowers in Illinois, USA: Natural Areas Journal, v. 23, p. 341-348.

Fuller, R.J., and Gill, R.M.A., 2001, Ecological impacts of increasing numbers of deer in British woodland: Forestry (Oxford), v. 74, p. 193-199.

Gates, R.R., 1917, A systematic study of the North American genus Trillium, its variability, and its relation to Paris and Medeola: Annals of the Missouri Botanical Garden, v. 4, p. 43-92. 
Hanzawa, F.M., and Kalisz, S., 1993, The relationship between age, size, and reproduction in Trillium grandiflorum (Liliaceae): American Journal of Botany, v. 80, p. 405-410.

Heckel, C.D., Bourg, N.A., McShea, W.J., and Kalisz, S., 2010, Nonconsumptive effects of a generalist ungulate herbivore drive decline of unpalatable forest herbs: Ecology, v. 91, p. 319-326.

Heffner, R.A., Butler, M.J., IV, and Reilly, C.K., 1996, Pseudoreplication revisited: Ecology, v. 77, p. 2558-2562.

Hurlbert, S.H., 1984, Pseudoreplication and the design of ecological field experiments: Ecological Monographs, v. 54, p. 187-211.

Ida, T.Y., and Kudo, G., 2008, Timing of canopy closure influences carbon translocation and seed production of an understorey herb, Trillium apetalon (Trilliaceae): Annals of Botany, v. 101, p. 435-446.

Jenkins, M.A., Webster, C.R., and Rock, J.H., 2007, Effects of chronic herbivory and historic land use on population structure of a forest perennial, Trillium catesbaei: Applied Vegetation Science, v. 10, p. 441-450.

Jones, C.G., Ostfeld, R.S., Richard, M.P., Schauber, E.M., and Wolff, J.O., 1998, Chain reactions linking acorns to gypsy moth outbreaks and Lyme disease risk: Science, v. 279, p. 1023-1026.

Jules, E.S., 1998, Habitat fragmentation and demographic change for a common plant-Trillium in old-growth forest: Ecology, v. 79, p. 1645-1656.

Kalisz, S., Hanzawa, F.M., Tonsor, S.J., Thiede, D.A., and Voigt, S., 1999, Ant-mediated seed dispersal alters pattern of relatedness in a population of Trillium grandiflorum: Ecology, v. 80, p. 2620-2634.

Kawano, S., Ohara, M., and Utech, F.H., 1986, Life history studies on the genus Trillium (Liliaceae), II. Reproductive biology and survivorship of four eastern North American species: Plant Species Biology, v. 1, p. 47-58.

Kirschbaum, C.D., and Anacker B.L., 2005, The utility of Trillium and Maianthemum as phyto-indicators of deer impact in northwestern Pennsylvania, USA: Forest Ecology and Management, v. 217, p. 54-66.

Knight, T.M., 2003, Floral density, pollen limitation, and reproductive success in Trillium grandiflorum: Oecologia, v. 137, p. $557-563$.

Knight, T.M., 2004, The effects of herbivory and pollen limitation on a declining population of Trillium grandiflorum: Ecological Applications, v. 14, p. 915-928.
Knight, T.M., 2007, Population-level consequences of herbivory timing in Trillium grandiflorum: American Midland Naturalist, v. 157, p. 27-38.

Knight T.M., Caswell, H., and Kalisz, S., 2009a, Population growth rate of a common understory herb decreases non-linearly across a gradient of deer herbivory: Forest Ecology and Management, v. 257, p. 1095-1103.

Knight, T.M., Dunn, J.L., Smith, L.A., Davis, J., and Kalisz, S., 2009b, Deer facilitate invasive plant success in a Pennsylvania forest understory: Natural Areas Journal, v. 29, p. 110-116.

Koh, S., Bazely, D.R., Tanentzap, A.J., Voigt, D.R., and Da Silva, E., 2010, Trillium grandiflorum height is an indicator of white-tailed deer density at local and regional scales: Forest Ecology and Management, v. 259, p. 1472-1479.

Lapointe, L., Bussières, J., Crête, M., and Ouellet, J.-P., 2010, Impact of growth form and carbohydrate reserves on tolerance to simulated deer herbivory and subsequent recovery in Liliaceae: American Journal of Botany, v. 97, p. 913-924.

McCabe, T.R., and McCabe, R.E., 1997, Recounting white-tails past, in McShea, W.J., Underwood, H.B., and Rappole, J.H., eds., The science of overabundance-Deer ecology and population management: Washington, D.C., Smithsonian Institution Press, p. 11-26.

Mudrak, E.L., Johnson, S.E., and Waller, D.M., 2009, Fortyseven year changes in vegetation at the Apostle IslandsEffects of deer on the forest understory: Natural Areas Journal, v. 29, p. 167-176.

Ohara, M., and Utech, F.H., 1988, Life history studies on the genus Trillium (Liliaceae), V. Reproductive biology and survivorship of three declinate-flowered species: Plant Species Biology, v. 3, p. 35-41.

Patterson, B.R., and Power, V.A., 2002, Contributions of forage competition, harvest, and climate fluctuation to changes in population growth of northern white-tailed deer: Oecologia, v. 130, p. 62-71.

Pepoon, H.S., 1927, An annotated flora of the Chicago Region: Chicago, Ill., Chicago Academy of Sciences, 554 p.

Potvin, F., and Huot, J., 1983, Estimating carrying capacity of a white-tailed deer wintering area in Québec: Journal of Wildlife Management, v. 47, p. 463-475.

Powers, M.D., and Nagel, L.M., 2009, Pennsylvania sedge cover, forest management and deer density influence tree regeneration dynamics in a northern hardwood forest: Forestry, v. 82, p. 241-254.

Rooney, T.P., 2009, High white-tailed deer densities benefit graminoids and contribute to biotic homogenization of forest ground-layer vegetation: Plant Ecology, v. 202, p. 103-111. 
Royo, A.A., Stout, S.L., deCalesta, D.S., and Pierson, T.G., 2010, Restoring forest herb communities through landscape-level deer herd reductions-Is recovery limited by legacy effects?: Biological Conservation 143, p. 2425-2434.

Rooney, T.P., and Waller, D.M., 2001, How experimental defoliation and leaf height affect growth and reproduction in Trillium grandiflorum: Journal of the Torrey Botanical Society, v. 128, p. 393-399.

Sawyer, N.W., 2010, Reproductive ecology of Trillium recurvatum (Trilliaceae) in Wisconsin: American Midland Naturalist, v. 163, p. 146-160.

Swink, F., and Wilhelm, G., 1994, Plants of the Chicago Region (4th ed.): Indianapolis, Ind., Indiana Academy of Sciences, $921 \mathrm{p}$.

Tabachnick, B.G. and Fidell, L.S., Using multivariate statistics ( $4^{\text {th }}$ ed.): Boston, Mass., Allyn and Bacon, 966 p.

Tallmon, D.A., Jules, E.S., Radke, N.J., and Mills, L.S., 2003, Of mice and men and trillium-Cascading effects of forest fragmentation: Ecological Applications, v. 13, p. 1193-1203.

Tappe, P.A., Kissel, R.E, Jr., and McCammon, E.E., 2003, Ground-based and aerial thermal infrared imaging for estimating white-tailed deer population densities: Monticello, Ark., University of Arkansas, School of Forest Resources, 29 p.

Thompson, J.A., and Sharpe, W.E., 2005, Soil fertility, whitetailed deer, and three Trillium species-A field study: Northeastern Naturalist, v. 12, p. 379-390.

Underwood, H.B., and Knutson, R., 2011, Analysis of nightspotlighting counts for white-tailed deer, Indiana Dunes National Lakeshore, 1991-2006: Fort Collins, Colo. U.S. Department of the Interior, National Park Service, Natural Resource Technical Report NPS/GLKN/NRTR2011/424.

Utech, F.H., 2002, Liliaceae Jusasieu, Lily family, in Flora of North America Editorial Committee, eds. Flora of North America: New York, Oxford University Press, v. 26, Magnoliophyta—Liliadae; Liliales and Orchidales, p. 20-347.
Vellend, M., Myers, J.A., Gardescu, S., and Marks, P.L., 2003, Dispersal of Trillium seeds by deer-Implications for long-distance migration of forest herbs: Ecology, v. 84, p. 1067-1072.

Webster, C.R., and Jenkins, M.A., 2008, Age structure and spatial patterning of Trillium populations in old-growth forests: Plant Ecology, v. 199, p. 43-54.

Webster R.D., Jenkins, M.A., and Parker, G.R., 2001, A field test of herbaceous plant indicators of deer browsing intensity in mesic hardwood forests of Indiana, USA: Natural Areas Journal, v. 21, p. 149-158.

Webster, C.R., Jenkins, M.A., and Rock, J.H., 2005, Longterm response of spring flora to chronic herbivory and deer exclusion in Great Smoky Mountains National Park, USA: Biological Conservation, v. 125, p. 297-307.

Wilhelm, G.S., 1990, Special vegetation of the Indiana Dunes National Lakeshore: Omaha, Nebr., U.S. Department of Interior, National Park Service, Indiana Dunes National Lakeshore Research Program Report 90-02, 373 p.

Williams, C.E., Mosbacher, E.V., and Moriarity, W.J., 2000, Use of turtlehead (Chelone glabra L.) and other herbaceous plants to assess intensity of white-tailed deer browsing on Allegheny Plateau riparian forests, USA: Biological Conservation, v. 92 , p. $207-215$.

Zelikova, T.J., Dunn, R.R., and Sanders, N.J., 2008, Variation in seed dispersal along an elevational gradient in Great Smoky Mountains National Park: Acta Oecologica, v. 34, p. $155-162$.

Zuur, A.F., Ieno, E.N., and Elphick, C.S., 2010, A protocol for data exploration to avoid common statistical problems: Methods in Ecology and Evolution, v. 1, p. 3-14. 


.

啇.

言

(

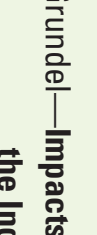

政

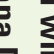

을

2

$\frac{8}{8}$

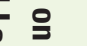

突

$\stackrel{2}{2}$

웅

主

.

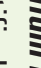

.

,

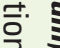

.

范

윽

등

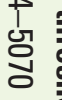

ISSN 2328-0328 (online) 